Animação de fluidos em imagens digitais

\author{
Marcos Aurélio Batista
}




\title{
Animação de fluidos em imagens digitais
}

\author{
Marcos Aurélio Batista
}

\section{Orientador: Prof. Dr. Luis Gustavo Nonato}

Tese apresentada ao Instituto de Ciências Matemáticas e de Computação - ICMC-USP, como parte dos requisitos para obtenção do título de Doutor em Ciências - Ciências de Computação e Matemática Computacional. VERSÃO REVISADA

\section{USP - São Carlos}

Outubro de 2011 
Ficha catalográfica elaborada pela Biblioteca Prof. Achille Bassi e Seção Técnica de Informática, ICMC/USP, com os dados fornecidos pelo(a) autor(a)

Batista, Marcos Aurélio
Bn28a
Aurélio Batista; orientador Luis Gustavo Nonato --
São Carlos, 2011.
111 p.
Tese (Doutorado - Programa de Pós-Graduação em
Ciências de Computação e Matemática Computacional) --
Instituto de Ciências Matemáticas e de Computação,
Universidade de São Paulo, 2011.
1. Animação de Fluidos. 2. Águas Rasas. 3. Imagens
Digitais. I. Nonato, Luis Gustavo, orient. II. Título.




\section{Resumo}

Esta tese apresenta uma nova metodologia para animação de objetos líquidos em imagens. Contrariamente às técnicas existentes, este método é baseado em um modelo físico, o que proporciona efeitos realísticos. A perspectiva da imagem é obtida com a intervenção do usuário, por um esquema simples de calibração da câmera, o qual permite a projeção da camada da imagem a ser animada sobre um plano horizontal no espaço tridimensional. As equações de águas rasas conduzem a simulação e as informações de altura são projetadas de volta ao espaço da imagem utilizando traçado de raios. Além disso, efeitos de refração e iluminação são aplicados durante este estágio, resultando em animações realísticas e convincentes.

\section{Palavras-chave:}

AnimaÇÃo de Fluidos · Águas Rasas · Imagens Digitais 


\section{Abstract}

This work presents a new methodology for animating liquid objects depicted in a still image. In contrast to existing techniques, the proposed method relies on a physical model to accomplish the animation, resulting in realistic effects. Image perspective is handled through a simple user assisted camera calibration scheme which allows one to project the image layers to be animated onto the horizontal plane in the three-dimensional space. Shallow-Water equations drive the simulation and the resulting height field is projected back to the image space via ray-tracing. Refraction and lighting effects are also accomplished during the ray-tracing stage, resulting in realistic and convincing animations.

\section{Keywords:}

Fluid Animation · Shallow Water · Still Image 


\section{Sumário}

$\begin{array}{ll}\text { Resumo } & \mathbf{v}\end{array}$

Abstract vi vi v

\begin{tabular}{lll}
\hline 1 & Introdução & 1
\end{tabular}

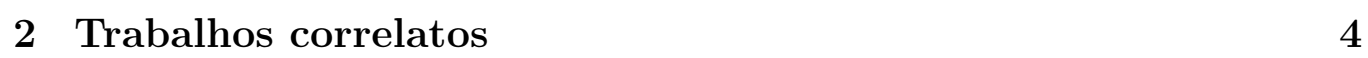

2.1 Espaço da imagem $\ldots \ldots \ldots \ldots \ldots$

2.2 Técnicas baseadas em vídeo . . . . . . . . . . . . . . . . . . . 9

2.3 Auxílio tridimensional . . . . . . . . . . . . . . . . . . . 11

2.4 Animando fluidos em imagens . . . . . . . . . . . . . . 13

2.5 Animação baseada em águas rasas . . . . . . . . . . . . . . . . 17

\begin{tabular}{lll}
\hline 3 & Abordagem proposta & 21
\end{tabular}

\begin{tabular}{lll}
\hline 4 & Inferência tridimensional & 26
\end{tabular}

4.1 Linha do horizonte . . . . . . . . . . . . . . . . . . 27

4.2 Distância focal $\ldots \ldots \ldots$. . . . . . . . . . . . . . . . . . . . 30

4.3 Calibração da câmera . . . . . . . . . . . . . . . . . . . . 31

4.4 Projeção inversa do corpo d'água . . . . . . . . . . . . . . 36

4.5 Determinando o domínio de simulação . . . . . . . . . . . 37 
5 Construção do domínio de simulação 39

6 Simulação física 44

6.1 Resolução numérica . . . . . . . . . . . . . . . . . . . . . . . . 45

6.2 Considerações sobre os arquivos de entrada . . . . . . . . . . . 52

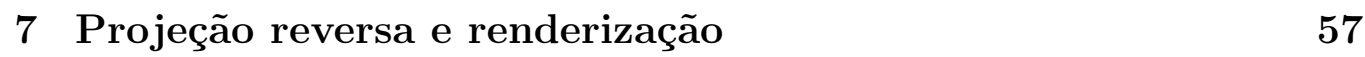

\begin{tabular}{lll}
\hline 8 & Resultados obtidos & 61
\end{tabular}

8.1 Rio em movimento . . . . . . . . . . . . . . . . . 63

8.2 Animação de fluxo em uma represa $\ldots . . . . . .65$

8.3 Vulcão $\ldots \ldots \ldots 6$

8.4 Chuvas . . . . . . . . . . . . . . . . . . . . . 67

8.5 Balanço natural . . . . . . . . . . . . . . . . . . . . 68

8.6 Transporte de textura $\ldots \ldots \ldots \ldots$. . . . . . . . . . 70

8.7 Efeito Coriolis . . . . . . . . . . . . . . . . . . . . 71

8.8 Inserção de objetos $\ldots \ldots \ldots$. . . . . . . . . . . . . . 75

8.9 Comparações . . . . . . . . . . . . . . . . . . 81

\begin{tabular}{lll}
\hline & Conclusão & 83
\end{tabular}

Trabalhos Futuros . . . . . . . . . . . . . . . . 83

\begin{tabular}{|l|l|}
\hline A Águas rasas & 85
\end{tabular}

A.1 Características físicas das águas rasas . . . . . . . . . . . . . 85

A.2 2 Equações de Navier-Stokes . . . . . . . . . . . . . . . . . . 86

A.3 $\quad$ Equacionamento do movimento das águas rasas . . . . . . . . 89

A.4 As equações de águas rasas . . . . . . . . . . . . . . . . . . . . 96

\begin{tabular}{ll}
\hline Referências bibliográficas & 97
\end{tabular} 


\section{Capítulo 1}

\section{Introdução}

A manipulação de fotografias e pinturas tem sido objeto de grande interesse em computação gráfica [Freeman, Adelson \& Heeger 1991, Litwinowicz \& Williams 1994], estimulando uma grande quantidade de métodos para edição [Barrett \& Cheney 2002, Igarashi, Moscovich \& Hughes 2005], animação [Hornung, Dekkers \& Kobbelt 2007, Xu, Wan, Liu, Wong, Wang \& Leung 2008] e criação de efeitos atraentes [Chu, Hsu, Mitra, Cohen-Or, Wong \& Lee 2010, Shesh, Criminisi, Rother \& Smyth 2009] a partir de imagens. Entretanto, a animação realística de fenômenos naturais em imagens permanece um desafio. As poucas técnicas existentes são muito complexas, exigindo uma intensa e especializada intervenção do usuário [Okabe, Anjyo, Igarashi \& Seidel 2009], ou simula apenas fenômenos suaves, como o efeito de um vento brando em um lago [Chuang, Goldman, Zheng, Curless, Salesin \& Szeliski 2005]. Além disso, a maioria destas técnicas apoia-se em síntese de texturas para simular fenômenos naturais, produzindo animações nem sempre realísticas.

Uma das principais dificuldades dos métodos de animação de fenômenos naturais em imagens, que utilizam modelos físicos, é a carência de informa- 
ções sobre a estrutura tridimensional da cena. Sem as informações tridimensionais dificilmente conseguiríamos simular ondas e o movimento de objetos em harmonia com a cena retratada na imagem, resultando em efeitos não convincentes.

Nesta tese, tratamos as dificuldades mencionadas com uma nova técnica para animação de líquidos em imagens, a qual se baseia em modelos físicos. A falta de informações tridimensionais é resolvida com um esquema simples de calibração da câmera, o que permite o posicionamento, no espaço tridimensional, do domínio de simulação. A técnica de traçado de raios é empregada para projetar o resultado da simulação de volta ao espaço da imagem. Além de fornecer um bom casamento entre a propagação da onda e a perspectiva da cena, o mecanismo permite, naturalmente, recursos adicionais de renderização, como refração e iluminação, os quais são explorados para intensificar o realismo e introduzir novos elementos à cena.

Nós utilizamos como modelo físico, no processo de animação, as equações de águas rasas. Além de permitir animações realísticas, o modelo de águas rasas fornece um conjunto de parâmetros que podem servir para modular efeitos específicos no fluido. Ademais, utilizamos camadas da imagem como um mecanismo para definir os parâmetros envolvidos na simulação, permitindo mudanças no comportamento do fluido e criando efeitos interessantes.

\section{Contribuições}

As principais contribuições deste trabalho podem ser resumidos em:

- Inferência tridimensional: um esquema simples de calibração de câmera, conduzido pelo usuário, é empregado para inferir o domínio tridimensional onde ocorrerá a simulação física. 
- Animação fisicamente baseada: em contraste às técnicas de animação em imagens, nossa abordagem apoia-se fortemente em um modelo físico (águas rasas) para gerar os efeitos de movimento, resultando em animações realísticas.

- Projeção reversa via traçado de raios: o traçado de raios é utilizado para projetar o resultado da simulação de volta ao espaço da imagem, preservando a perspectiva da cena enquanto efeitos adicionais são aplicados, tais como refração e iluminação. Até onde sabemos, esta é a primeira vez que o traçado de raios é utilizado em animação de imagens em conjunto com simulações físicas.

Para apresentar esta proposta ao leitor fazemos, no segundo capítulo, uma breve análise dos trabalhos correlatos. Nos capítulos seguintes apresentamos nossa proposta e em seguida uma amostra dos resultados obtidos. Fechamos com um capítulo de conclusão, onde apresentamos algumas propostas de trabalhos futuros.

Esta tese não tem a pretensão de ser um tratado sobre o movimento de fluidos e nem mesmo do movimento de águas rasas. Os rigores matemáticos e físicos de um tratado desta natureza podem ser encontrados em [Kinnmark 1984, Weiyan 1992, Galdi 1998a, Galdi 1998b]. Para manter o texto completo, porém, fornecemos detalhes do modelo de águas rasas, bem como a estratégia de discretização adotada. 


\section{Capítulo 2}

\section{Trabalhos correlatos}

A admiração que o ser humano tem adquirido por pinturas e fotografias artísticas ao longo de milênios de nossa evolução é fruto da capacidade de abstrair o significado da cena, muitas vezes, pelo movimento intrínseco da mesma.

Já não é de hoje que a Computação Gráfica gera movimento a partir de duas ou mais imagens, seja na interpolação de quadros a partir de criações artísticas em tempos específicos da cena ou a partir de sequências de imagens capturadas de uma cena real, seja nas famosas técnicas de metamorfose, iniciadas artisticamente por Georges Meliès ${ }^{1}$ no início do séculd ${ }^{2}$. Técnica esta onde, a partir de duas imagens distintas, uma alomorfia entre elas é gerada através de quadros que evoluem a partir de uma imagem em direção a outra, utilizando técnicas de deformações em imagens [Gomes \& Velho 1994]. O artigo [Wolberg 1998] nos dá um panorama das técnicas de metamorfose entre imagens desenvolvidas no século passado (veja também wWw .visgraf .impa.br/morph).

\footnotetext{
${ }^{1}$ Ilusionista Francês, 1861-1938.

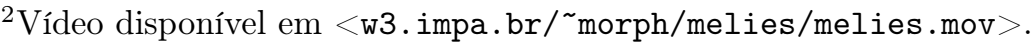


Recentemente, o artigo [Bonilla, Velho, Nachbin \& Nonato 2009] apresenta uma técnica de deformação de imagens, onde a imagem é considerada um campo de densidades imerso em um fluido que, ao movimentar-se sob a ação de forças externas, parâmetro informado pelo usuário, deforma a imagem.

Mas animar uma imagem a partir do significado intrínseco que a mesma passa aos nossos olhos é um grande desafio. A demanda prática é um tanto óbvia, visto que gerar movimento a partir de uma imagem dada diminui consideravelmente o custo de uma animação. Este desafio tem sido objeto de estudo desde o fim da década de 70, quando uma técnica de variação de cores na imagem foi proposta [Shoup 1979].

Para melhor contextualizar nosso trabalho, organizamos as técnicas de animação de objetos em imagens pelo nível de informações tridimensionais requeridas. Mais especificamente, agrupamos as técnicas em três categorias: técnicas onde todo o processamento acontece no espaço bidimensional da imagem, técnicas que utilizam vídeos preexistentes como exemplos, e métodos apoiados em algum tipo de informação tridimensional.

\subsection{Espaço da imagem}

Técnicas que realizam o processo de animação no espaço da imagem abrangem desde ilusão de movimento baseado em filtragem [Freeman et al. 1991] até métodos sofisticados de animação, envolvendo ciclos de movimento de animais [Xu et al. 2008], as quais contam com ferramentas de manipulação de imagem tais como manipulação de formas [Igarashi et al. 2005, Schaefer, McPhail \& Warren 2006], edição [Barrett \& Cheney 2002], e deformação de imagens [Litwinowicz \& Williams 1994]. Na realidade, as ferramentas 
básicas de manipulação de imagem, juntamente com a utilização do canal alfa [Sun, Jia, Tang \& Shum 2004] e do retoque digital [Drori, Cohen-Or \& Yeshurun 2003] são fundamentais para a maioria dos métodos existentes. Falemos sobre alguns destes trabalhos que tratam da geração de animação.

Na década de 90 o artigo [Freeman et al. 1991] apresenta a geração de um vídeo a partir de uma imagem simples aplicando um filtro, com diferença de fase de $90^{\circ}$, duas vezes na imagem e, a partir destas imagens chamadas $G$ e $H$, gera os quadros: $F_{t}=\cos (\theta t) G+\operatorname{sen}(\theta t) H$, onde $\theta=\frac{2 \pi}{T}$ e $T$ é o tempo total de um ciclo do vídeo $\left(360^{\circ}\right)$. Assim a imagem final é igual à imagem inicial $(G)$, gerando uma sequência circular de movimento, tendo como imagens intermediárias $H,-G$ e $-H$ (respectivamente, $\theta t=\frac{\pi}{2}$, $\pi$ e $\left.\frac{3 \pi}{2}\right)$.

Ainda na mesma década, Peter Litwinowicz e Lance Williams [Litwinowicz \& Williams 1994], da Apple Computer, Inc apresentam uma técnica de animação em imagens onde, a partir de uma sequência de quadros tomado como modelo e da imagem dada, gera os esboços dos quadros desta imagem e deforma cada um dos esboços, preservando a textura interna aos contornos, gerando os respectivos quadros de animação. A sequência para a geração desta animação pode ser acompanhada na figura 2.1.

1. a imagem no canto inferior esquerdo de 2.1p é a imagem dada,

2. a sequência de quadros na parte superior de 2.19 é o vídeo tomado como modelo,

3. o esboço no canto superior esquerdo de 2.1b foi extraído da imagem dada,

4. a sequência de esboços na parte inferior de 2.1 foi extraída do modelo, 


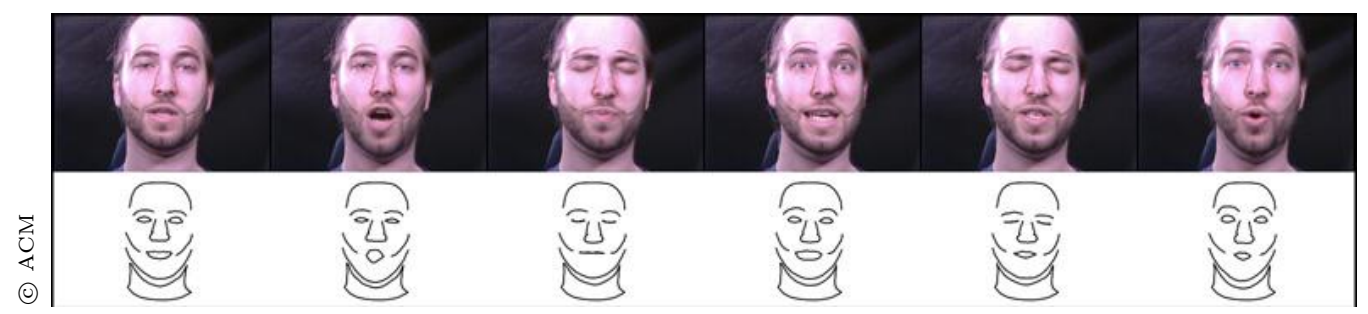

(a)

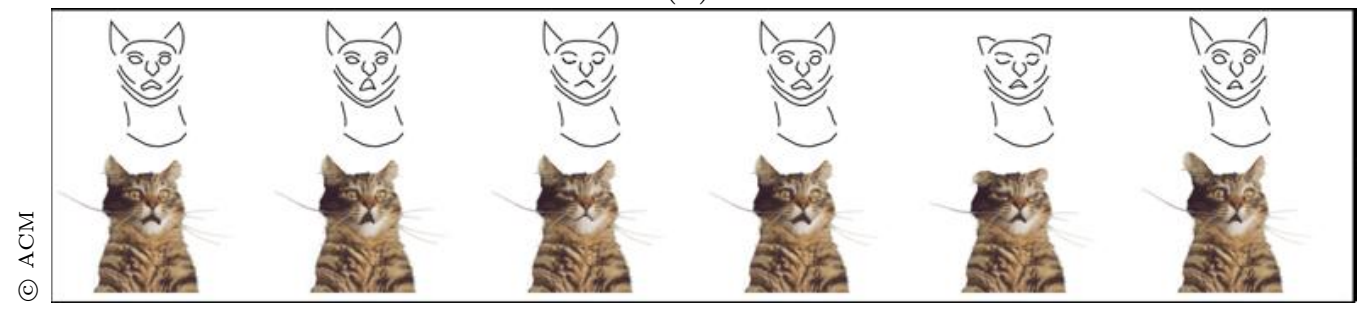

(b)

Figura 2.1: Animação da imagem de um gato (canto inferior esquerdo) a partir dos contornos do vídeo de uma pessoa (linha superior). [Litwinowicz \& Williams 1994]

5. a sequência de esboços na parte superior de 2.1b foi gerada a partir dos esboços da imagem dada e do modelo,

6. finalmente, a sequência na parte inferior de 2.1b é o vídeo gerado.

Já no início deste século, é apresentada uma técnica que gera movimento em uma imagem a partir da seleção de um ou mais objetos nesta imagem e de suas segmentações automáticas. A partir desta segmentação o usuário pode mudar a forma, o tamanho e a localização do objeto ou de parte deste objeto [Barrett \& Cheney 2002]. Um exemplo de aplicação da técnica pode ser visto na figura 2.2 , onde a imagem à esquerda é a imagem original, o objeto selecionado é o relógio e a imagem à direita é a imagem modificada.

Já uma técnica de manipulação de formas é apresentada na figura 2.3 . onde um objeto dado é coberto por uma malha triangular e manipulado pelo usuário a partir de pontos arbitrários [Igarashi et al. 2005]. A técnica consiste em, dada uma imagem com textura regular e um objeto de contorno fechado: 


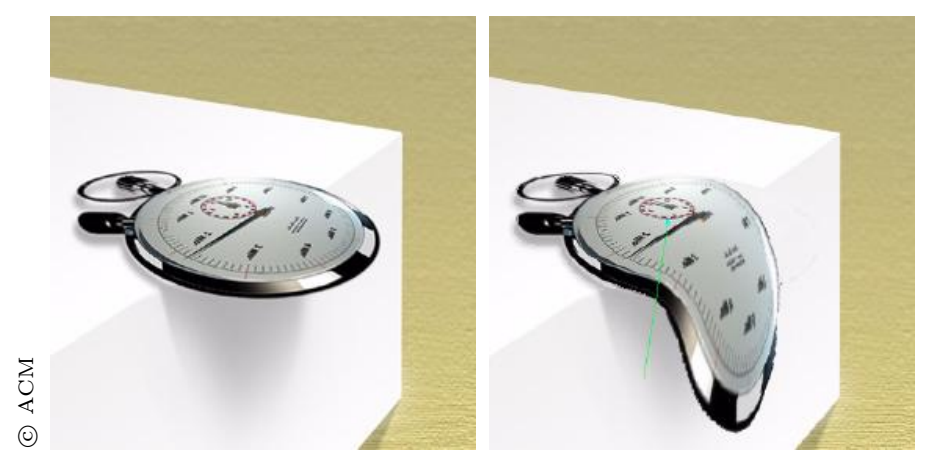

Figura 2.2: Relógio fluindo. [Barrett \& Cheney 2002]

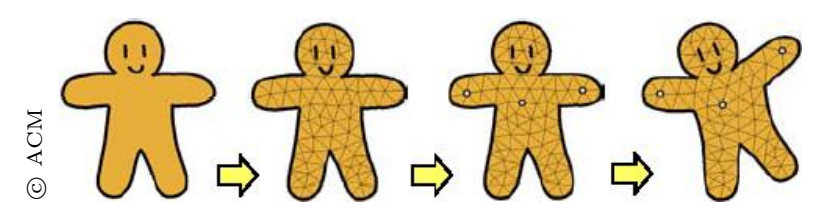

Figura 2.3: Visão geral de uma técnica de manipulação de formas. [Igarashi et al. 2005]

1. o objeto é coberto por uma malha triangular,

2. pontos de manipulação, ou de fixação, são selecionados pelo usuário e os mesmos são atribuídos a vértices da malha,

3. o usuário, a partir dos pontos selecionados, manipula o objeto como se manipula uma marionete,

4. a malha se adapta à manipulação deformando os triângulos e preservando os vértices associados aos pontos selecionados,

5. em cada intervalo predeterminado, a textura original dos triângulos é repintada e um quadro é gerado,

6. os quadros gerados formam a animação.

Outro interessante trabalho de animação a partir de imagens, proposto em [Xu et al. 2008], consiste em, dada uma imagem como na figura 2.4 


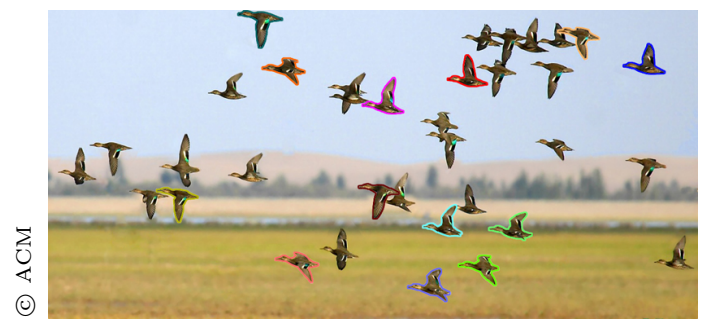

(a)

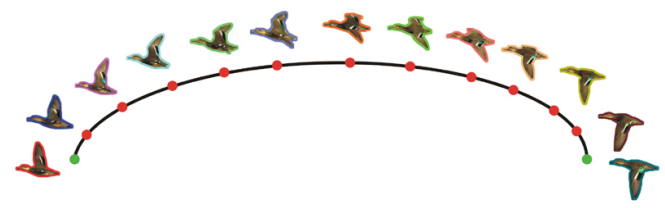

(b)

Figura 2.4: Seleção de objetos e inferência de movimento. [Xu et al. 2008]

os objetos são extraídos e ordenados, gerando uma sequência de movimento inferido como apresentado na figura $2.4 \mathrm{~b}$, o fundo da imagem é retocado e a sequência de movimento é gerada, reinserindo os objetos na cena a partir de sua posição original e, a cada quadro, inserindo os objetos na sequência do movimento inferido.

Ainda que efetivas para a animação em certas classes de imagens, como os cartoons e faces humanas, técnicas atuando apenas no espaço da imagem não são adequadas para a modelagem de fenômenos naturais, como estamos interessados.

\subsection{Técnicas baseadas em vídeo}

Vídeo textura e síntese de textura têm sido amplamente utilizados para sintetizar sequências de vídeos. A maioria destas técnicas são capazes de estender uma sequência de vídeo de maneira bastante convincente, mas elas são extremamente restritivas em relação à intervenção do usuário. Métodos interativos também foram propostos, tornando possível a geração de animações a partir de esboços e fluxos definidos pelo usuário. Dividimos os métodos de síntese de texturas baseados em vídeo, em três categorias:

- Métodos que propiciam ao usuário a expansão de um vídeo já existente: 
- [Wei \& Levoy 2000] propõem um algoritmo para síntese de volume 3D dinâmicos.

- [Bar-Joseph, El-Yaniv, Lischinski \& Werman 2001] propõem um algoritmo estocástico para síntese de sequências de vídeo utilizando análise de multirresolução.

- [Schödl, Szeliski, Salesin \& Essa 2000] propõem um método de texturização baseado em vídeo para concatenar apropriadamente subsequências previamente escolhidas.

- [Doretto, Chiuso, Wu \& Soatto 2003] propõem um método de texturização dinâmica utilizando filtros autorregressivos.

- Métodos que propiciam a modificação de um vídeo preexistente, criando uma nova animação de fluido:

- [Wang \& Zhu 2003] analisam uma animação de fluidos e representaa com textons para sintetizar um sequência diferente de vídeo.

- [Bhat, Seitz, Hodgins \& Khosla 2004] propõem um esboço de interface e um algoritmo para sintetizar uma animação de fluidos a partir de um vídeo modelo, onde o usuário pode mudar a aparência do fluido.

- [Kwatra, Essa, Bobick \& Kwatra 2005] propõem um método para modelar a texturização da animação de um fluxo sobre um local específico designado pelo usuário.

- [Narain, Kwatra, Lee, Kim, Carlson \& Lin 2007] transferem as texturas de um vídeo para uma superfície fluídica 3D ou outra sequência de vídeo. 
- Métodos que modificam a aparência de um vídeo utilizando uma imagem simples como modelo:

- [Hertzmann, Jacobs, Oliver, Curless \& Salesin 2001] utilizando uma técnica de comparação de imagens.

- [Hashimoto, Johan \& Nishita 2003] estende a técnica anterior para filtragem de vídeo.

Mais relacionado ao problema de geração de animação a partir de imagens, o trabalho [Hashimoto et al. 2003] sintetiza uma sequência de vídeo a partir de imagens exemplo. O sistema de animação em [Lin, Wang, Wang, Kang \& Fang 2007] também faz uso de múltiplas imagens para gerar a animação. Já o problema de animação de fluidos em imagens, que retomaremos na seção 2.4 foi bem abordado em [Okabe et al. 2009], tirando proveito de vídeos exemplos e traços definidas pelo usuário para sintetizar a animação.

Embora flexíveis, capazes de gerar diferentes tipos de animação, os modelos carecem de fundamentos físicos, impedindo que as técnicas baseadas em vídeo produzam efeitos realísticos em animações de fenômenos naturais que envolvam fluxos ondulatórios.

\subsection{Auxílio tridimensional}

O uso de modelos tridimensionais no auxílio de animações bidimensionais, como é o caso de nosso trabalho, tem sua origem no início da computação gráfica, principalmente na animação de cartoons. A abordagem usual neste contexto é a construção de modelos tridimensionais cujas silhuetas sejam compatíveis com os traços e contornos delineados a mão, podendo ser defor- 
mados e renderizados de acordo com o modelo tridimensional [Corrêa, Jensen, Thayer \& Finkelstein 1998, Ono, Chen \& Nishita 2004, Rademacher 1999].

Observamos também manipulações a partir de imagens simples para exibições virtuais, como em [Zhang, Pan, Ren \& Wang 2007] ou em reconstruções tridimensionais a partir de imagens, como em [Horry, Anjyo \& Arai 1997, Criminisi, Reid \& Zisserman 2000, Oh, Chen, Dorsey \& Durand 2001, Sun, Liang, Wen \& Shum 2007, Wu, Sun, Tang \& Shum 2008, Shesh \& Chen 2008].

Trabalhos mais recentes fazem uso de informações tridimensionais para animar objetos em imagens. [Hornung et al. 2007], por exemplo, apresenta um sistema de animação que utiliza um esqueleto bidimensional, especificado pelo usuário, para determinar, aproximadamente, a posição da câmera e procurar por um modelo de pose ideal em um banco de dados tridimensional de movimentos. Oclusões e partes faltantes são recortadas com técnicas utilizando Poisson e preenchidas com técnicas de retoque digital.

Mais especificamente relacionado ao nosso trabalho, o sistema de animação proposto em [Chuang et al. 2005], que detalharemos na seção 2.4. é capaz de animar objetos como árvores e água, modelando as forças da natureza estocasticamente, evitando uma simulação baseada em modelos físicos. Embora árvores e similares possam ser animadas utilizando apenas informações bidimensionais, a síntese do movimento da água requer a intervenção do usuário para definir um plano no espaço tridimensional, para modelar corretamente os efeitos de perspectiva.

Como não utilizam, ao contrário do nosso, modelos físicos para conduzir a animação, torna-se difícil a geração de efeitos com comportamentos específicos como ondas direcionais. Além disso, estes sistemas não suportam refração e efeitos de iluminação. 


\subsection{Animando fluidos em imagens}

A animação de fluidos em imagens estáticas é um grande desafio e poucos

o têm atacado. Apresentamos aqui dois artigos que geram movimentos em imagens nos quais, apesar de não simularem fisicamente o movimento de fluidos, a animação gerada é visualmente realística.

No primeiro, com "o objetivo de sintetizar um vídeo estocástico a partir de uma simples imagem", os autores propõem, para criar um "movimento interessante, complexo e plausível", a seguinte técnica de animação [Chuang et al. 2005]:

1. Tome uma imagem $I$ que passe a idéia de movimento que possa ser reproduzido aleatoriamente.

2. Selecione os diversos objetos da imagem:

(a) Selecione os objetos da imagem $I$ que estão totalmente visíveis.

(b) Identifique cada objeto como $O_{i}$, incrementando $i$ sequencialmente a partir da unidade.

(c) Crie uma nova imagem $L_{i}$ contendo o objeto $O_{i}$ na mesma posição da imagem $I$ e vazia nas demais posições.

(d) Utilize uma técnica de Retoque Digital e remova os objetos selecionados, reconstruindo o fundo da imagem $I$.

(e) Repita o processo até selecionar todos os objetos da imagem $I$.

3. Classifique os objetos $O_{i}$ em:

(a) Árvore (movimento de oscilação).

(b) Água (movimento ondulatório). 
(c) Barco (movimento de sacudimento).

(d) Nuvem (movimento de translação).

(e) Imóvel (sem movimento).

4. Uma função deslocamento $d_{i}(p, t)$ é associada a cada imagem $L_{i}$ de acordo com a classificação do objeto $O_{i}$. Esta função leva cada pixel $p$ da imagem $L_{i}$ ao deslocamento do objeto $O_{i}$ no intervalo de tempo $t$.

5. Uma função $L_{i}(p)$ de reposicionamento de cada pixel do objeto $O_{i}$ é definida como sendo o valor do pixel antes do deslocamento, ou seja, $L_{i}\left(p+d_{i}(p, t)\right)=L_{i}(p)$, onde $L_{i}(p) \equiv L_{i}$.

6. A imagem é recomposta para cada instante $t$ através do agrupamento dos objetos, na ordem inversa de criação, ou seja,

(a) $I_{m}(p, t)=L_{m}\left(p+d_{l}(p, t)\right)$, onde $m$ é a quantidade total de objetos.

(b) $I_{i}(p, t)=I_{i+1}(p, t)+L_{i}\left(p+d_{i}(p, t)\right)$, para $0 \leq i<m$.

7. Sendo $I$ a imagem no instante inicial, fazemos de $I_{0}(p, t)$ a imagem no instante $t$, ou seja,

(a) $I^{0} \equiv I$.

(b) $I^{t} \equiv I_{0}(p, t)$.

8. A animação é obtida a partir da sequência de quadros $I^{t}$.

Esta sequência pode ser observada na figura 2.5

Este método aborda o problema de animação em imagem que representem fenômenos naturais e, em relação a movimentos fluídicos, apenas oscila a superfície da água com ondulações estocásticas. 


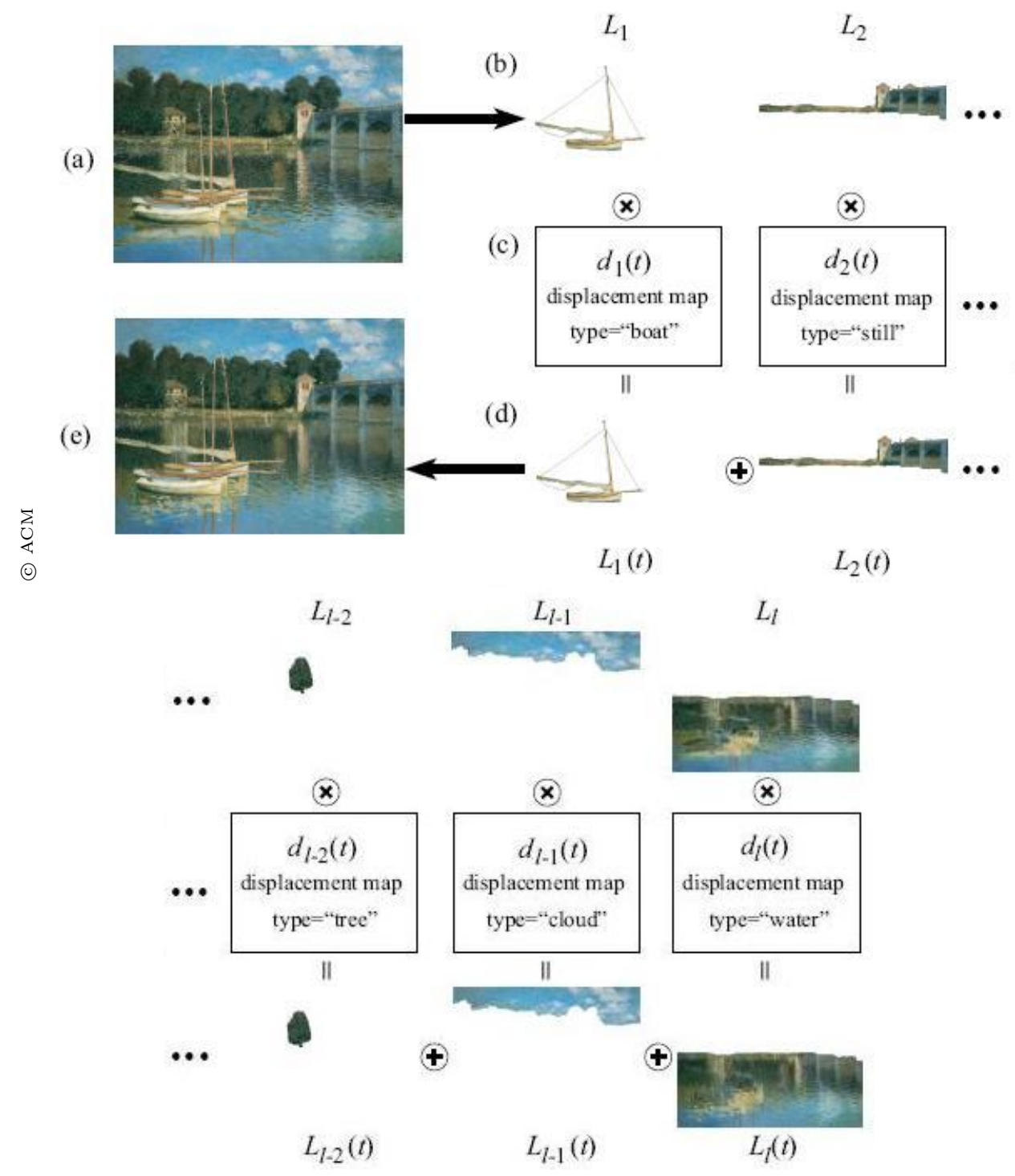

Figura 2.5: Sequência de animação de imagem utilizando movimentos estocásticos.

[Chuang et al. 2005] 
Uma outra técnica de animação de imagens utilizando vídeos pré-selecionados é proposta por [Okabe et al. 2009]. A técnica consiste em, dada uma imagem contendo uma cena de fluido em movimento implícito, ou seja, uma cena estática que da idéia de movimento, e admitindo seu fluxo em regime permanente, o usuário escolhe um vídeo, realístico ou não, que será tomado como modelo na animação (figura 2.6). Este vídeo é subdividido nas seguintes partes:

imagem média: é a média pixel a pixel dos quadros do vídeo tomado como modelo.

vídeo diferença: é gerado a partir das diferenças entre cada quadro e a imagem média.

fluxo ótico: é o 'vídeo' formado por 'quadros deslocamento' obtidos pela diferença euclidiana entre os vetores posição de um pixel em um quadro do vídeo diferença e o quadro seguinte.

imagem média do fluxo ótico: é a média vetorial, pixel a pixel, dos quadros do fluxo ótico.

vídeo residual: é o vídeo obtido pelo 'erro' entre a indicação de movimento da imagem média do fluxo ótico em cada quadro do vídeo diferença e o quadro seguinte.

A geração do vídeo a partir da imagem é efetuada pelo processo inverso ao descrito acima, admitindo a imagem média como sendo a imagem dada inicialmente e o fluxo ajustado pelo usuário (figura 2.7). Alguns resultados podem ser observados no sítio de Makoto Okade

\footnotetext{
${ }^{3}<$ www.mpi-inf .mpg.de/ ${ }^{\sim m o k a b e / A n i m e P i c F l u i d ~}>$.
} 


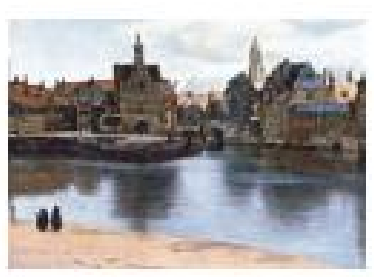

Water Surface

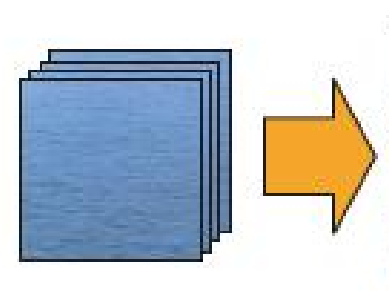

Video Example

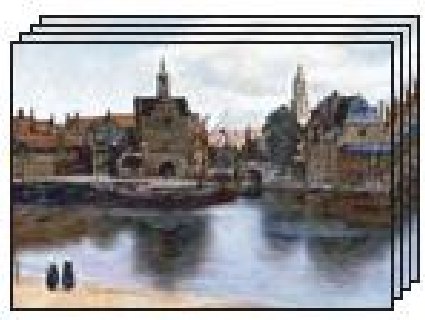

Synthesized Animation

Figura 2.6: Animação de fluido a partir de um modelo. [Okabe et al. 2009]

Como pudemos observar, nosso objeto de estudo difere substancialmente dos trabalhos apresentados, mas compartilham alguns aspectos, o que nos possibilitou um indicativo de contexto de nosso trabalho.

\subsection{Animação baseada em águas rasas}

A revisão bibliográfica apresentada mostra que nenhuma técnica de animação de imagens se baseia em um modelo físico para criar animações realísticas de fluidos. O método proposto nesta tese se baseia em um modelo físico para conduzir a simulação, resultando em animações realísticas e convincentes. Além disso, a projeção reversa baseada no traçado de raios, presente em nosso processo de animação, flexibiliza grandemente a implementação das técnicas descritas.

Para conduzir o processo físico de nosso modelo, utilizaremos o equacionamento de águas rasas, cujo modelo se baseia em um ambiente bidimensional que nos dá informações sobre as alterações (ondulações) ocorridas na superfície do fluido. Águas rasas são fluidos cujo equacionamento pode ser considerado uma simplificação das equações do movimento de fluidos, utilizando algumas hipóteses com relação à geometria do problema. Esta simplificação é apresentada no apêndice A. 


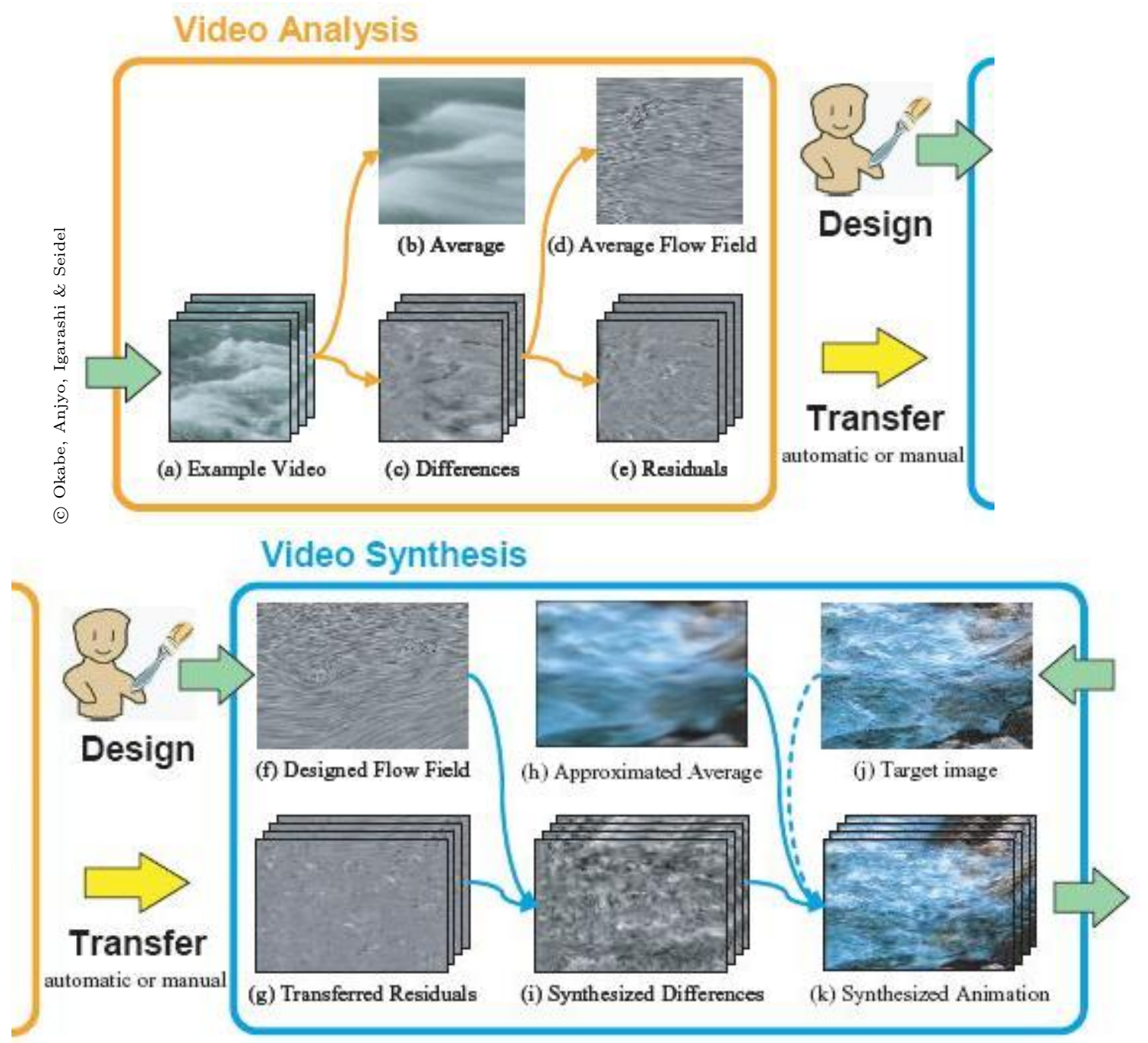

Figura 2.7: Processo de geração de animação em imagem a partir de um modelo. [Okabe et al. 2009] 
Em 1990, Michael Kass e Gavin Miller apresentaram as equações de águas rasas à comunidade de Computação Gráfica em uma simulação de chuva, obtendo resultados "encorajadoramente realísticos" [Kass \& Miller 1990].

Desde então, vários autores apresentaram simulações baseadas em águas rasas:

- [Layton \& van de Panne 2002] apresentam, após um survey dos modelos de simulação de fluidos baseados nas equações de Navier-Stokes, um modelo que é baseado nas equações de águas rasas e que, segundo os autores, simula eficientemente movimentos suaves, superposição de ondas, objetos sendo levados pela correnteza, obstáculos variados e fronteiras de várias formas.

- [Hagen, Hjelmervik, Lie, Natvig \& Henriksen 2005] simulam áreas com topografia não trivial sendo alagadas e escoadas. A simulação é efetuada diretamente na GPU, obtendo resultados rápidos.

- [Wang, Miller \& Turk 2007] simulam uma variedade de efeitos aquáticos, inclusive acoplamento de corpos rígidos flutuantes, de maneira rápida e estável.

- [Drasek III, Bookout \& Lake 2009] simulam ondas oceânicas em tempo real possibilitando a iteração do usuário na modificação de parâmetros dinamicamente, produzindo uma variedade de formas de ondas em águas oceânicas rasas.

Modelos híbridos têm sido utilizados para simular o movimento de águas, como em [Irving, Guendelman, Losasso \& Fedkiw 2006], que resolve as equações de Navier-Stokes em células regulares em volta da superfície da água e, abaixo desta superfície, utiliza uma malha não uniforme, evitando o mo- 
delo de águas rasas para capturar detalhes que o modelo não simula, como respingos.

Estas animações são totalmente ambientadas tridimensionalmente, o que não é nosso interesse pois nosso ambiente original é uma imagem estática. 


\section{Capítulo 3}

\section{Abordagem proposta}

Nossa técnica assume como entrada uma imagem decomposta em várias partes ou camadas, algumas das quais definem as partes da imagem a serem animadas (figura 3.1 - esquerda). Como ilustrado na figura 3.1, a sequência proposta para animação é composta de quatro passos principais, quais sejam: (1) estimativa da posição da câmera, (2) construção do domínio de simulação, (3) simulação de águas rasas e (4) projeção reversa utilizando o traçador de raios.

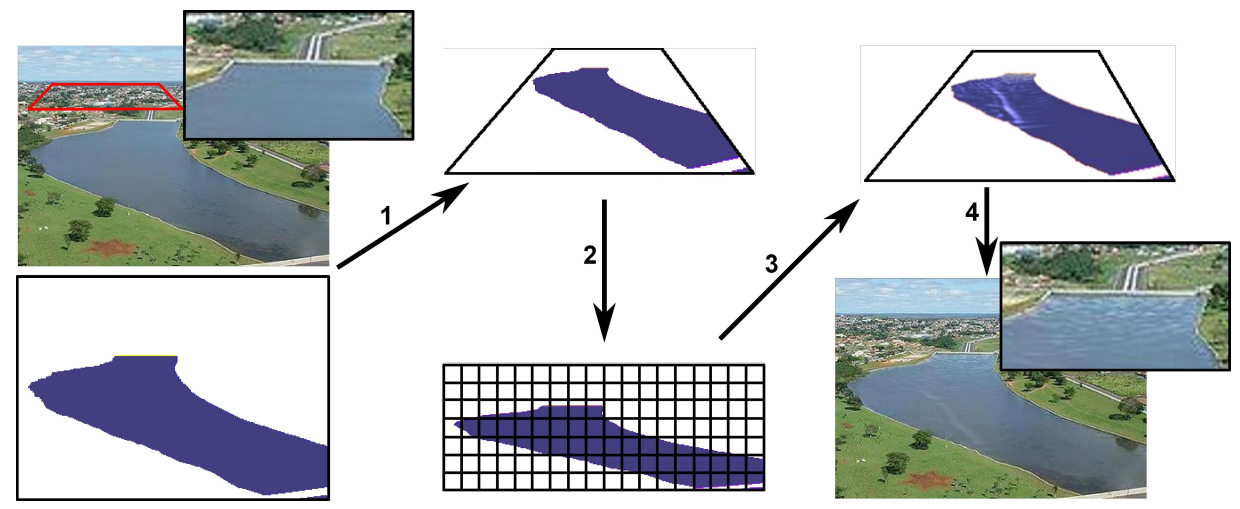

Figura 3.1: Visão geral do método. 


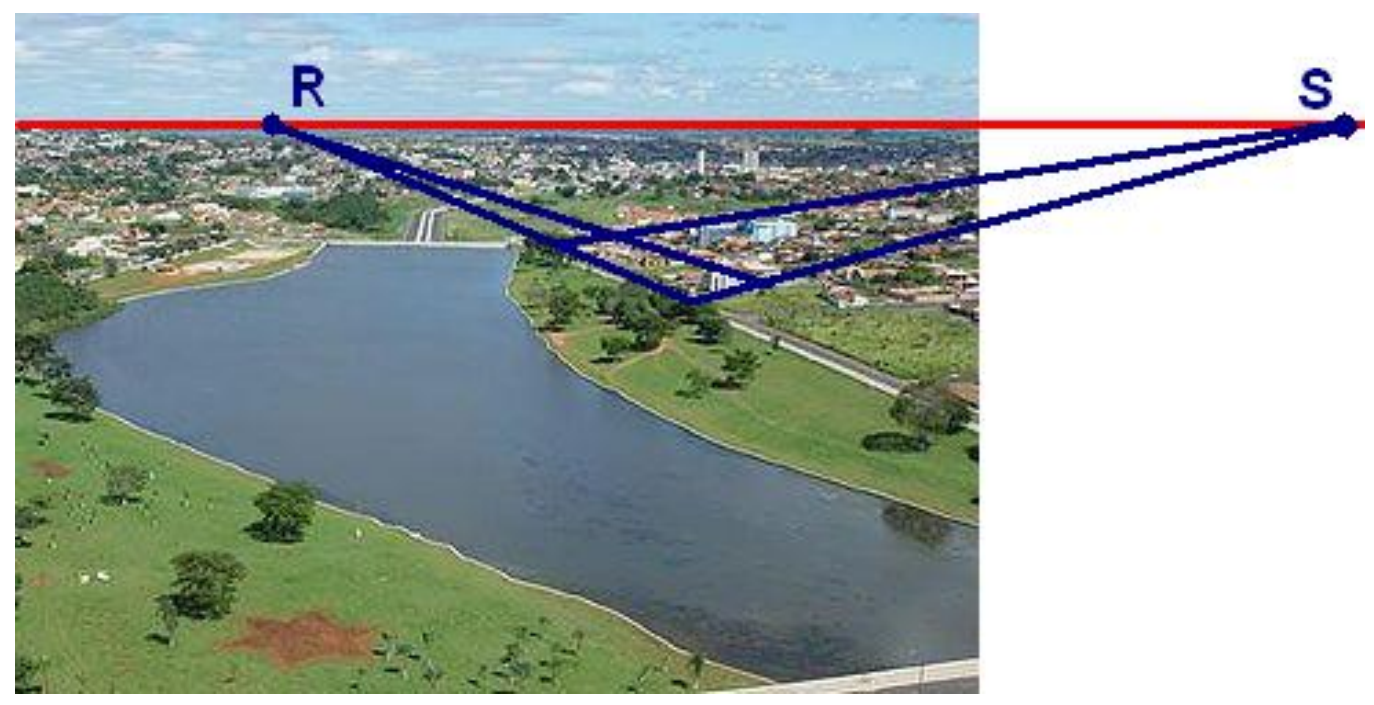

Figura 3.2: Pontos $R$ e $S$ no infinito obtidos a partir do quadrilátero em azul. A reta em vermelho é a linha do horizonte.

A estimativa da posição da câmera é necessária para o correto posicionamento do domínio de simulação no espaço tridimensional, de forma a considerar os efeitos de perspectiva. A posição da câmera é estimada por um mecanismo, assistido pelo usuário, baseado em pontos no infinito (cap. 4). Mais especificamente, o usuário desenha um quadrilátero na imagem original (quadro em vermelho na figura 3.1, acima à esquerda), através do qual são calculados alguns dos parâmetros da câmera.

O usuário pode utilizar como referência para desenhar o quadrilátero, estruturas da imagem conhecidamente formadas por retas paralelas. Por exemplo, a figura 3.2 mostra o quadrilátero alternativo ao apresentado na figura 3.1. em azul, e os pontos no infinito correspondentes, obtidos pela extensão dos segmentos de reta do quadrilátero.

Uma vez que a posição da câmera está bem determinada, utilizamos as transformações de perspectiva para projetar as camadas a serem animadas no plano horizontal, no espaço tridimensional (figura 3.1 central acima). O 


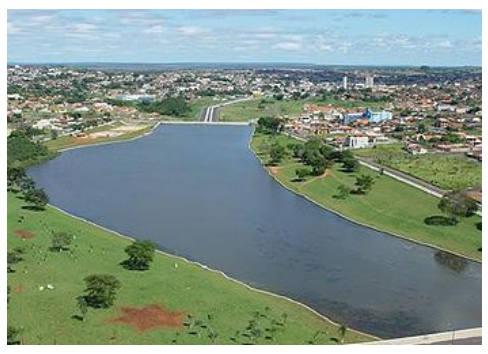

(a)

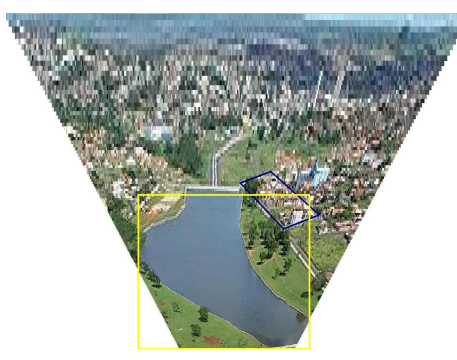

(b)

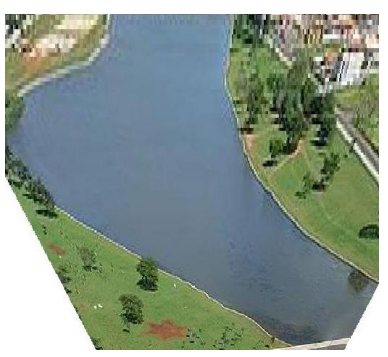

(c)

Figura 3.3: (a) imagem original, (b) projeção no plano do objeto e (c) domínio de simulação.

quadrilátero projetado é convertido em um paralelogramo, determinando o domínio de simulação (figura 3.1 centro inferior e figura 3.3). Detalhes do processo são apresentados no próximo capítulo.

A simulação do fluxo, representada na figura 3.4 baseado nas equações de águas rasas, detalhada no capítulo 6, é executada em uma malha retilínea. O comportamento do fluxo é controlado pelas condições de fronteira e parâmetros, informações estas contidas nas camadas da imagem, definidas pelo usuário. Estas camadas são delimitações, na imagem, da localização do objeto líquido a ser animado, bem como suas fronteiras. Outras partições possíveis, opcionalmente inseridas pelo usuário, são o relevo do leito do objeto líquido e o coeficiente de Chezzy, indicando o atrito em cada ponto do leito, a partir de informações em tons de cinza, na posição equivalente da imagem.

Finalmente, as informações de altura resultantes da simulação são mapeadas (distorcidas) na camada correspondente (figura 3.1, no alto à direita) que é projetada de volta ao espaço da imagem via traçador de raios (figura 3.1, abaixo à direita). Efeitos de refração e iluminação são também incorporados durante o estágio da projeção reversa, para aumentar o realismo, 


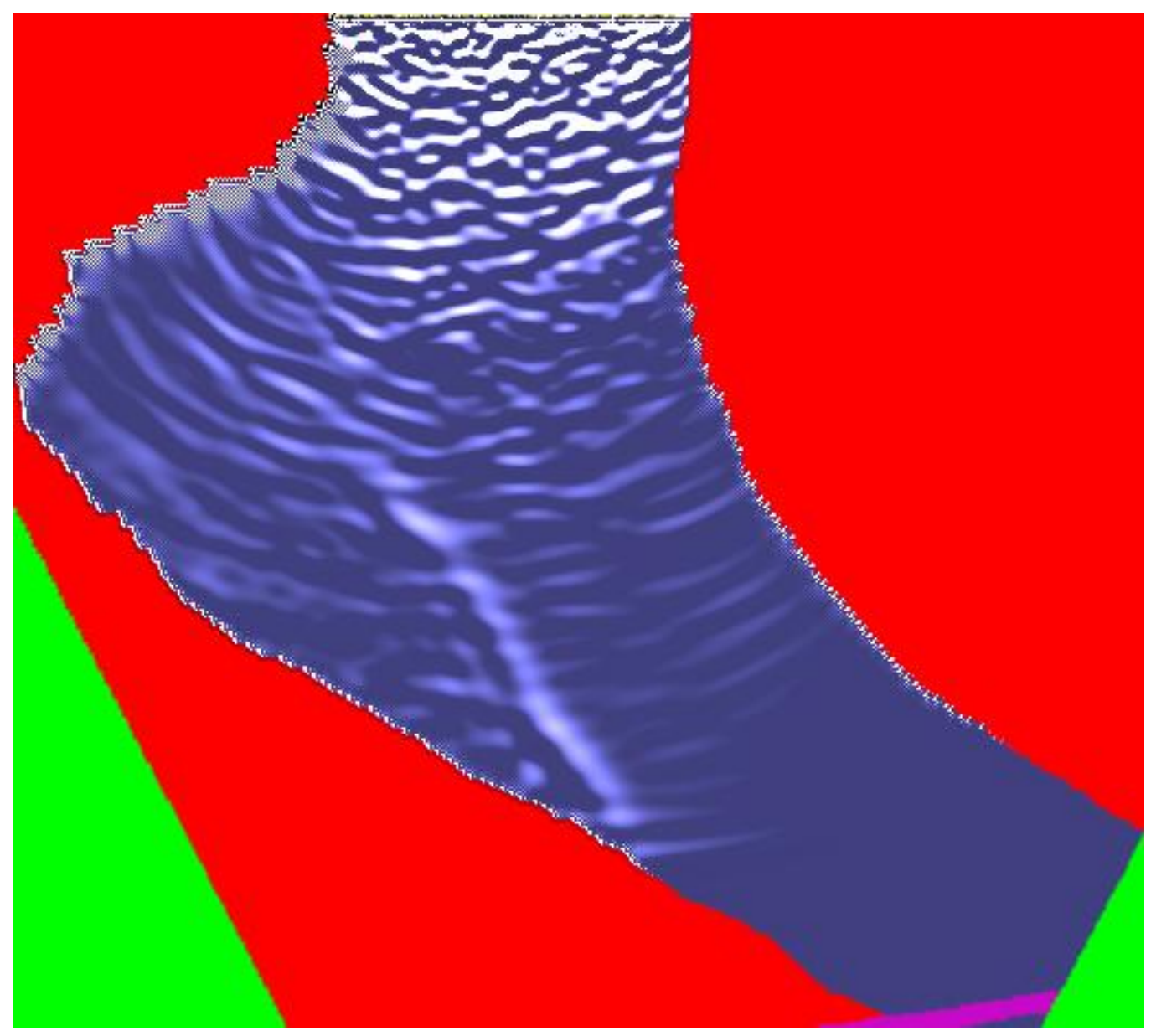

Figura 3.4: Simulação do fluxo a partir das equações de águas rasas. 


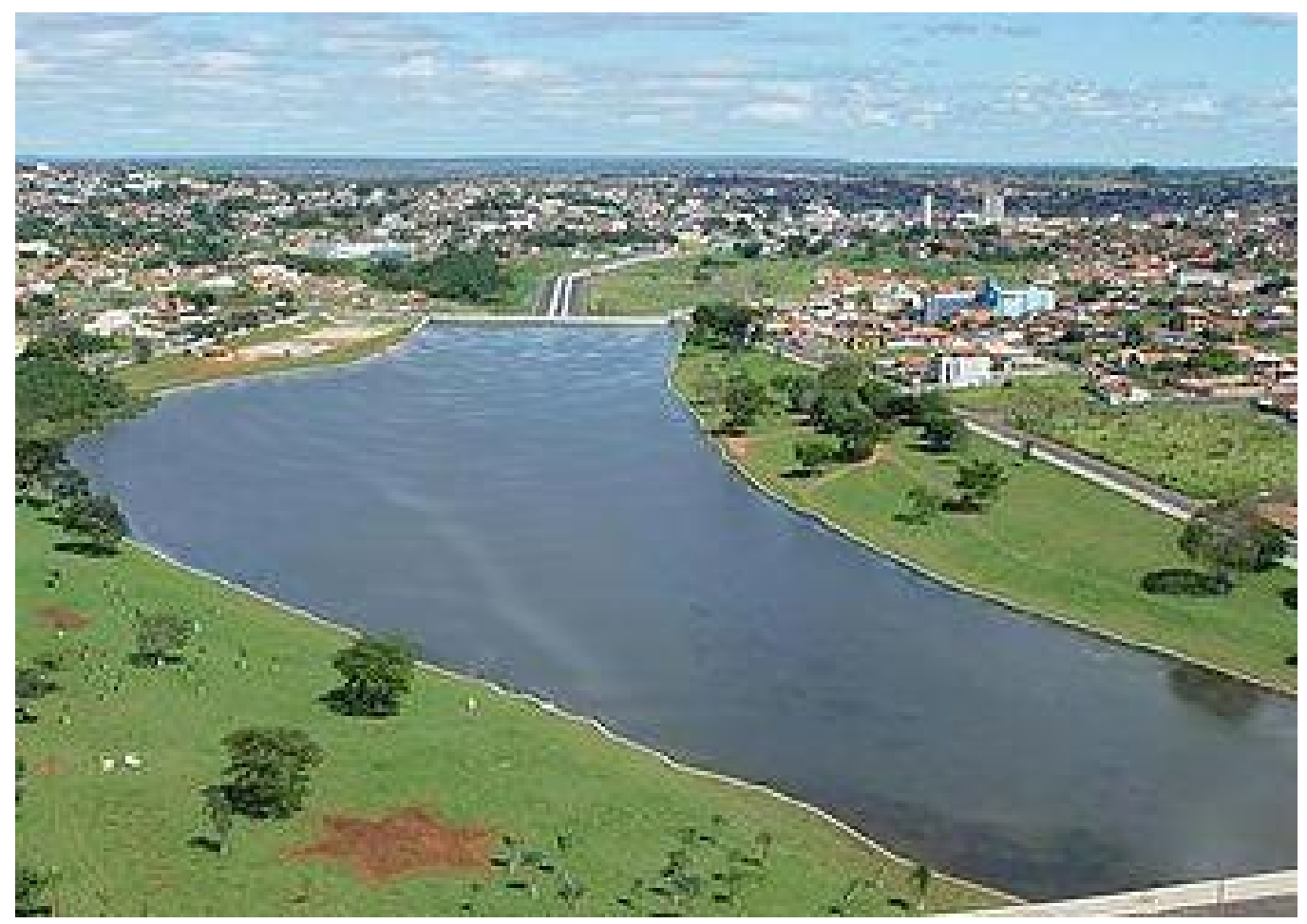

Figura 3.5: Quadro resultante da aplicação do modelo proposto.

como discutido no capítulo 7. A figura 3.5 mostra o resultado da aplicação do modelo proposto.

Nos próximos capítulos, discutimos detalhadamente cada um dos passos apresentados aqui. 


\section{Capítulo 4}

\section{Inferência tridimensional}

Chamamos de inferência tridimensional a caracterização do corpo d'água em seu plano original com relação ao plano da imagem dada. Esta caracterização é obtida a partir de algumas informações intrínsecas à imagem dada, quais sejam:

- linha do horizonte,

- inclinação frontal da câmera e

- inclinação lateral da câmera.

Inicialmente, vamos posicionar a imagem em um ambiente tridimensional, com relação ao corpo d'água e à câmera. Assumiremos aqui que o corpo d'água está no plano $x y$ de nosso ambiente tridimensional, a imagem está localizada no plano $\alpha$, que faz um ângulo $\theta$ com o plano $x y$ e a câmera está a uma distância $d_{f}$ do centro da imagem. A figura 4.1 esquematiza o ambiente relatado. Assumimos ainda que a projeção do plano $x y$ em $\alpha$, gerada pela câmera, é cônica. 


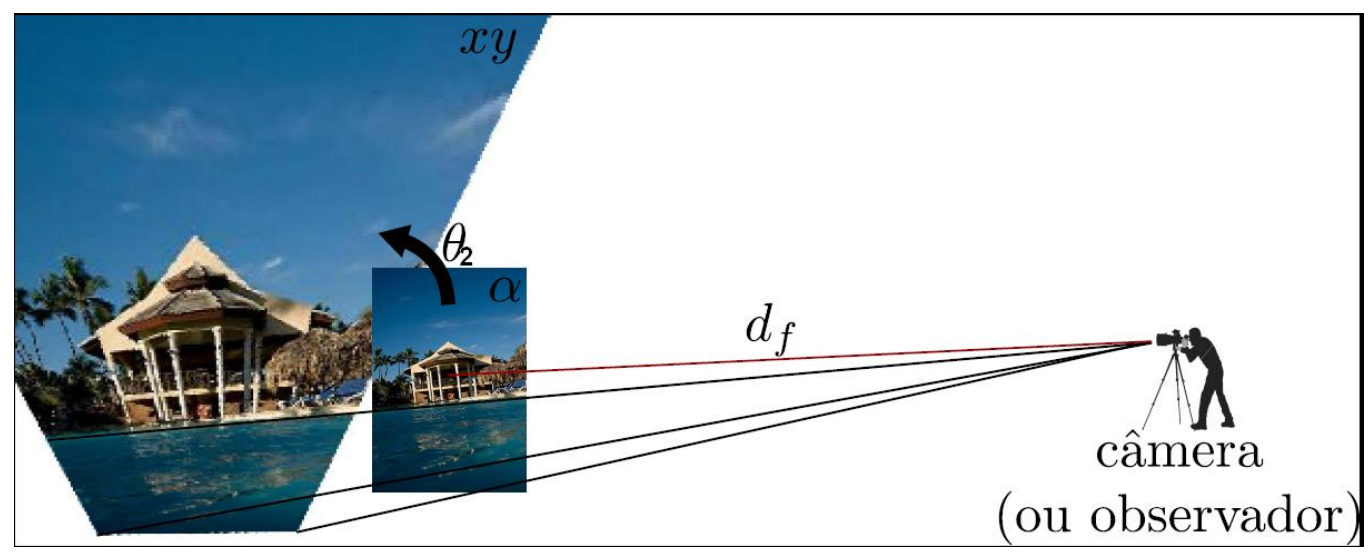

Figura 4.1: Posicionamento tridimensional da imagem.

Nas seções seguintes vamos caminhar para a inferência do ambiente relatado e, para isso, algumas definições e resultados tradicionais são adaptados ao nosso modelo.

\subsection{Linha do horizonte}

Definição 4.1 (Projeção Cônica) Uma projeção cônica de um dado objeto $\kappa$, a partir de um ponto $P$, em um plano $\alpha$ entre $\kappa$ e $P$, é o mapeamento dos pontos deste objeto, interceptados pelo segmento de reta iniciado em $P$ e finalizado em $\kappa$, na interseção deste segmento com o plano $\alpha$.

Teorema 4.1 Retas paralelas no plano xy, quando projetadas conicamente em um plano $\alpha$ não paralelo a xy, a partir de um ponto fora de $x y \cup \alpha$, ou se encontram em um único ponto de $\alpha$ ou são paralelas a $x y \cap \alpha$.

Prova. A prova deste teorema pode ser encontrada em [Hilbert \& CohnVossen 1952]. 
A primeira etapa desta fase consiste na identificação manual (na imagem) de dois pares de retas paralelas (em $x y$ ), com o objetivo de determinar a linha do horizonte (que pode, alternativamente, ser definida pelo usuário), a qual definiremos a seguir. Para isto o usuário deve desenhar, na imagem, quatro segmentos de reta $r_{1}^{\alpha}, r_{2}^{\alpha}, s_{1}^{\alpha}$ e $s_{2}^{\alpha}$, os quais são projeções de retas em $x y$ que chamaremos, respectivamente, de $r_{1}, r_{2}, s_{1}$ e $s_{2}$. Estas retas devem ser tais que:

- $r_{1}^{\alpha} \nmid r_{2}^{\alpha}$

- $s_{1}^{\alpha} \nVdash s_{2}^{\alpha}$

- $r_{1}\left\|r_{2} \nVdash s_{1}\right\| s_{2}$

Ou seja, o usuário deve identificar dois pares de retas, como indicado na figura 4.2-esquerda, que, no corpo d'água (no plano $x y$ ), sejam paralelas com seus pares, mas não sejam paralelas quando tomadas de pares diferentes; além disso, a projeção destes pares em $\alpha$ não deve originar retas paralelas.

Teorema $4.2 O$ conjunto de todos os pontos em $\alpha$ de intersecção de retas correspondentemente paralelas em xy formam uma reta.

Prova. A prova deste teorema pode ser encontrada em [Hilbert \& CohnVossen 1952].

Definição 4.2 (Linha do Horizonte) Linha do horizonte é a reta em $\alpha$, formada pelos pontos de interseção de retas correspondentemente paralelas em $x y$. 


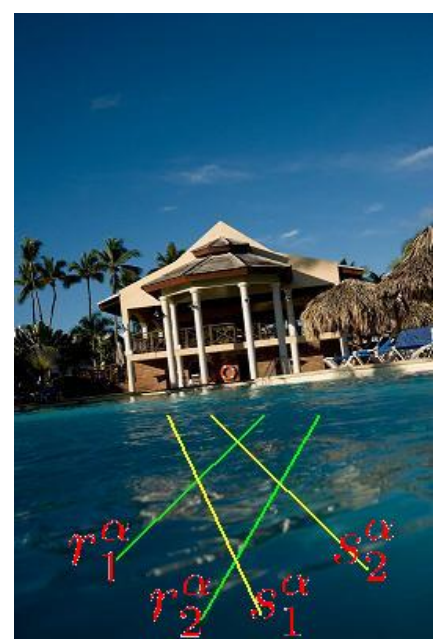

(a)

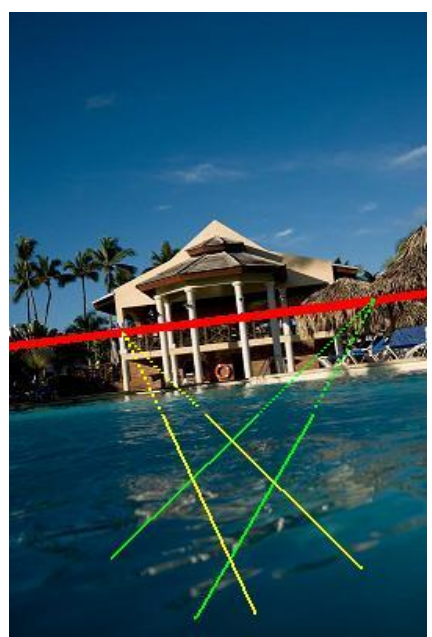

(b)

Figura 4.2: Identificação, à esquerda, de dois pares de segmentos de retas paralelas no plano do objeto e, à direita, determinação da linha do horizonte a partir dos prolongamentos destes segmentos.

Nossa linha do horizonte, então, é a reta que passa pelos pontos de intersecção dos prolongamentos de $r_{1}^{\alpha}$ e $r_{2}^{\alpha}$ e dos prolongamentos de $s_{1}^{\alpha}$ e $s_{2}^{\alpha}$. Ou seja as retas $r_{1}^{\alpha}, r_{2}^{\alpha}, s_{1}^{\alpha}$ e $s_{2}^{\alpha}$ são prolongadas e a reta $\overline{P_{r} P_{s}}$, formada pelos pontos $P_{r}=r_{1}^{\alpha} \cap r_{2}^{\alpha}$ e $P_{s}=s_{1}^{\alpha} \cap s_{2}^{\alpha}$, é chamada de linha do horizonte. Veja a ilustração na figura 4.2 -direita.

Observe que a linha do horizonte não tem correspondente na projeção em $x y$ e todo o plano $x y$ é projetado "abaixo" da linha do horizonte em $\alpha$.

Se a linha do horizonte, que chamaremos de $\hbar$, for paralela à linha longitudina 1 da imagem, dizemos que a imagem não está inclinada. Caso contrário, o ângulo $\theta_{1}$ entre a linha do horizonte e o prolongamento da linha longitudinal da imagem nos dá a inclinação da imagem (figura 4.3).

\footnotetext{
${ }^{1}$ Linha que corta a imagem de lado a lado, perpendicular à altura.
} 


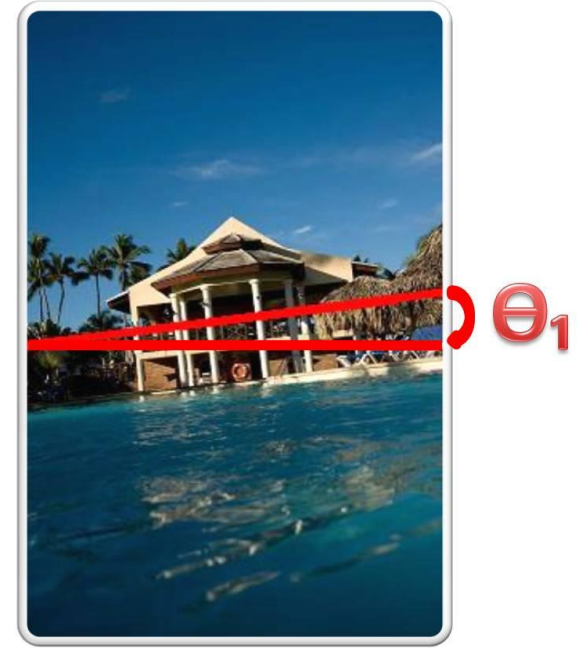

Figura 4.3: Ângulo de inclinação lateral da câmera.

\subsection{Distância focal}

Definição 4.3 (Eixo focal) O eixo do cone de projeção, em uma projeção cônica, é chamado de eixo focal.

Definição 4.4 (Ponto focal) O ponto de intersecção do eixo focal com o plano de projeção é chamado de ponto focal.

Definição 4.5 (Distância focal) A distância da câmera ao ponto focal é chamada de distância focal.

Concluímos, então, que distância focal é a distância da câmera ao ponto do plano da imagem para o qual a câmera está "olhando".

Assumiremos, neste trabalho, que a câmera "olha" para o centro da imagem, sempre na direção perpendicular ao plano da imagem. Ora, como assumimos que a câmera está a uma distância $d_{f}$ do centro da image, $d_{f}$ é a distância focal e a reta que liga o centro da imagem e a câmera é o eixo focal. 


\subsection{Calibração da câmera}

Dizemos que uma câmera está calibrada quando temos, em um ambiente tridimensional, bem determinados, o ponto de observação, os eixos ótico e de inclinação, a distância focal e a tela virtual. Vejamos:

- o ponto de observação é o ponto onde se localiza a câmera virtual,

- o eixo ótico, ou eixo focal, é a reta perpendicular ao plano de projeção (plano da imagem) e que passa pela câmera,

- o eixo de inclinação é a reta paralela ao plano da imagem, no sentido longitudinal, e que passa pela câmera,

- a distância focal é a distância da câmera ao plano de projeção e

- a tela virtual é o retângulo no plano de projeção, com centro no eixo ótico, correspondente à imagem original.

Para facilitar nosso trabalho, consideraremos três referenciais cartesianos ortonormais tridimensionais:

- o referencial do corpo d'água, dado por $\left(\mathbf{E},\left\{\overrightarrow{\mathbf{e}_{\mathbf{1}}}, \overrightarrow{\mathbf{e}_{\mathbf{2}}}, \overrightarrow{\mathbf{e}_{\mathbf{3}}}\right\}\right)$,

- o referencial da câmera, dado por $(\mathbf{O},\{\overrightarrow{\mathbf{o}}, \overrightarrow{\mathbf{v}}, \overrightarrow{\mathbf{l}}\})$ e

- o referencial da imagem, dado por $(\mathbf{C},\{\overrightarrow{\mathbf{i}}, \overrightarrow{\mathbf{j}}, \mathbf{k}\})$,

onde:

$\left(\mathbf{E},\left\{\overrightarrow{\mathbf{e}_{\mathbf{1}}}, \overrightarrow{\mathbf{e}_{\mathbf{2}}}, \overrightarrow{\mathbf{e}_{\mathbf{3}}}\right\}\right)$ é o referencial cartesiano,

O é a posição da câmera,

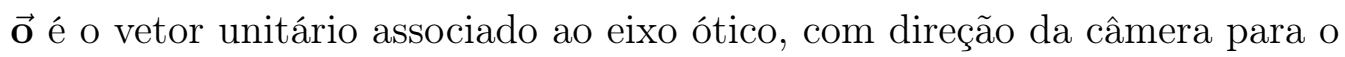
plano de projeção $\alpha$, 

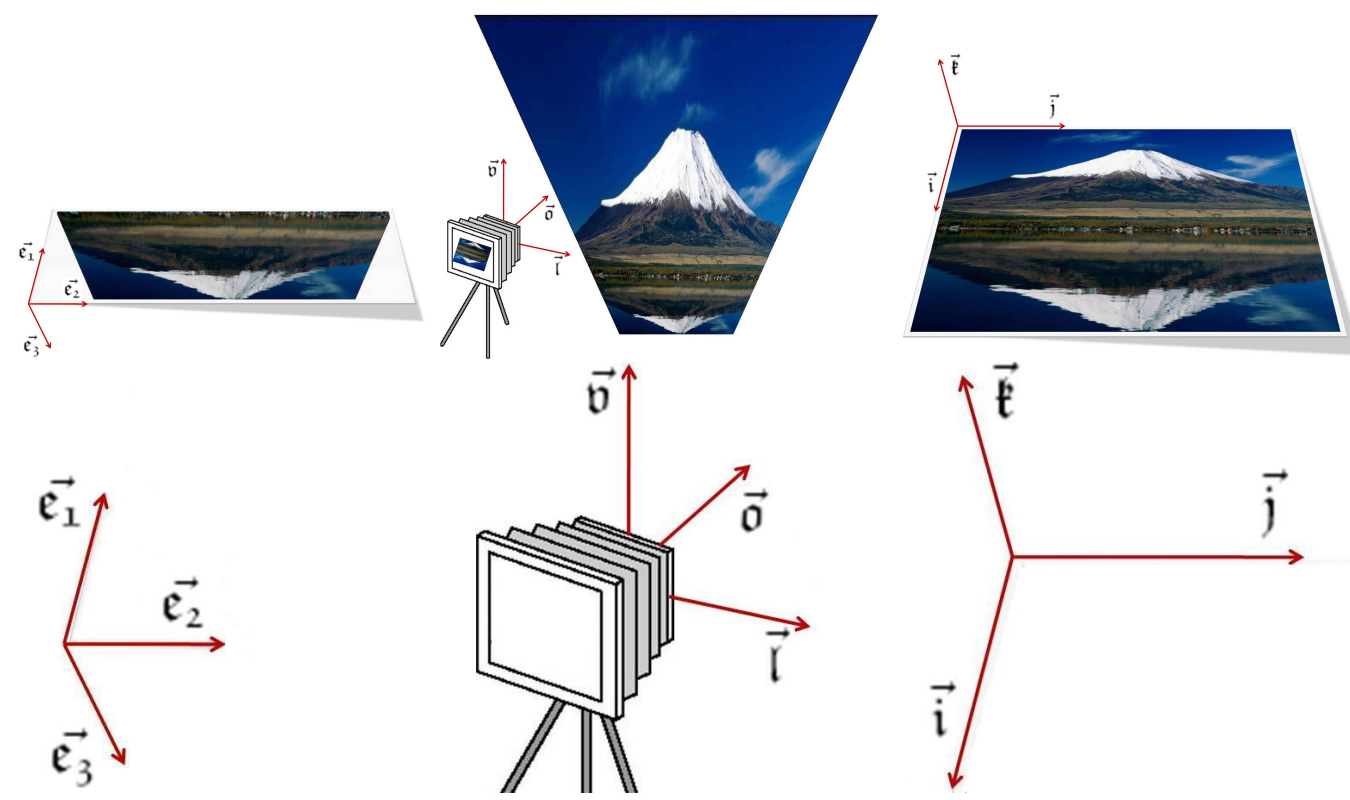

Figura 4.4: Referenciais cartesianos ortonormais, da esquerda para a direita, referencial do corpo d'água, referencial da câmera e referencial da imagem.

$\overrightarrow{\mathrm{l}}$ é o vetor unitário associado ao eixo de inclinação, também chamado eixo lateral, com direção da câmera para a direita da imagem à frente da câmera,

$\overrightarrow{\mathbf{v}}=\overrightarrow{\mathbf{l}} \times \overrightarrow{\mathbf{o}}$

C é o canto superior esquerdo da imagem, no plano $\alpha$,

$\overrightarrow{\mathbf{i}}$ é o vetor unitário associado à lateral da imagem, com direção de cima para baixo,

$\overrightarrow{\mathbf{j}}$ é o vetor unitário associado à longitude da imagem, com direção da esquerda para a direita e

$\overrightarrow{\mathbf{k}}=\overrightarrow{\mathbf{i}} \times \overrightarrow{\mathbf{j}}$

A figura 4.4 dá uma idéia esquemática dos três referenciais. 


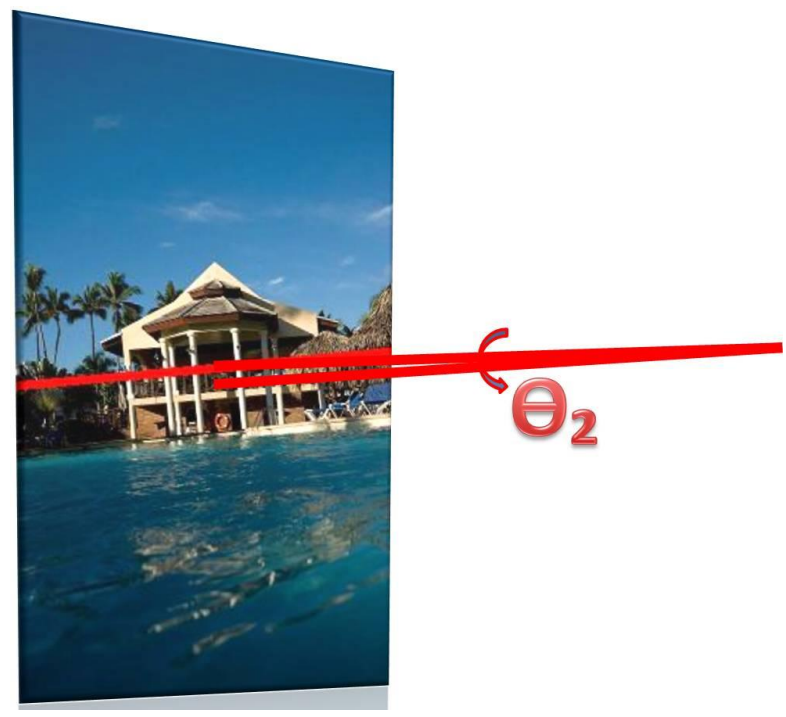

Figura 4.5: Ângulo de inclinação frontal da câmera.

Precisamos agora posicionar os referenciais da câmara e da imagem em relação ao referencial do objeto. Faremos esta inferência posicionando os referenciais, da câmara e da imagem, "encaixados" no referencial do objeto e, através de translações e rotações específicas, obteremos os valores de $\mathbf{O}$, $\mathrm{C}, \overrightarrow{\mathbf{o}}, \overrightarrow{\mathbf{v}}, \overrightarrow{\mathbf{l}}, \overrightarrow{\mathbf{i}}, \overrightarrow{\mathbf{j}}$ e $\overrightarrow{\mathbf{k}}$.

Antes de prosseguirmos, falta calcularmos duas importantes inclinações, quais sejam, as inclinações lateral e frontal da câmara. A inclinação lateral da câmera é a inclinação da imagem, ou seja, é dada pelo ângulo $\theta_{1}$ (figura 4.3) entre $\hbar$ e $\overrightarrow{\mathbf{j}}$, obtido, por definição, de $\overrightarrow{\mathbf{j}}$ para $\hbar$ na direção de $\overrightarrow{\mathbf{j}}$. A inclinação frontal da câmera é obtida admitindo-se que a câmara está de frente para o plano da imagem, ou seja $\overrightarrow{\mathbf{o}} \| \overrightarrow{\mathbf{k}}$ com a inclinação lateral dada anteriormente, ou seja, $\overrightarrow{\mathbf{v}} \| \hbar$. O ângulo $\theta_{2}$ (figura 4.5) entre o eixo ótico e a reta passando por $\mathbf{O}$ e perpendicular a $\hbar$ é a inclinação frontal da câmara. Observemos que, dado que conhecemos $\hbar$ e $d_{f}$ então conhecemos também $\theta_{1}$ e $\theta_{2}$.

Passemos então à calibração da câmara, inicialmente posicionando o referencial da câmara coincidente com o referencial do objeto e, em seguida, 


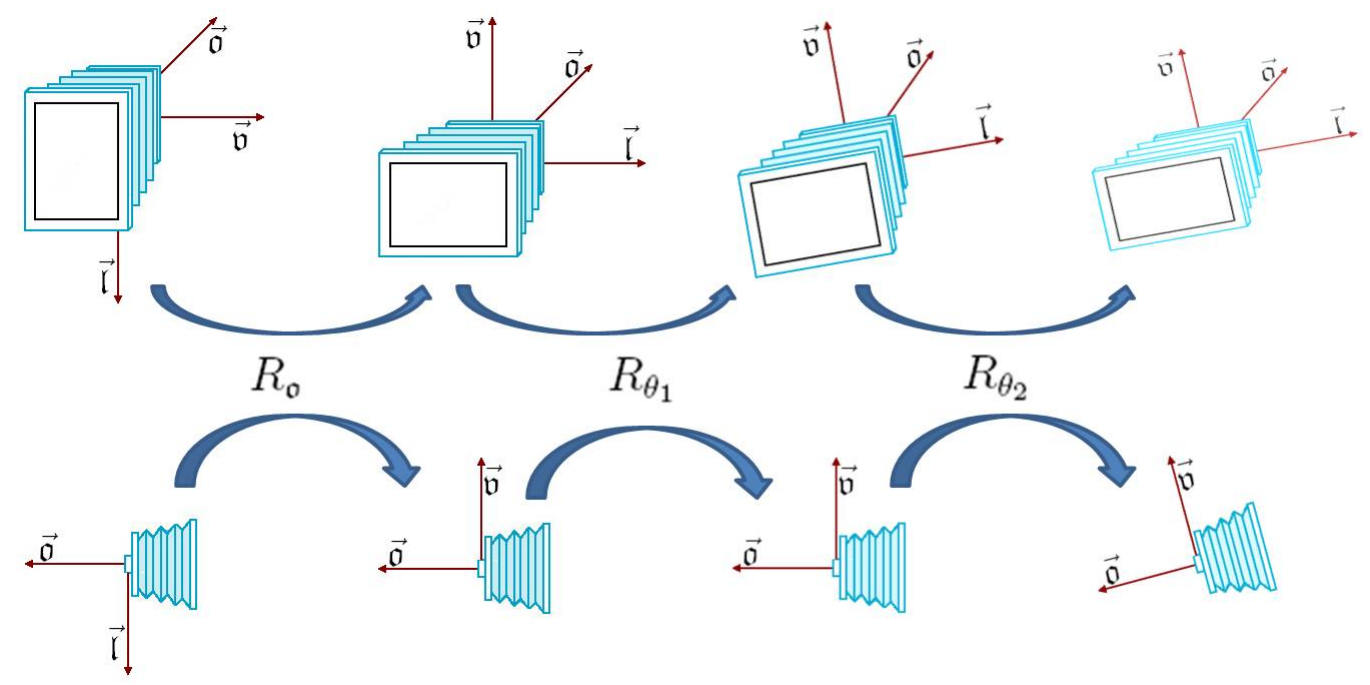

Figura 4.6: Sequência de rotações para calibração da câmera.

conforme o resumo esquemático na figura 4.6, rotacionando a câmara $-90^{\circ}$ em torno do eixo $\overrightarrow{\mathbf{e}_{\mathbf{1}}}$, ou seja, uma rotação de $90^{\circ}$ no sentido de $\overrightarrow{\mathbf{e}_{\mathbf{3}}}$ para $\overrightarrow{\mathbf{e}_{\mathbf{2}}}$. Esta rotação é obtida pela matriz de transformação, cuja dedução pode ser encontrada em [Foley, van Dam, Feiner \& Hughes 1996]:

$$
R_{\mathbf{o}}=\left[\begin{array}{cccc}
1 & 0 & 0 & 0 \\
0 & \cos \left(-\frac{\pi}{2}\right) & -\operatorname{sen}\left(-\frac{\pi}{2}\right) & 0 \\
0 & \operatorname{sen}\left(-\frac{\pi}{2}\right) & \cos \left(-\frac{\pi}{2}\right) & 0 \\
0 & 0 & 0 & 1
\end{array}\right]=\left[\begin{array}{cccc}
1 & 0 & 0 & 0 \\
0 & 0 & 1 & 0 \\
0 & -1 & 0 & 0 \\
0 & 0 & 0 & 1
\end{array}\right]
$$

Em seguida, uma rotação em torno do eixo ótico é necessária. Esta rotação inclina a câmera de tal maneira que a linha do horizonte fique na inclinação inferida anteriormente, ou seja, de um ângulo de $\theta_{1}$. Observe que, inclinar a linha do horizonte para a direita ou para a esquerda, é equivalente a inclinar a câmera, na mesma intensidade, para a esquerda ou para a direita, respectivamente. Assim, devemos rotacionar a câmera de $-\theta_{1}$ em torno do 
eixo $\overrightarrow{\mathbf{e}_{\mathbf{1}}}$, o que obtemos a partir da matriz:

$$
R_{\theta_{1}}=\left[\begin{array}{cccc}
1 & 0 & 0 & 0 \\
0 & \cos \left(-\theta_{1}\right) & -\operatorname{sen}\left(-\theta_{1}\right) & 0 \\
0 & \operatorname{sen}\left(-\theta_{1}\right) & \cos \left(-\theta_{1}\right) & 0 \\
0 & 0 & 0 & 1
\end{array}\right]=\left[\begin{array}{cccc}
1 & 0 & 0 & 0 \\
0 & \cos \theta_{1} & \operatorname{sen} \theta_{1} & 0 \\
0 & -\operatorname{sen} \theta_{1} & \cos \theta_{1} & 0 \\
0 & 0 & 0 & 1
\end{array}\right]
$$

Finalmente, é necessário efetuarmos uma rotação para posicionarmos o plano de projeção no ângulo correto com o plano do objeto. Esta rotação é obtida rotacionando de $-\theta_{2}$, lembrando que $\theta_{2}$ é o ângulo entre o plano $x y$ e o plano $\alpha$, em torno do eixo $\overrightarrow{\mathbf{e}_{\mathbf{2}}}$, o que obtemos a partir da matriz, cuja dedução pode ser encontrada em [Foley et al. 1996]:

$$
R_{\theta_{2}}=\left[\begin{array}{cccc}
\cos \left(-\theta_{2}\right) & 0 & \operatorname{sen}\left(-\theta_{2}\right) & 0 \\
0 & 1 & 0 & 0 \\
-\operatorname{sen}\left(-\theta_{2}\right) & 0 & \cos \left(-\theta_{2}\right) & 0 \\
0 & 0 & 0 & 1
\end{array}\right]=\left[\begin{array}{cccc}
\cos \theta_{2} & 0 & -\operatorname{sen} \theta_{2} & 0 \\
0 & 1 & 0 & 0 \\
\operatorname{sen} \theta_{2} & 0 & \cos \theta_{2} & 0 \\
0 & 0 & 0 & 1
\end{array}\right]
$$

Quanto à disposição espacial da câmera em relação ao plano do objeto, terminamos os cálculos. Mas algumas operações ainda são necessárias para inferir a posição levando em conta o plano de projeção com a imagem obtida. A primeira delas tem o intuito de posicionar a câmera a uma distância $d_{f}$ do centro da imagem e é obtida pela matriz:

$$
T_{d_{f}}=\left[\begin{array}{cccc}
1 & 0 & 0 & -d_{f} \\
0 & 1 & 0 & \frac{n}{2} \\
0 & 0 & 1 & \frac{m}{2} \\
0 & 0 & 0 & 1
\end{array}\right]
$$

onde $m$ é a altura da imagem e $n$ é a largura. Esta translação é efetuada antes das rotações lateral e frontal da câmera. 
Após as rotações lateral e frontal, uma translação é efetuada, objetivando minimizar a distorção provocada pela projeção, e é dada pela matriz:

$$
T_{c}=\left[\begin{array}{cccc}
1 & 0 & 0 & 0 \\
0 & 1 & 0 & 0 \\
0 & 0 & 1 & -\frac{\sqrt{m^{2}+n^{2}}}{2} \\
0 & 0 & 0 & 1
\end{array}\right] .
$$

As matrizes $T_{d_{f}}$ e $T_{c}$ foram obtidas empiricamente, com o objetivo de colocar a câmera em uma posição que a projeção cônica gerasse, inversamente, um objeto de máxima resolução e mínima distorção. É claro que este mesmo processo empírico, se realizado individualmente, produz valores distintos para $T_{d_{f}}$ e para $T_{c}$, mas os valores apresentados se mostraram convenientes para todos os experimentos realizados, apesar de poderem não ser ideais.

Finalmente então temos a câmera calibrada, obtida pela sequência de transformações dada pela aplicação sucessiva das transformações $R_{\mathbf{o}}, T_{d_{f}}$, $R_{\theta_{1}}, R_{\theta_{2}}$ e, finalmente, $T_{c}$. A calibração da câmera é, então, dada por:

$$
M_{c}=T_{c} \cdot R_{\theta_{2}} \cdot R_{\theta_{1}} \cdot T_{d_{f}} \cdot R_{\mathbf{o}}
$$

\subsection{Projeção inversa do corpo d'água}

Tendo conhecimento da posição da câmera podemos também inferir a posição da imagem bastando, para isto, efetuarmos a aplicação da seguinte matriz:

$$
M_{i}=T_{c} \cdot R_{\theta_{2}} \cdot R_{\theta_{1}} \cdot R_{\mathbf{j}}
$$


onde $R_{\mathbf{j}}$ é uma rotação de $-90^{\circ}$ em torno do eixo $\mathbf{e}_{\mathbf{2}}$ e é dada por:

$$
R_{\mathbf{j}}=\left[\begin{array}{cccc}
\cos \left(-\frac{\pi}{2}\right) & 0 & \operatorname{sen}\left(-\frac{\pi}{2}\right) & 0 \\
0 & 1 & 0 & 0 \\
-\operatorname{sen}\left(-\frac{\pi}{2}\right) & 0 & \cos \left(-\frac{\pi}{2}\right) & 0 \\
0 & 0 & 0 & 1
\end{array}\right]=\left[\begin{array}{cccc}
0 & 0 & -1 & 0 \\
0 & 1 & 0 & 0 \\
1 & 0 & 0 & 0 \\
0 & 0 & 0 & 1
\end{array}\right] .
$$

Seja então $(i, j)$ um ponto da imagem, para obtermos sua posição tridimensional conforme as inferências obtidas, basta efetuarmos a operação $(x, y, z, 1)=M_{i} \cdot(i, j, 0,1)$ que o ponto $(x, y, z)$ é a posição, nas coordenadas do objeto, o equivalente ao ponto $(i, j, 0)$ nas coordenadas da imagem.

A posição da câmera é obtida atravéz da operação $\left(x_{0}, y_{0}, z_{0}, 1\right)=M_{c}$. $(0,0,0,1)$, onde o ponto $\left(x_{0}, y_{0}, z_{0}\right)$ é a posição da câmera. Lembrando que o ponto $(x, y, z)$ é projeção cônica, a partir de $\left(x_{0}, y_{0}, z_{0}\right)$, de um ponto no plano $x y$, então o ponto $(p, q, 0)$ pertencente à reta que passa pelos pontos $\left(x_{0}, y_{0}, z_{0}\right)$ e $(x, y, z)$ é o ponto do objeto correspondente ao ponto da imagem $(i, j)$.

Fazendo este mesmo procedimento para todos os pontos da imagem, obtemos todo o objeto. Isto nos dá não só as coordenadas do nosso corpo d'água, como também sua textura.

\subsection{Determinando o domínio de simulação}

A partir dos parâmetros da câmera podemos posicionar as partes da imagem a serem animadas no espaço tridimensional. Mais especificamente, a partir dos parâmetros da câmera podemos projetar as camadas da imagem a serem animadas, em um plano horizontal do espaço tridimensional, como ilustrado na Figura 4.7. As equações de águas rasas são discretizadas para as camadas 


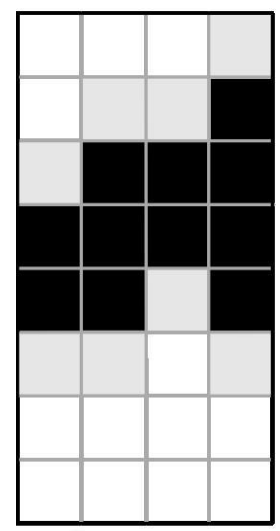

Camada da imagem

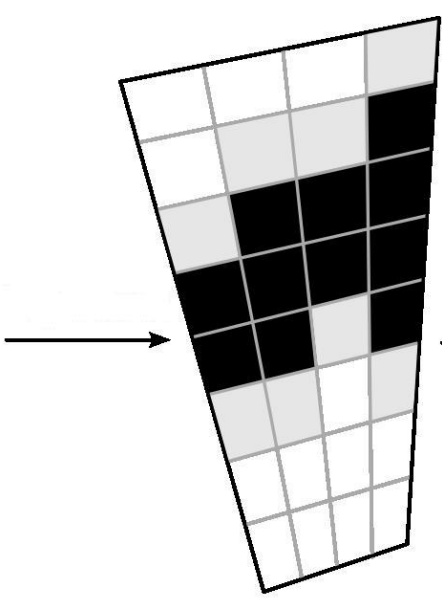

Camada projetada

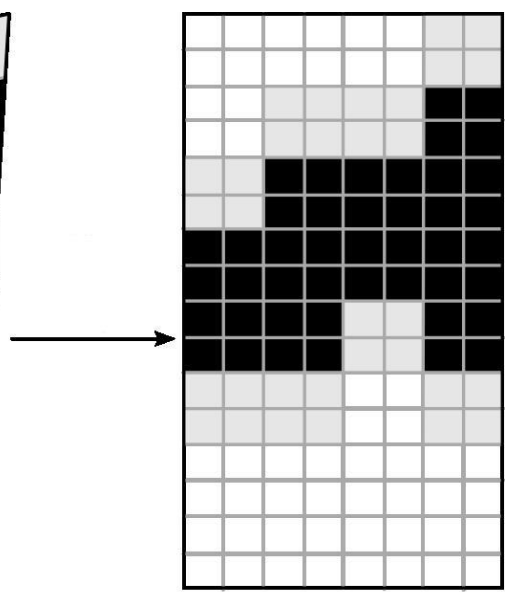

Grade de simulação

Figura 4.7: Mapeamento da imagem projetada no domínio de simulação.

projetadas, porém estes domínios não estão alinhados quadrilateralmente, o que prejudica a implementação do esquema de diferenças finitas.

Para executar o esquema numérico em uma malha cartesiana, o quadrilátero distorcido é mapeado em um domínio retangular com os eixos alinhados. O domínio retangular é então discretizado em uma malha regular, no mínimo duas vezes a resolução da imagem a ser animada. A malha cartesiana afinada proporciona a captura de mínimos detalhes do movimento durante a simulação, desta forma tornando a animação bastante realística.

Como mostrado na Figura 4.7, o mapa de segmentação, definindo as camadas da imagem, são também transportados para o domínio de simulação. Este recurso é utilizado para determinar as condições de fronteira e os parâmetros das equações de águas rasas. 


\section{Capítulo 5}

\section{Construção do domínio de simulação}

Nesta fase de nosso processo, o objetivo é determinar a malha em que será resolvido o sistema de equações de águas rasas.

Como resultado das fases anteriores, temos como dados de entrada:

- a imagem $I$ original, a ser animada;

- o objeto $O$ onde ocorrerá a simulação de águas rasas;

- o mapa de segmentação, presente na máscara $M$, indicando as fronteiras do objeto $O$ no plano da imagem $I$;

- a posição o do observador, onde está localizada a câmera;

- o plano $\alpha$, onde foi capturada a imagem $I$ pelo observador $o$;

- o plano $x y$, onde se localiza o objeto $O$.

Conforme ilustrado na figura 5.1, observemos que o objeto $O$ está mapeado, pela máscara $M$, no plano $\alpha$. Nosso primeiro objetivo aqui é mapear este 


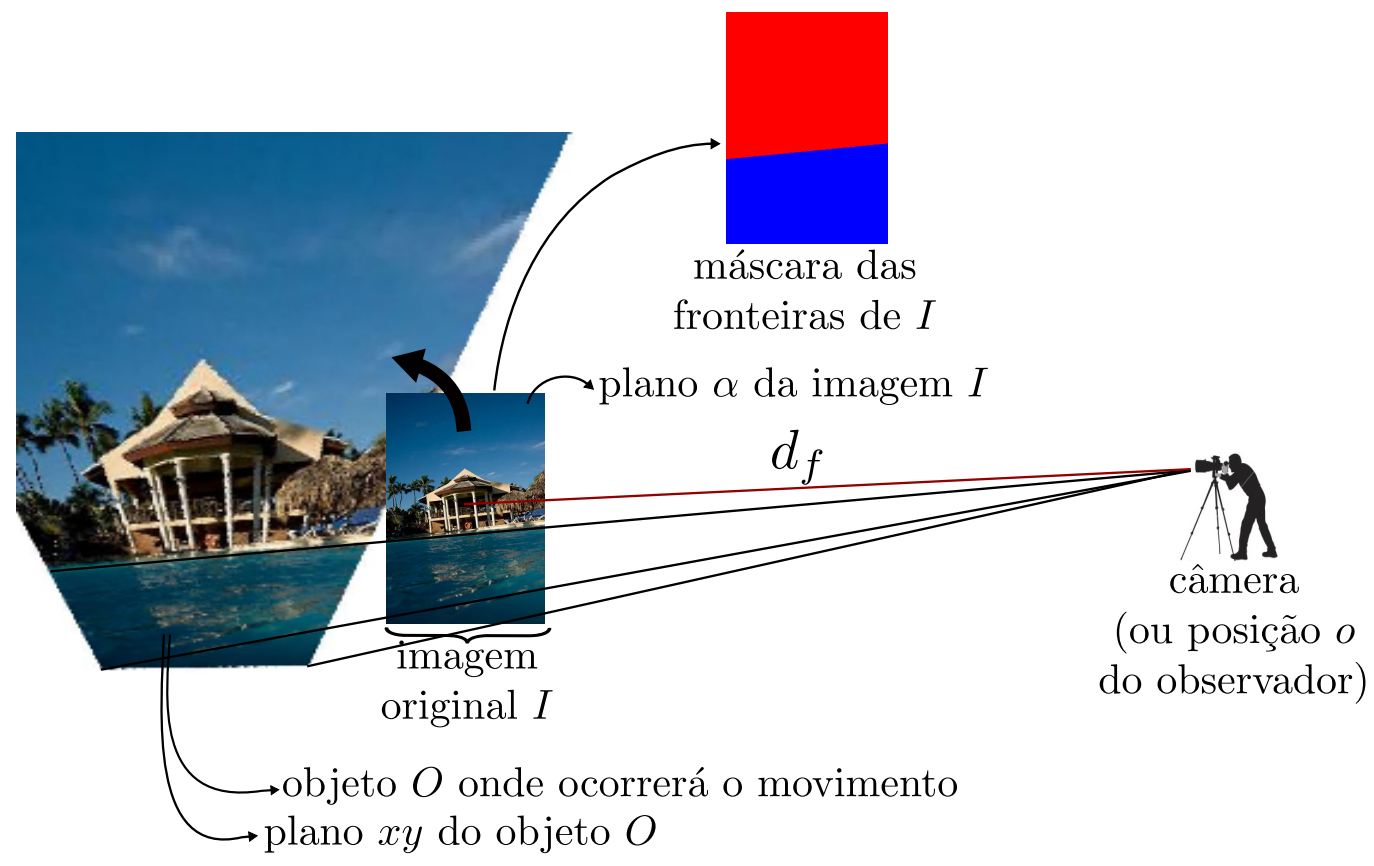

Figura 5.1: Dados de entrada para construção do domínio de simulação.

mesmo objeto $O$ no plano $x y$, para em seguida obtermos a malha desejada, também no plano $x y$.

Como, do capítulo anterior, sabemos mapear a imagem $I$, abaixo da linha do horizonte, no plano $x y$, podemos repetir o processo para $M$. Assim, efetuando o mesmo mapeamento para a máscara $M$ obteremos o mapeamento correspondente do objeto $O$ no plano $x y$. Temos, então, uma grade regular cobrindo o objeto $O$. Esta malha, mapeada no plano $x y$ e restrita aos limites do objeto $O$ em $x y$, é a que procuramos.

Ou seja, considerando que a projeção de $M$ em $x y$ tem células de dimensões unitárias $\left(\Delta_{x}=\Delta_{y}=1\right)$ e que cada uma corresponde a um elemento da projeção de $I$ em $x y$, a restrição ao objeto $O$, da projeção de $M$ em $x y$, nos dá uma malha de células unitárias que é a restrição do objeto $O$ da projeção de $M$ em $x y$. A mesma restrição, aplicada à projeção de $I$ em $x y$, nos dá a textura do objeto $O$. 
Observe a sequência ilustrada na figura 5.2 , inicialmente a imagem original (a) e sua máscara (b) são projetadas no plano $x y$ (c-d) e, em seguida a textura (e) e a malha (f) são obtidas restringindo as projeções aos limites do objeto aquoso. As figuras $5.3 \mathrm{a}$ e $5.3 \mathrm{~b}$ mostram, respectivamente, um zum de $10 \times$ e outro de $100 \times$ na malha representada na figura $5.2 \mathrm{f}$.

É importante observar que a malha, assim gerada, traz informações adicionais a cada célula, a partir do mapa de segmentação, dizendo:

- onde é "fronteira aberta", indicando a presença do fluido mesmo após este ponto,

- onde é "fronteira fechada", indicando que, ali, o fluido encontra um obstáculo,

- e onde deve ser simulado o movimento, isto é, os objetos aquosos, visíveis ou oclusos,

informações estas, presentes na máscara $M$, conforme indicado na figura 5.4 .

Esta malha, obtida "naturalmente" a partir da projeção reversa do objeto, nos induz a utilizar um método numérico apropriado a uma malha regular, o que será tratado no próximo capítulo, que utilizará esta malha para a resolução do sistema de equações de águas rasas e a fase seguinte poderá utilizar a textura correspondente no processo de renderização. 


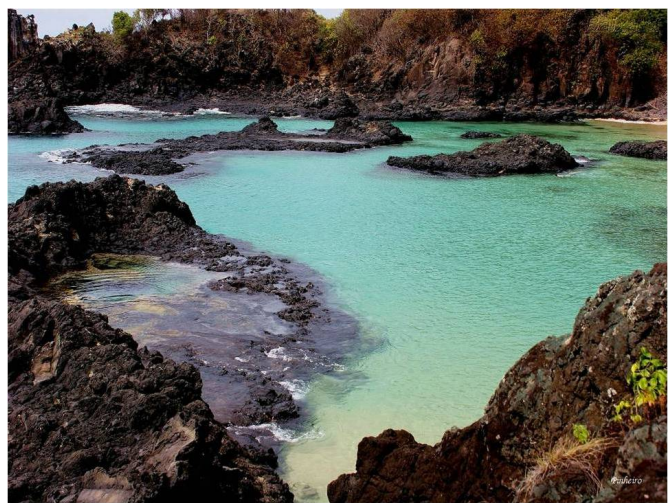

(a)

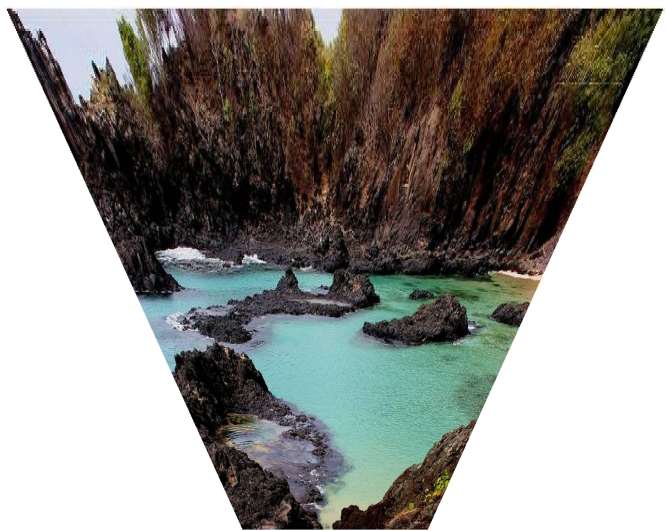

(c)

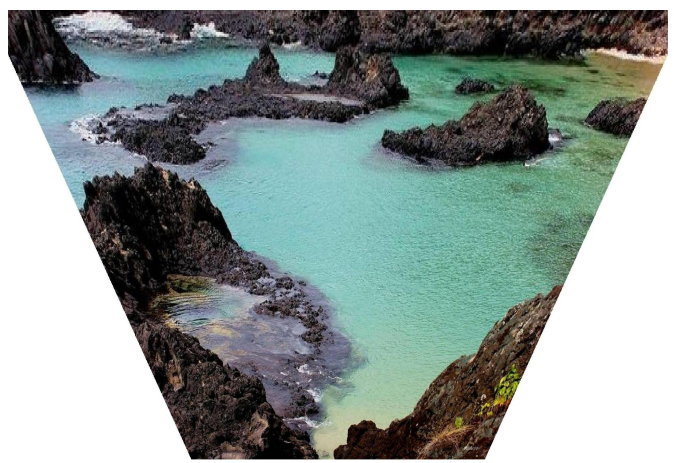

(e)

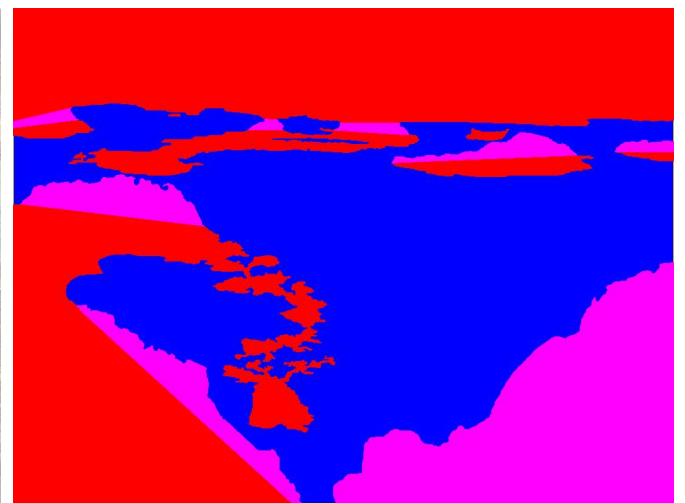

(b)

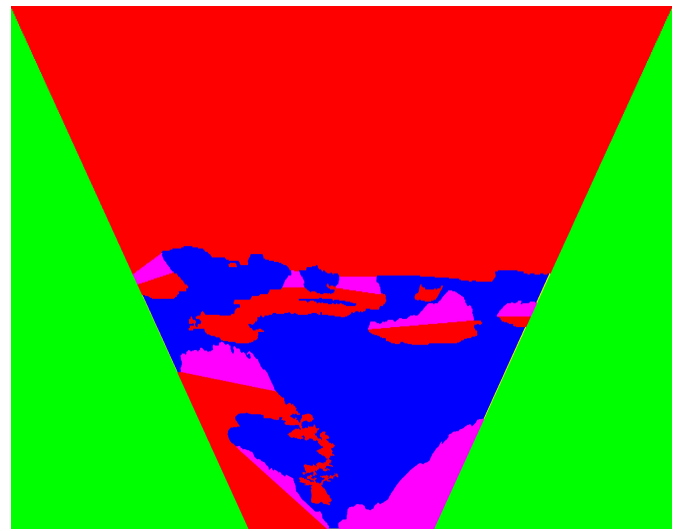

(d)

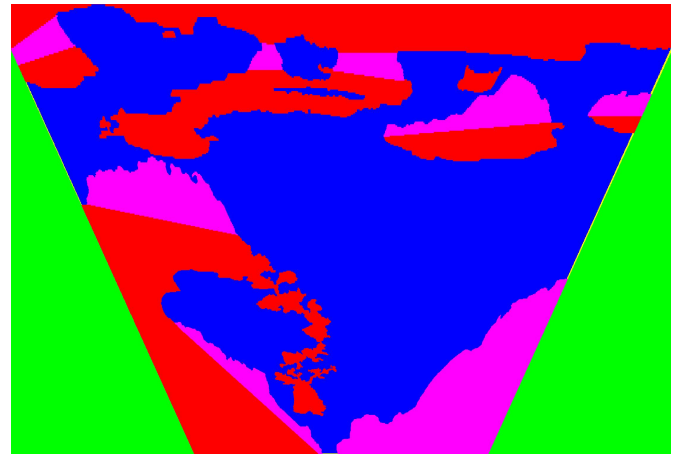

(f)

Figura 5.2: Sequência de malhamento. (a) imagem original no plano $\alpha$, (b) máscara no plano $\alpha$, (c) e (d) projeções no plano $x y$, (e) textura do objeto, restrição de (c), e (f) domínio de simulação $\Omega$, com informações de malha, restrição de (d). 


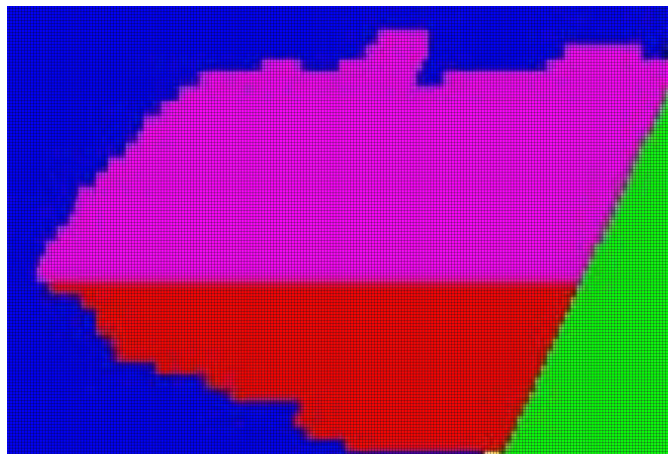

(a)

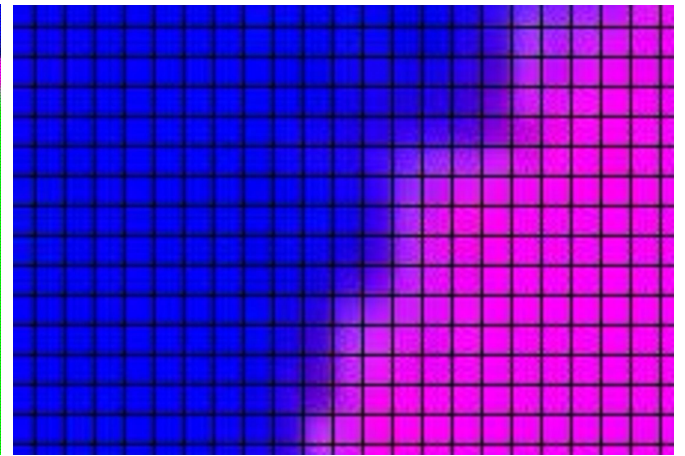

(b)

Figura 5.3: Zum da malha apresentada na figura 5.2:

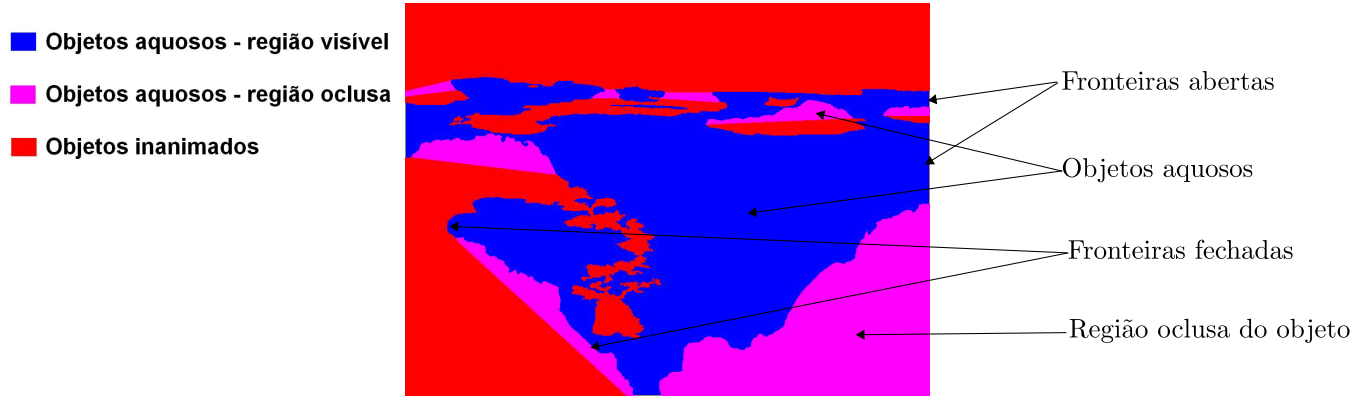

Figura 5.4: Máscara, fornecida pelo usuário, com o mapa de segmentação indicando as fronteiras do objeto. 


\section{Capítulo 6}

\section{Simulação física}

Nesta fase vamos resolver numericamente as equações de águas rasas, discutidas no apêndice A, e que são reproduzidas aqui para melhor conveniência:

$$
\begin{aligned}
& \frac{\partial h}{\partial t}+\frac{\partial(h u)}{\partial x}+\frac{\partial(h v)}{\partial y}=0 \\
& \frac{\partial(h u)}{\partial t}+\frac{\partial(h u v)}{\partial y}+\frac{\partial}{\partial x}\left(h u^{2}+\frac{g}{2}\left(h^{2}-H^{2}\right)\right) \\
&= \\
& f h v+g(h-H) \frac{\partial H}{\partial x}-\frac{g|\vec{u}| u}{C^{2} h}+F_{1} \\
& \frac{\partial(h v)}{\partial t}+\frac{\partial(h u v)}{\partial x}+\frac{\partial}{\partial y}\left(h v^{2}+\frac{g}{2}\left(h^{2}-H^{2}\right)\right) \\
&= \\
&-f h u+g(h-H) \frac{\partial H}{\partial y}-\frac{g|\vec{u}| v}{C^{2} h}+F_{2}
\end{aligned}
$$

Onde $t$ é o tempo, $(x, y)$ a posição espacial, $\vec{u}=(u, v)$ a velocidade do fluido, $g$ o módulo da acelaração da gravidade, $C$ o coeficiente de Chezy, $\left(F_{1}, F_{2}\right)$ 
a ação do vento na superfície, $f$ a aceleração de Coriolis e $H$ é o termo que define a topografia do fundo, relativamente ao nível médio da água, como ilustrado na figura 6.1 .
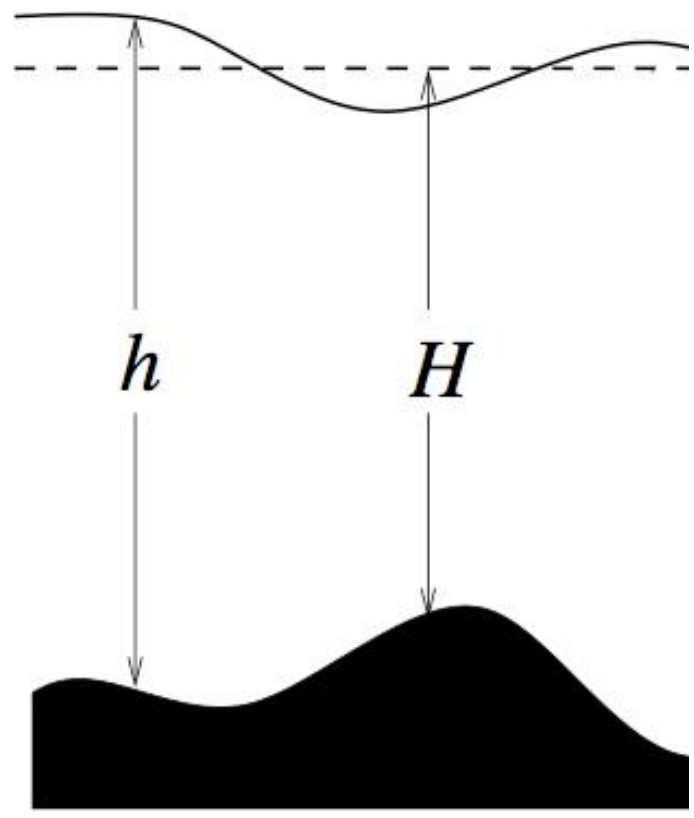

Figura 6.1: Altura instantânea $h$ e altura média $H$ do corpo d'água.

Na figura 6.1 ilustramos também o campo altura $h$, o qual varia com o tempo e possibilita, com isso, a visualização das ondas e o movimento do fluido, que é a essência de nosso processo de animação.

\subsection{Resolução numérica}

As equações 6.1, 6.2 e 6.3 serão resolvidas na malha obtida no capítulo anterior e consideraremos, como já foi dito, que nossa malha é composta por células dispostas uniformemente no plano $x y$ e de dimensões unitárias $(\Delta x=\Delta y=1)$. O método utilizado para resolvermos as referidas equações, apresentado a seguir, é baseado no método tradicional de Lax-Wendroff de 
dois passos [Lax \& Wendroff 1960] que duplica a densidade de nossa malha e onde, em um primeiro passo, resolvemos as equações governantes no tempo $t+\frac{\Delta t}{2}$, nos pontos intermediários de nossa malha e, num segundo passo, resolvemos as mesmas equações no tempo $t+\Delta t$, nos pontos originais da malha.

Inicialmente, vejamos as discretizações que iremos utilizar: considerando a função $\mathfrak{f}$ contínua e suficientemente diferenciável em $t$, podemos expandí-la em série de Taylor, com acréscimo $\Delta t$ a partir de $t$ e utilizando a notação $\mathfrak{f}^{\prime}(t) \equiv \frac{\partial \mathfrak{f}}{\partial t}$ e $\mathfrak{f}^{k}(t) \equiv \frac{\partial^{k} \mathfrak{f}}{\partial t^{k}}:$

$$
\mathfrak{f}(t+\Delta t)=\mathfrak{f}(t)+\Delta t \cdot \mathfrak{f}^{\prime}(t)+\sum_{k=2}^{\infty} \frac{(\Delta t)^{k}}{k !} \mathfrak{f}^{k}(t)
$$

com acréscimo $\frac{\Delta t}{2}$ a partir de $t$ :

$$
\mathfrak{f}\left(t+\frac{\Delta t}{2}\right)=\mathfrak{f}(t)+\frac{\Delta t}{2} \mathfrak{f}^{\prime}(t)+\sum_{k=2}^{\infty} \frac{(\Delta t)^{k}}{2^{k} k !} \mathfrak{f}^{k}(t)
$$

e com acréscimo $\frac{\Delta t}{2}$ a partir de $t+\frac{\Delta t}{2}$ :

$$
\mathfrak{f}(t+\Delta t)=\mathfrak{f}\left(t+\frac{\Delta t}{2}\right)+\frac{\Delta t}{2} \mathfrak{f}^{\prime}\left(t+\frac{\Delta t}{2}\right)+\sum_{k=2}^{\infty} \frac{(\Delta t)^{k}}{2^{k} k !} \mathfrak{f}^{k}\left(t+\frac{\Delta t}{2}\right)
$$

Substituindo a equação 6.5 na equação 6.6 obtemos:

$$
\mathfrak{f}(t+\Delta t)=\mathfrak{f}(t)+\frac{\Delta t}{2} \mathfrak{f}^{\prime}(t)+\frac{\Delta t}{2} \mathfrak{f}^{\prime}\left(t+\frac{\Delta t}{2}\right)+\sum_{k=2}^{\infty} \frac{(\Delta t)^{k}}{2^{k} k !}\left(\mathfrak{f}^{k}(t)+\mathfrak{f}^{k}\left(t+\frac{\Delta t}{2}\right)\right)
$$

a partir da equação 6.4 temos:

$$
\mathfrak{f}^{\prime}(t)=\frac{\mathfrak{f}(t+\Delta t)-\mathfrak{f}(t)}{\Delta t}-\sum_{k=2}^{\infty} \frac{(\Delta t)^{k-1}}{k !} \mathfrak{f}^{k}(t)
$$


e substituindo 6.8 em 6.7 obtemos:

$$
\begin{aligned}
\mathfrak{f}(t+\Delta t) & =\mathfrak{f}(t)+\frac{\Delta t}{2}\left(\frac{\mathfrak{f}(t+\Delta t)-\mathfrak{f}(t)}{\Delta t}-\sum_{k=2}^{\infty} \frac{(\Delta t)^{k-1}}{k !} \mathfrak{f}^{k}(t)\right)+ \\
& +\frac{\Delta t}{2} \mathfrak{f}^{\prime}\left(t+\frac{\Delta t}{2}\right)+\sum_{k=2}^{\infty} \frac{(\Delta t)^{k}}{2^{k} k !}\left(\mathfrak{f}^{k}(t)+\mathfrak{f}^{k}\left(t+\frac{\Delta t}{2}\right)\right) \\
& \Downarrow \\
\mathfrak{f}(t+\Delta t) & =\mathfrak{f}(t)+\frac{\mathfrak{f}(t+\Delta t)-\mathfrak{f}(t)}{2}+\frac{\Delta t}{2} \mathfrak{f}^{\prime}\left(t+\frac{\Delta t}{2}\right)+ \\
& +\sum_{k=2}^{\infty} \frac{(\Delta t)^{k}}{2^{k} k !}\left(\mathfrak{f}^{k}(t)+\mathfrak{f}^{k}\left(t+\frac{\Delta t}{2}\right)\right)-\sum_{k=2}^{\infty} \frac{(\Delta t)^{k}}{2 k !} \mathfrak{f}^{k}(t) \\
& \Downarrow \\
2 \mathfrak{f}(t+\Delta t) & =\mathfrak{f}(t)+\mathfrak{f}(t+\Delta t)+\Delta t \mathfrak{f}^{\prime}\left(t+\frac{\Delta t}{2}\right)+ \\
& +\sum_{k=2}^{\infty} \frac{(\Delta t)^{k}}{k !}\left(\frac{\mathfrak{f}^{k}(t)+\mathfrak{f}^{k}\left(t+\frac{\Delta t}{2}\right)}{2^{k-1}}\right)-\sum_{k=2}^{\infty} \frac{(\Delta t)^{k}}{k !} \mathfrak{f}^{k}(t) \\
& \Downarrow \mathfrak{f l}_{k=2}^{\infty} \frac{(\Delta t)^{k}}{k !}\left(\frac{\mathfrak{f}^{k}(t)+\mathfrak{f}^{k}\left(t+\frac{\Delta t}{2}\right)}{2^{k-1}}-\mathfrak{f}^{k}(t)\right) \\
& \left.+\sum_{\mathfrak{f}(t)+\Delta t+\mathfrak{f}^{\prime}\left(t+\frac{\Delta t}{2}\right)+} \sum^{\infty}\right)
\end{aligned}
$$

Considerando os erros da ordem de $(\Delta t)^{2}$ desprezíveis, a partir da equação 6.5 obtemos a aproximação

$$
\mathfrak{f}\left(t+\frac{\Delta t}{2}\right) \approx \mathfrak{f}(t)+\frac{\Delta t}{2} \mathfrak{f}^{\prime}(t)
$$

que é a equação base do primeiro passo de nosso método e, a partir da equação 6.9 obtemos a aproximação

$$
\mathfrak{f}(t+\Delta t) \approx \mathfrak{f}(t)+\Delta t \mathfrak{f}^{\prime}\left(t+\frac{\Delta t}{2}\right)
$$

que é a equação base do segundo passo.

Assim, no $1^{\circ}$ passo calculamos $h,(h u)$ e $(h v)$ no tempo $t+\frac{\Delta t}{2}$ conforme a equação 6.10 e, no $2^{\circ}$ passo calculamos $h,(h u)$ e $(h v)$ no tempo $t+\Delta t$ conforme a equação 6.11 . 


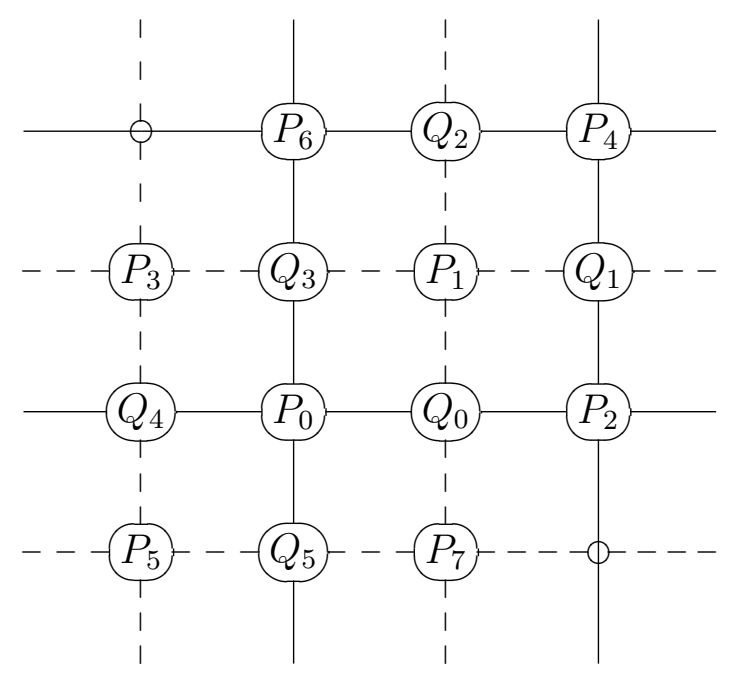

Figura 6.2: Estêncil utilizado no método apresentado.

O estêncil representado na figura 6.2 mostra os pontos de malha onde ocorrerão os cálculos. Os pontos $P_{0}, P_{2}, P_{4}$ e $P_{6}$ são originais da malha, já os pontos $P_{1}, P_{3}, P_{5}$ e $P_{7}$ são os pontos adicionados à malha no intuito de duplicar sua densidade e onde são efetuados os cálculos referentes ao $1^{\circ}$ passo do método. Os pontos $Q_{0}, Q_{1}, Q_{2}, Q_{3}, Q_{4}$ e $Q_{5}$ são auxiliares para os cálculos das derivadas parciais referentes às coordenadas espaciais e são obtidos pela média dos dois vizinhos mais próximos calculados no passo anterior ao passo em questão.

Exemplificando, seja o ponto $P_{0}$ do estêncil associado ao ponto $(i, j)$ da malha e admitamos conhecer todos os pontos do estêncil no tempo $t$. No tempo $t+\frac{\Delta t}{2}$ obtemos os valores no ponto $P_{1} \equiv\left(i+\frac{1}{2}, j+\frac{1}{2}\right)$ a partir da equação 6.10 de tal maneira que ao final do $1^{\circ}$ passo os valores nos pontos $P_{1}$, $P_{3}, P_{5}$ e $P_{7}$ são conhecidos, os pontos $Q_{0}, Q_{3}, Q_{4}$ e $Q_{5}$ são obtidos por média destes, ou seja, $Q_{0}=\frac{P_{1}+P_{7}}{2}$ e assim por adiante e os valores do ponto $P_{0}$, para efeito de cálculo de derivadas parciais referentes às coordenadas espaciais é 
obtido a partir da média $\frac{P_{1}+P_{3}+P_{5}+P_{7}}{4}$. Já no tempo $t+\Delta t$ os valores no ponto $P_{0}$ são calculados a partir da equação 6.11 sendo que ao final do $2^{\circ}$ passo os valores nos pontos $P_{0}, P_{2}, P_{4}$ e $P_{6}$ são conhecidos, e os pontos $Q_{0}, Q_{1}, Q_{2}$ e $Q_{3}$ são obtidos como anteriormente $\left(Q_{0}=\frac{P_{0}+P_{2}}{2}\right.$, etc. $)$.

As derivadas parciais referentes à coordenada temporal requeridas nas equações 6.10 e 6.11 são obtidas a partir do sistema de equações apresentado no início do capítulo. As equações A.10, A.36 e A.37 são aproximadas conforme as equações 6.10 e 6.11, fazendo $\mathfrak{f}=h, \mathfrak{f}=(h u)$ e $\mathfrak{f}=(h v)$, obtendo aproximações para $\frac{\partial h}{\partial t}$ e $\frac{\partial(h u)}{\partial t}$ e $\frac{\partial(h v)}{\partial t}$ em cada um dos passos do processo. As derivadas parciais referentes às coordenadas espaciais são obtidas através das aproximações centradas:

$$
\frac{\partial \mathfrak{f}(x, y)}{\partial x} \approx \frac{\mathfrak{f}\left(x+\frac{\Delta x}{2}, y\right)-\mathfrak{f}\left(x-\frac{\Delta x}{2}, y\right)}{\Delta x}
$$

$\mathrm{e}$

$$
\frac{\partial \mathfrak{f}(x, y)}{\partial y} \approx \frac{\mathfrak{f}\left(x, y+\frac{\Delta y}{2}\right)-\mathfrak{f}\left(x, y-\frac{\Delta y}{2}\right)}{\Delta y}
$$

assim, basta fazermos $\mathfrak{f}=(h u), \mathfrak{f}=(h v), \mathfrak{f}=\frac{(h u)(h v)}{h}, \mathfrak{f}=(h u)^{2}+\frac{g}{2}\left(h^{2}-H^{2}\right)$, $\mathfrak{f}=(h v)^{2}+\frac{g}{2}\left(h^{2}-H^{2}\right)$ e $\mathfrak{f}=H$ para obtermos as derivadas parciais $\frac{\partial(h u)}{\partial x} \mathrm{e}$ etc, necessárias para a resolução do sistema de equações de águas rasas.

Assim, lembrando que nossa malha tem dimensões unitárias, utilizando a notação $\mathfrak{f}_{i, j}^{t}$ para o valor de $\mathfrak{f}$ no ponto de malha $(i, j)$ no tempo $t$ e considerando $u_{i, j}^{t}=\frac{(h u)_{i, j}^{t}}{h_{i, j}^{t}}$ e $v_{i, j}^{t}=\frac{(h v)_{i, j}^{t}}{h_{i, j}^{t}}$, as versões discretas das equações A.10, A.36 e A.37, referentes ao primeiro passo do modelo apresentado são, respectivamente:

$$
\begin{aligned}
h_{i+\frac{1}{2}, j+\frac{1}{2}}^{t+\frac{\Delta t}{2}} & =h_{i+\frac{1}{2}, j+\frac{1}{2}}^{t}+ \\
& -\frac{\Delta t}{2}\left((h u)_{i+1, j+\frac{1}{2}}^{t}-(h u)_{i, j+\frac{1}{2}}^{t}+(h v)_{i+\frac{1}{2}, j+1}^{t}-(h v)_{i+\frac{1}{2}, j}^{t}\right)
\end{aligned}
$$




$$
\begin{aligned}
& (h u)_{i+\frac{1}{2}, j+\frac{1}{2}}^{t+\frac{\Delta t}{2}}=(h u)_{i+\frac{1}{2}, j+\frac{1}{2}}^{t}+\frac{\Delta t}{2}\left(f(h v)_{i+\frac{1}{2}, j+\frac{1}{2}}^{t}+\right. \\
& -\frac{g \sqrt{\left(u_{i+\frac{1}{2}, j+\frac{1}{2}}^{t}\right)^{2}+\left(v_{i+\frac{1}{2}, j+\frac{1}{2}}^{t}\right)^{2}} u_{i+\frac{1}{2}, j+\frac{1}{2}}^{t}}{\left(C_{i+\frac{1}{2}, j+\frac{1}{2}}\right)^{2} h_{i+\frac{1}{2}, j+\frac{1}{2}}^{t}}+ \\
& +g\left(h_{i+\frac{1}{2}, j+\frac{1}{2}}^{t}-H_{i+\frac{1}{2}, j+\frac{1}{2}}\right)\left(H_{i+1, j+\frac{1}{2}}-H_{i, j+\frac{1}{2}}\right)+ \\
& -\left(\left((h u)_{i+1, j+\frac{1}{2}}^{t} u_{i+1, j+\frac{1}{2}}^{t}+\frac{g}{2}\left(\left(h_{i+1, j+\frac{1}{2}}^{t}\right)^{2}-\left(H_{i+1, j+\frac{1}{2}}\right)^{2}\right)\right)+\right. \\
& \left.-\left((h u)_{i, j+\frac{1}{2}}^{t} u_{i, j+\frac{1}{2}}^{t}+\frac{g}{2}\left(\left(h_{i, j+\frac{1}{2}}^{t}\right)^{2}-\left(H_{i, j+\frac{1}{2}}\right)^{2}\right)\right)\right)+ \\
& \text { - } \left.\left((h u)_{i+\frac{1}{2}, j+1}^{t} v_{i+\frac{1}{2}, j+1}^{t}-(h u)_{i+\frac{1}{2}, j}^{t} v_{i+\frac{1}{2}, j}^{t}\right)+\frac{\tau_{1}}{\rho}\right) \\
& (h v)_{i+\frac{1}{2}, j+\frac{1}{2}}^{t+\frac{\Delta t}{2}}=(h v)_{i+\frac{1}{2}, j+\frac{1}{2}}^{t}+\frac{\Delta t}{2}\left(-f(h u)_{i+\frac{1}{2}, j+\frac{1}{2}}^{t}+\right. \\
& -\frac{g \sqrt{\left(u_{i+\frac{1}{2}, j+\frac{1}{2}}^{t}\right)^{2}+\left(v_{i+\frac{1}{2}, j+\frac{1}{2}}^{t}\right)^{2}} v_{i+\frac{1}{2}, j+\frac{1}{2}}^{t}}{\left(C_{i+\frac{1}{2}, j+\frac{1}{2}}\right)^{2} h_{i+\frac{1}{2}, j+\frac{1}{2}}^{t}}+ \\
& +g\left(h_{i+\frac{1}{2}, j+\frac{1}{2}}^{t}-H_{i+\frac{1}{2}, j+\frac{1}{2}}\right)\left(H_{i+\frac{1}{2}, j+1}-H_{i+\frac{1}{2}, j}\right)+ \\
& \text { - }\left(\left((h v)_{i+\frac{1}{2}, j+1}^{t} v_{i+\frac{1}{2}, j+1}^{t}+\frac{g}{2}\left(\left(h_{i+\frac{1}{2}, j+1}^{t}\right)^{2}-\left(H_{i+\frac{1}{2}, j+1}\right)^{2}\right)\right)+\right. \\
& \left.-\left((h v)_{i+\frac{1}{2}, j}^{t} v_{i+\frac{1}{2}, j}^{t}+\frac{g}{2}\left(\left(h_{i+\frac{1}{2}, j}^{t}\right)^{2}-\left(H_{i+\frac{1}{2}, j}\right)^{2}\right)\right)\right)+ \\
& \text { - } \left.\left((h u)_{i+1, j+\frac{1}{2}}^{t} v_{i+1, j+\frac{1}{2}}^{t}-(h u)_{i, j+\frac{1}{2}}^{t} v_{i, j+\frac{1}{2}}^{t}\right)+\frac{\tau_{2}}{\rho}\right)
\end{aligned}
$$

e as versões discretas das equações A.10, A.36 e A.37, referentes ao segundo passo do modelo apresentado são, respectivamente:

$$
\begin{aligned}
h_{i, j}^{t+\Delta t} & =h_{i, j}^{t}+ \\
& -\Delta t\left((h u)_{i+\frac{1}{2}, j}^{t+\frac{\Delta t}{2}}-(h u)_{i-\frac{1}{2}, j}^{t+\frac{\Delta t}{2}}+(h v)_{i, j+\frac{1}{2}}^{t+\frac{\Delta t}{2}}-(h v)_{i, j-\frac{1}{2}}^{t+\frac{\Delta t}{2}}\right)
\end{aligned}
$$




$$
\begin{aligned}
& (h u)_{i, j}^{t+\Delta t}=(h u)_{i, j}^{t}+\Delta t\left(f(h v)_{i, j}^{t+\frac{\Delta t}{2}}+\right. \\
& -\frac{g \sqrt{\left(u_{i, j}^{t+\frac{\Delta t}{2}}\right)^{2}+\left(v_{i, j}^{t+\frac{\Delta t}{2}}\right)^{2}} u_{i, j}^{t+\frac{\Delta t}{2}}}{\left(C_{i, j}\right)^{2} h_{i, j}^{t+\frac{\Delta t}{2}}}+ \\
& +g\left(h_{i, j}^{t+\frac{\Delta t}{2}}-H_{i, j}\right)\left(H_{i+\frac{1}{2}, j}-H_{i-\frac{1}{2}, j}\right)+ \\
& -\left(\left((h u)_{i+\frac{1}{2}, j}^{t+\frac{\Delta t}{2}} u_{i+\frac{1}{2}, j}^{t+\frac{\Delta t}{2}}+\frac{g}{2}\left(\left(h_{i+\frac{1}{2}, j}^{t+\frac{\Delta t}{2}}\right)^{2}-\left(H_{i+\frac{1}{2}, j}\right)^{2}\right)\right)+\right. \\
& \left.-\left((h u)_{i-\frac{1}{2}, j}^{t+\frac{\Delta t}{2}} u_{i-\frac{1}{2}, j}^{t+\frac{\Delta t}{2}}+\frac{g}{2}\left(\left(h_{i-\frac{1}{2}, j}^{t+\frac{\Delta t}{2}}\right)^{2}-\left(H_{i-\frac{1}{2}, j}\right)^{2}\right)\right)\right)+ \\
& \left.-\left((h u)_{i, j+\frac{1}{2}}^{t+\frac{\Delta t}{2}} v_{i, j+\frac{1}{2}}^{t+\frac{\Delta t}{2}}-(h u)_{i, j-\frac{1}{2}}^{t+\frac{\Delta t}{2}} v_{i, j-\frac{1}{2}}^{t+\frac{\Delta t}{2}}\right)+\frac{\tau_{1}}{\rho}\right) \\
& (h v)_{i, j}^{t+\Delta t}=(h v)_{i, j}^{t}+\Delta t\left(-f(h u)_{i, j}^{t+\frac{\Delta t}{2}}+\right. \\
& -\frac{g \sqrt{\left(u_{i, j}^{t+\frac{\Delta t}{2}}\right)^{2}+\left(v_{i, j}^{t+\frac{\Delta t}{2}}\right)^{2}} v_{i, j}^{t+\frac{\Delta t}{2}}}{\left(C_{i, j}\right)^{2} h_{i, j}^{t+\frac{\Delta t}{2}}}+ \\
& +g\left(h_{i, j}^{t+\frac{\Delta t}{2}}-H_{i, j}\right)\left(H_{i, j+\frac{1}{2}}-H_{i, j-\frac{1}{2}}\right)+ \\
& -\left(\left((h v)_{i, j+\frac{1}{2}}^{t+\frac{\Delta t}{2}} v_{i, j+\frac{1}{2}}^{t+\frac{\Delta t}{2}}+\frac{g}{2}\left(\left(h_{i, j+\frac{1}{2}}^{t+\frac{\Delta t}{2}}\right)^{2}-\left(H_{i, j+\frac{1}{2}}\right)^{2}\right)\right)+\right. \\
& \left.-\left((h v)_{i, j-\frac{1}{2}}^{t+\frac{\Delta t}{2}} v_{i, j-\frac{1}{2}}^{t+\frac{\Delta t}{2}}+\frac{g}{2}\left(\left(h_{i, j-\frac{1}{2}}^{t+\frac{\Delta t}{2}}\right)^{2}-\left(H_{i, j-\frac{1}{2}}\right)^{2}\right)\right)\right)+ \\
& \left.-\left((h u)_{i+\frac{1}{2}, j}^{t+\frac{\Delta t}{2}} v_{i+\frac{1}{2}, j}^{t+\frac{\Delta t}{2}}-(h u)_{i-\frac{1}{2}, j}^{t+\frac{\Delta t}{2}} v_{i-\frac{1}{2}, j}^{t+\frac{\Delta t}{2}}\right)+\frac{\tau_{2}}{\rho}\right)
\end{aligned}
$$

As equações 6.14 a 6.19 foram implementas considerando $f, g, \frac{\tau_{1}}{\rho}$ e $\frac{\tau_{2}}{\rho}$ dados numéricos de entrada e $h^{0}, H$ e $C$ matrizes numéricas de mesma dimensão da malha, inseridas a partir de imagens de entrada. 


\subsection{Considerações sobre os arquivos de entrada}

Na simulação física relatada, alguns parâmetros de entradas são informados pelo usuário, quais sejam:

- altura média $H$ do corpo d'água,

- altura inicial $h^{0}$ do corpo d'água,

- coeficiente de Chezy $C$, que controla o atrito de fundo,

- ação do vento $\left(F_{1}, F_{2}\right)$ na superfície e

- aceleração $f$ de Coriolis.

Estes parâmetros, com exceção de $F_{1}, F_{2}$ e $f$, que são escalares, são inicializados a partir de imagens em tons de cinza. Estas imagens são interpretadas como um campo de valores associado ao respectivo parâmetro e cujos valores são associados ao intervalo $[0,1]$ conforme a intensidade de cinza de cada elemento da imagem, associando o zero ao preto e a unidade ao branco.

As figuras 6.3 e 6.4 mostram resultados de experimentos com imagens de entrada para os parâmetros $C$ e $H$, em diferentes tons de cinza. Cada coluna representa um experimento, mostrando quadros em diferentes posições temporais e, na última linha, apresentamos a imagem utilizada como parâmetro. Na figura 6.3 as imagens na última linha representam o coeficiente de Chezy $C$ enquanto $H$ é considerado constante e unitário. Já na figura 6.4. as imagens da última linha representam a altura média da água $H$, que nos dá o formato do leito, enquanto o coeficiente de Chezy, agora, é considerado constante e unitário.

Na figura 6.5 observamos exemplos de inicialização para $h^{0}$. Cada linha representa um experimento, onde apresentamos, na primeira imagem, a imagem utilizada na inicialização de $h^{0}$, ou seja, a altura da água no início do 

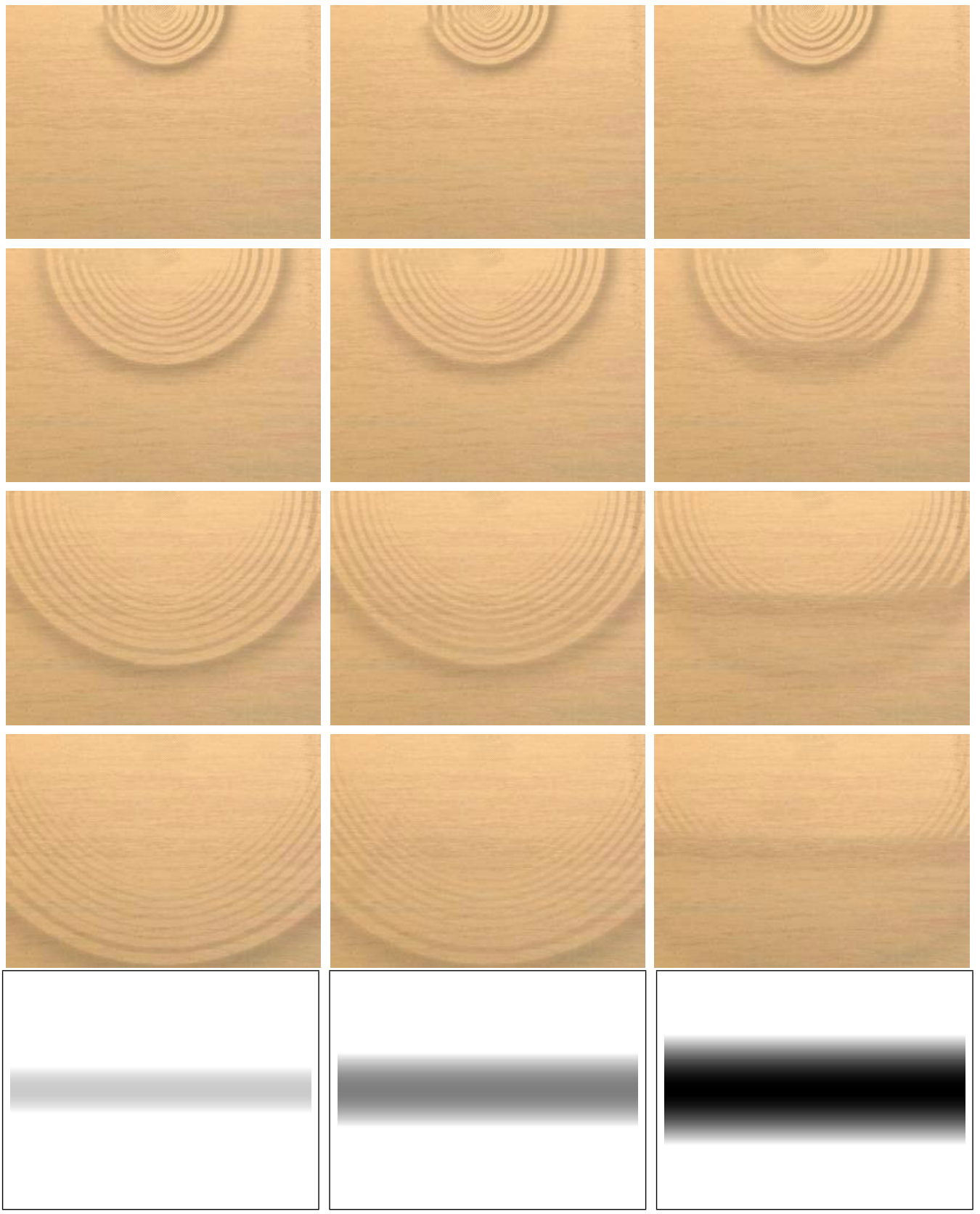

Figura 6.3: Variação no coeficiente de Chezy: cada coluna representa um experimento que tem como entrada do parâmetro $C$ a imagem na última linha e mantendo $H=1$ constante. Da esquerda para a direita, vemos o efeito do aumento do atrito na região central do objeto. 

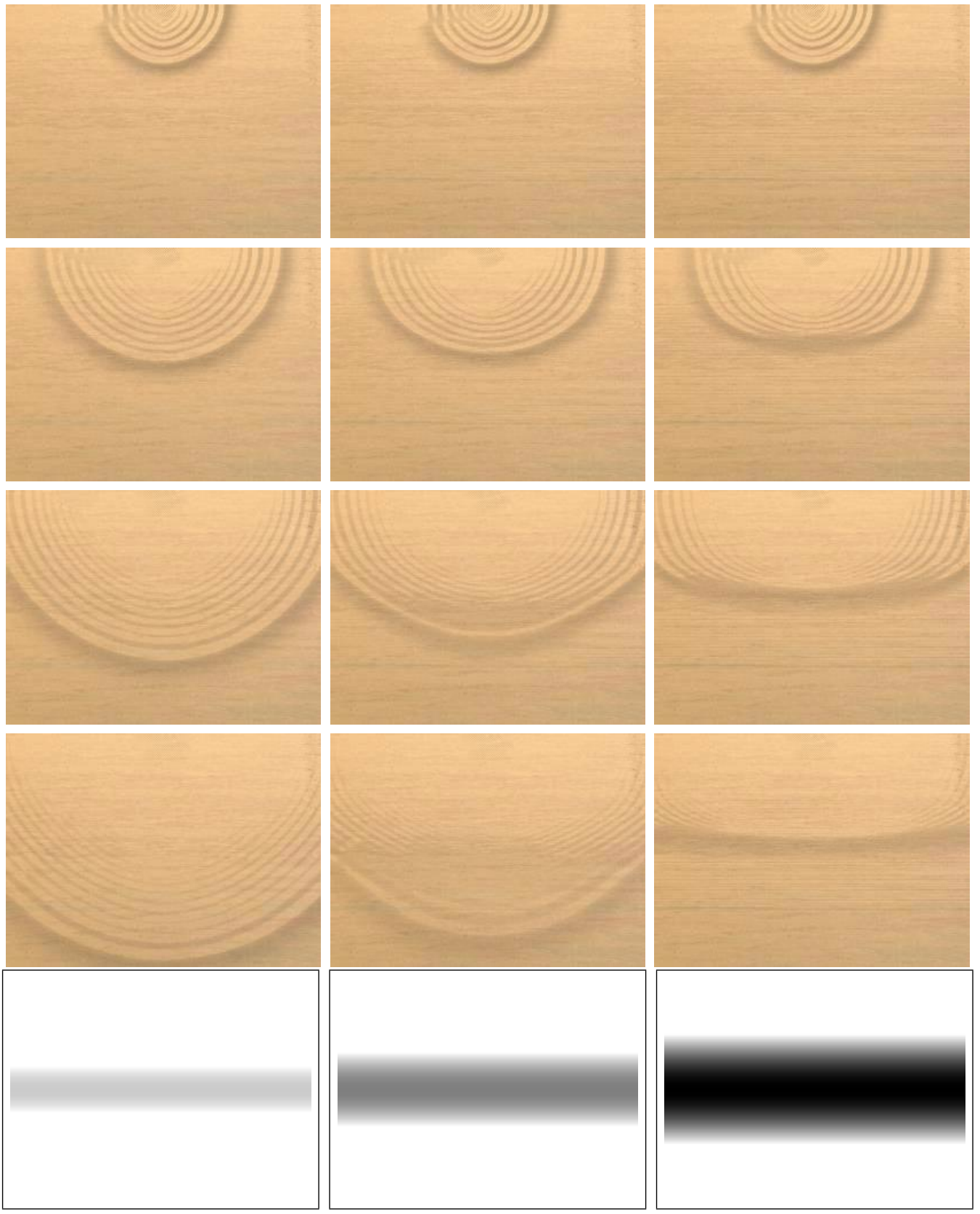

Figura 6.4: Variação na topografia: cada coluna representa um experimento que tem como entrada do parâmetro $H$ a imagem na última linha e mantendo $C=1$ constante. 

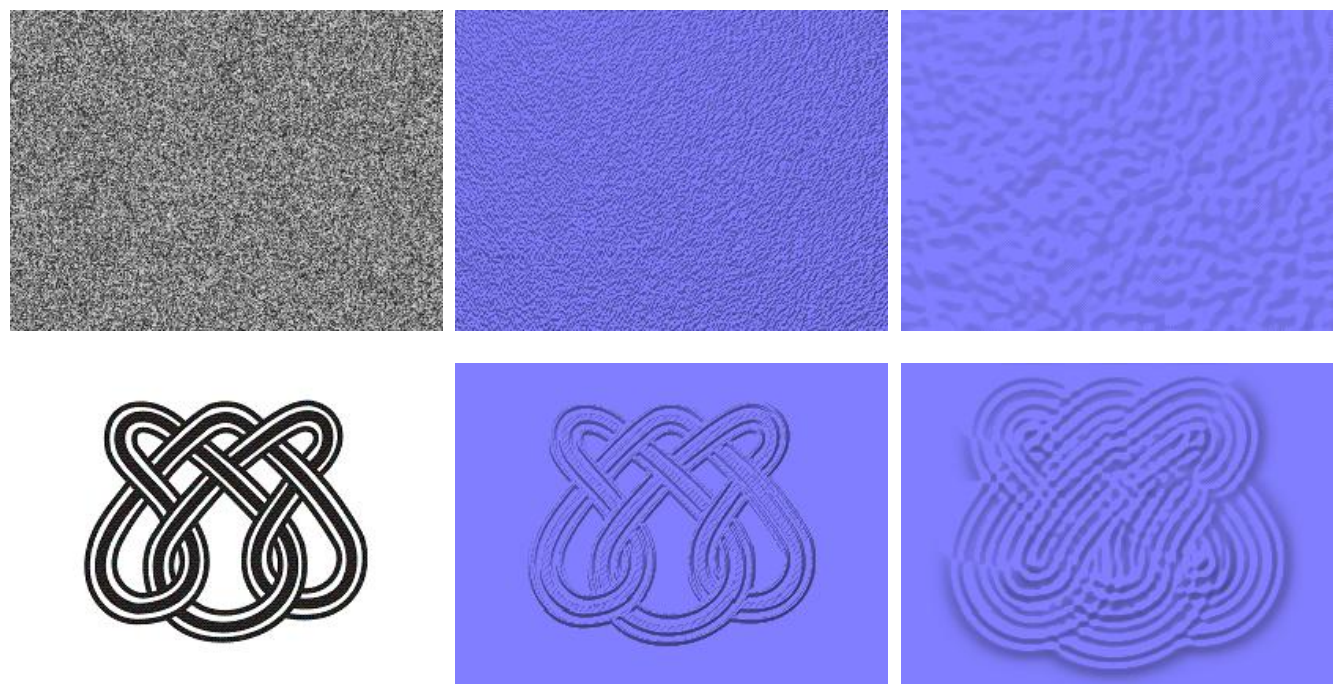

Figura 6.5: Dois experimentos com $h^{0}$ inicializados pelas imagens da esquerda. Imagens centrais indicando a inicialização da superfície e as imagens da direita, a superfície durante a simulação.

movimento. A segunda imagem é o primeiro quadro do movimento e a última é um quadro no transcorrer da simulação.

Além disso, o parâmetro $\left(F_{1}, F_{2}\right)$ e a altura da onda $h$, podem ser perturbados durante o experimento, como ocorre nos experimentos apresentados nas figuras 6.6 e 6.7 .

A figura 6.6 mostra um experimento com $\left(F_{1}, F_{2}\right)=(0,0)$ e uma onda gerada por uma perturbação inicial em $h^{0}$ em um único ponto de malha, no centro superior do objeto aquoso. Na segunda linha, efetuamos uma perturbação nas forças $\left(F_{1}, F_{2}\right)$ durante cinco intervalos de tempo, do tempo 50 ao tempo 55, voltando a zerá-las após este intervalo. O vetor correspondente à perturbação é representado ao lado.

Já na figura 6.7 é a altura da onda $h$ que é perturbada. Durante todo o experimento, a altura da onda $h$ é alterada, em posições aleatórias, rece- 

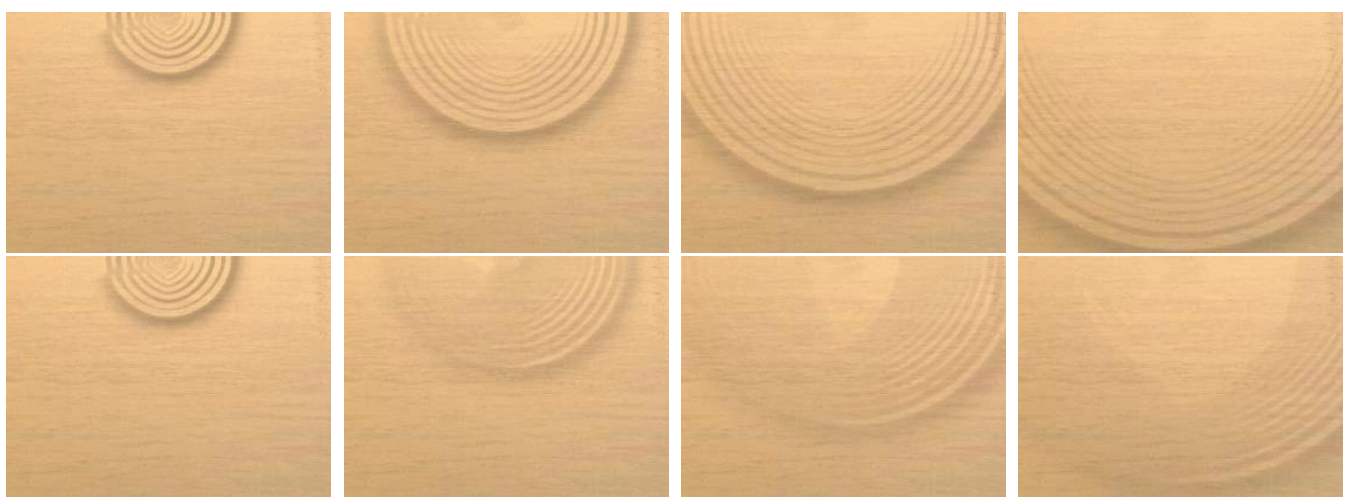

Figura 6.6: A primeira linha apresenta um experimento onde a ação do vento é nula. Na segunda linha, apresentamos a ação do vento aplicada na direção diagonal, no sentido do canto inferior esquerdo do objeto ao canto superior direito, durante os tempos 50 a 55 . Fora deste intervalo temporal a força é nula. As colunas representam, respectivamente, os resultados nos tempo 50, 100, 150 e 200.

bendo valores também aleatórios. Mostramos a imagem original utilizada no experimento e um quadro da simulação.
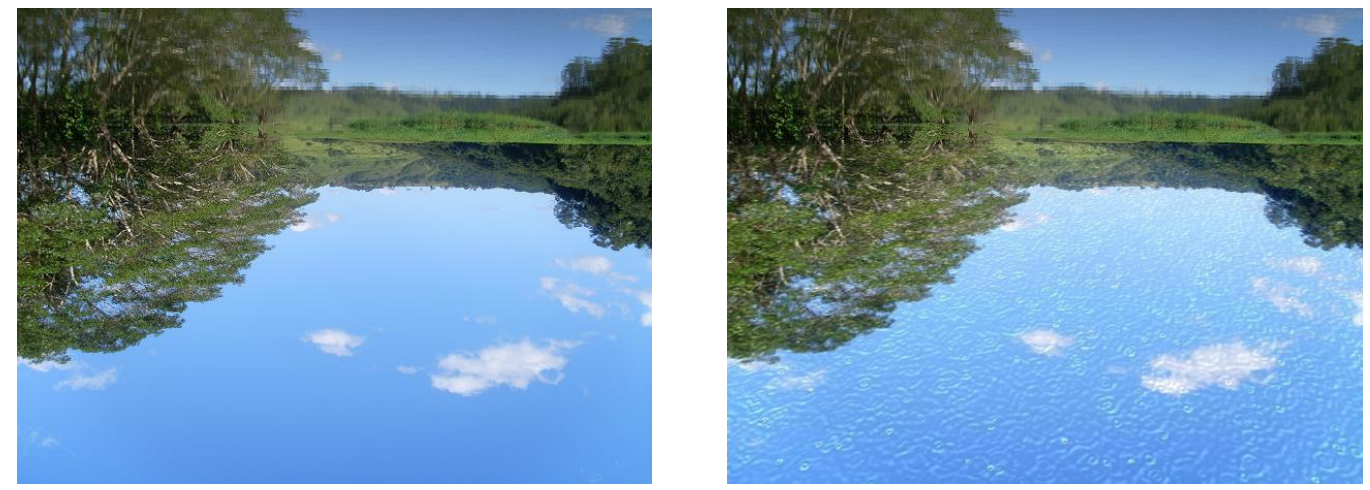

Figura 6.7: Experimento com perturbações aleatórias em $h$. Imagem original à esquerda e no tempo 100 à direita.

Outros experimentos são apresentados no capítulo de resultados. 


\section{Capítulo 7}

\section{Projeção reversa e renderização}

O processo de simulação descrito no capítulo 6 disponibiliza, a cada passo de tempo, o campo de alturas $h$, que descreve as ondas produzidas pelo fluxo no domínio de simulação. O campo de alturas produzido em cada passo de tempo deve ser transferido à imagem original para criar a animação. Este processo é como um mapeamento do campo de alturas em uma malha retangular sobre o domínio de projeção.

Um mecanismo traçador de raios é utilizado para transferir o "efeito de ondas" do campo de alturas para a imagem projetada. Mais especificamente, raios originados no ponto focal e passando por cada elemento da camada da imagem a ser animada são lançados em direção ao domínio de simulação, interceptando o campo de alturas. Efeitos de refração e iluminação são calculados e combinados para produzir a cor final de cada elemento.

A refração é um recurso importante quando animamos certas espécies de cenas, como cenas contendo líquidos transparentes, e é calculada utilizando a lei de Snell com os coeficientes água/ar. Cada raio refratado intercepta a superfície definida pelo campo de alturas $h$ e, em cada ponto de interseção, são combinados efeitos de iluminação para produzir a imagem final. 
A iluminação correta em cada ponto de interseção não pode ser calculada diretamente porque as posições das fontes de luz não são conhecidas. Uma estimativa automática da fonte de luz é um problema difícil. Em nossa implementação nós evitamos este problema fixando a fonte de luz atrás da câmera. Embora esta estratégia simples possa gerar uma inconsistência entre a iluminação da imagem e a onda, a mesma não afeta o resultado da animação ao ponto de despertar atenção. A intensidade da cor é modificada em função da alteração no ângulo de incidência do raio proveniente da fonte de luz, atravéz de uma reflexão difusa dada por $I_{\text {novo }}=k I(N \cdot L)$, onde $k$ é o coeficiente de difusão, $I$ é a intensidade determinada, $N$ é o vetor normal do campo altura e $L$ é o vetor direcional da fonte de luz.

Durante o processo de renderização, além da refração e da iluminação, podemos aplicar alterações na tonalidade em função da altura da onda, resultando em efeitos visuais interessantes, como podemos observar na figura 7.2. Estes efeitos são o "branqueamento", que aproxima a cor do pixel do branco em função da altura da onda e a "turbidez", que altera a saturação do pixel, conservando sua cromaticidade, também em função da altura da onda.

Embora heurístico, estes mecanismos resultam em efeitos agradáveis nos diversos experimentos que realizamos. Além disso, o mapeamento pode ser efetuado através da textura original do corpo d'água ou qualquer textura informada pelo usuário. Ou seja, o processo consiste de três etapas, sendo duas opcionais:

texturização (opcional) Etapa em que a textura original do corpo d'água pode ser modificada. Para isto, basta que o usuário informe uma imagem da mesma dimensão da textura original gerada durante a projeção do corpo d'água. 
refração Etapa padrão que remapeia a textura de acordo com a refração do raio de observação.

iluminação (opcional) Etapa em que a textura observada é alterada em sua intensidade e/ou em sua saturação.

A figura 7.2 ilustra resultados de diversas opções de iluminação em um mesmo experimento, em um mesmo instante de tempo. A primeira linha mostra o resultado aplicando apenas a refração, na segunda linha temos a refração seguida da iluminação propriamente dita, já na terceira e quarta linhas, mostramos o resultado da refração seguida, respectivamente, de um "branqueamento" e do efeito de "turbidez", comentados anteriormente neste capítulo.

Finalmente, como podemos visualizar pela figura 7.1, após passar pelo processo inverso exposto no capítulo 4, onde o corpo d'água é mapeado de volta no plano da imagem, a camada da imagem que não sofreu movimento é incorporada, gerando o quadro final para aquele instante de tempo. Então os quadros são concatenados, respeitando a sequência temporal e o filme de nossa animação está completo.
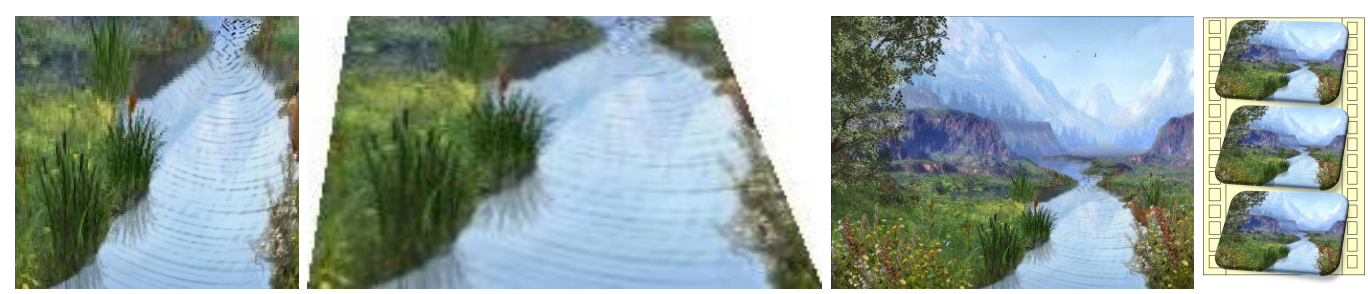

Figura 7.1: Sequência de quadrinização, da esquerda para a direita, quadro no plano do corpo d'água, quadro no plano da imagem, quadro completo e filme. 

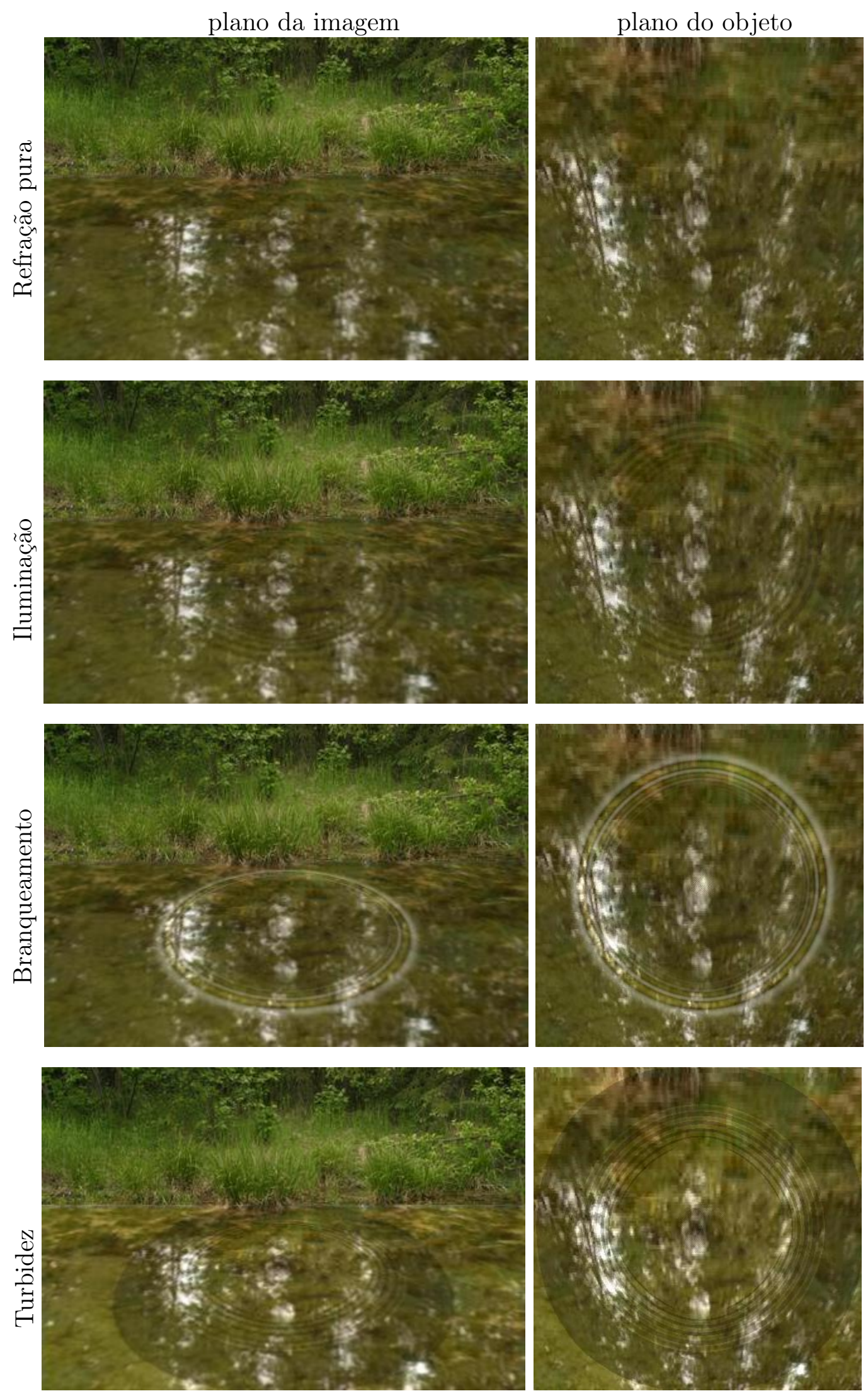

Figura 7.2: Opções de renderização. 


\section{Capítulo 8}

\section{Resultados obtidos}

Apresentaremos neste capítulo alguns resultados, no intuido de mostrar a aplicabilidade do método apresentado, sua robustez e qualidade gráfica, com diferentes parâmetros em diversas imagens.

Cada experimento, se não informado o contrário, é executado com os seguintes parâmetros:

- Profundidade média do corpo d'água constante e unitária.

- Profundidade inicial do corpo d'água constante e unitária.

- Aceleração de Coriolis nula.

- Força do vento nula.

- Coeficiente de Chezy constante e unitário.

- Variações espaciais infinitesimais constantes e equivalentes a uma célula da malha.

- Variações temporais variáveis e inferiores a $\frac{1}{\sqrt{\max _{i \in \Omega} h_{i}}}$.

- Um quadro é gerado a cada unidade de tempo. 
Um filme gerado com taxa de exibição de quinze quadros por segundo, é produzido para cada um dos experimentos relatados a seguir e o endereço onde o mesmo pode ser visualizado é apresentado. O custo computacional é função da resolução da imagem, dos parâmetros da câmera e do tamanho do objeto. Em média, imagens com resolução $400 \times 300$ cuja malha do objeto foi inferida em $500 \times 500$, gastam $30^{\prime \prime}$ a cada passo de tempo na simulação de águas rasas e 1'30" por quadro durante a fase de projeção reversa e renderização, quando executados em um computador portátil de $500 M b$ de memória RAM e processador Intel Centrino de 1,6 $\mathrm{MHz}$. Como estas duas fases podem ser executadas em paralelo, o tempo de processamento de um minuto de vídeo é, em média, de 22, 5 horas para experimentos com imagens desta resolução. 


\subsection{Rio em movimento}

Neste experimento vamos ilustrar o movimento das águas de um rio, com uma onda refletindo na imagem. A figura 8.1, utilizada como imagem original, é uma foto da represa de Catalão (GO).

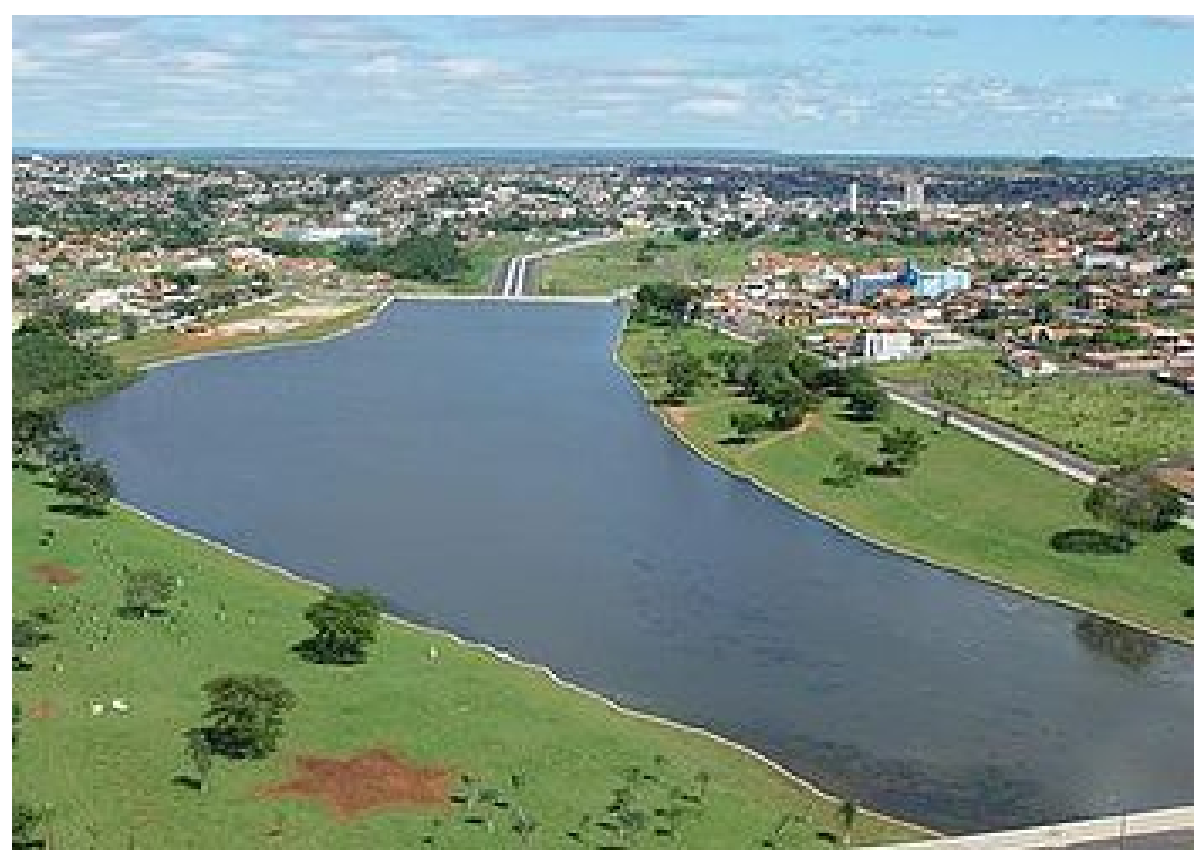

Figura 8.1: Imagem original do experimento.

Com parâmetros default, foram aplicadas perturbações randômicas na altura da onda, na barragem. No filme gerado e na figura 8.2 , podemos observar o movimento das ondas provenientes de tal perturbação, bem como seu comportamento ao encontrar a margem do rio. Com $34^{\prime \prime}$ de vídeo, a geração deste filme durou cerca de 12 horas. 


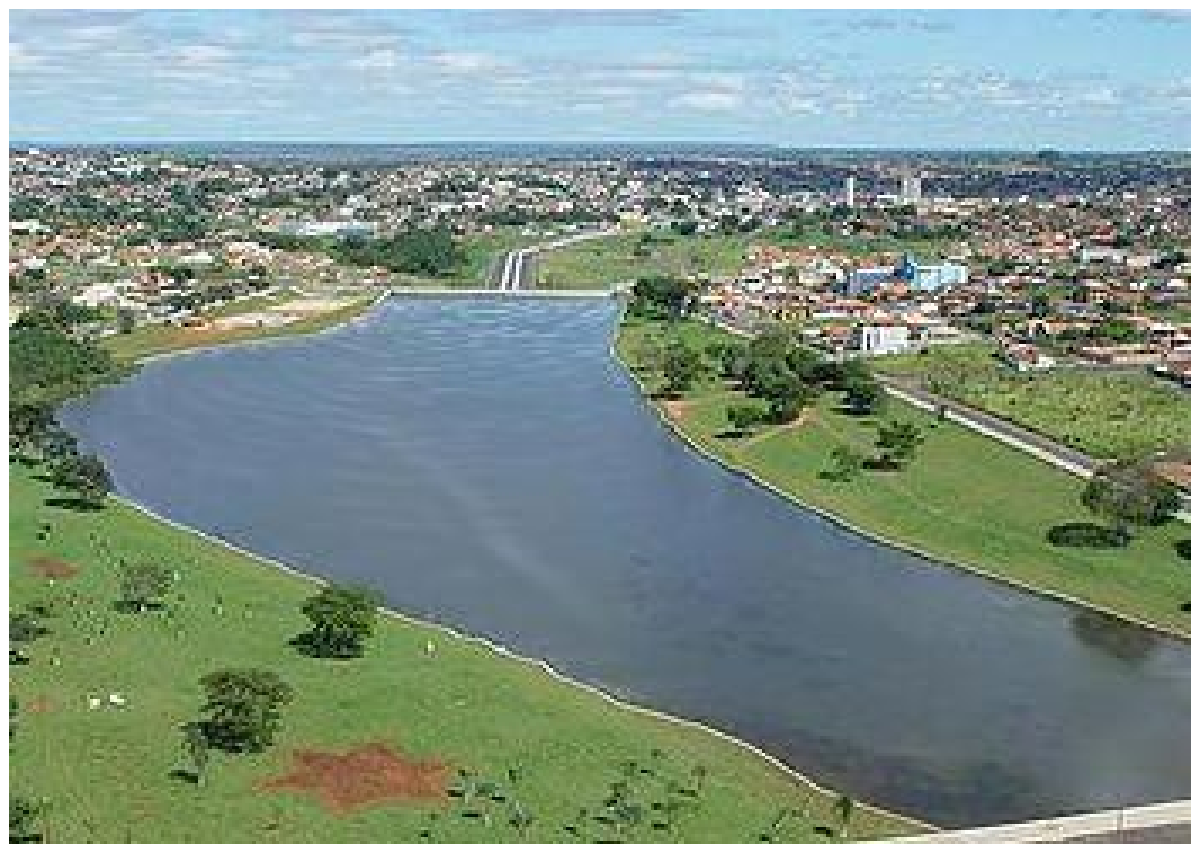

Figura 8.2: Quadro gerado pelo experimento.

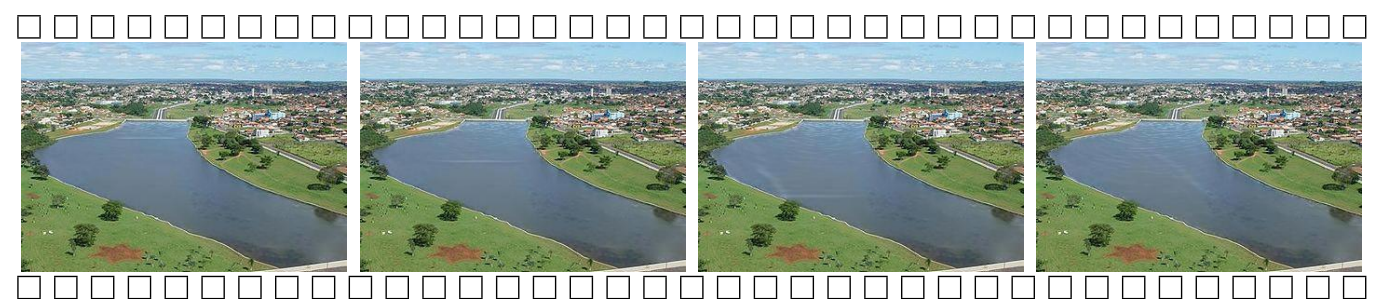
www. vipigraf .ufu.br/marcos/tese/catalao.wmv 


\subsection{Animação de fluxo em uma represa}

Neste experimento ilustramos o fluxo das águas na saída das comportas de uma represa. As figura 8.3 c e $8.3 \mathrm{~d}$ mostram quadros de uma animação obtida com perturbações no campo de alturas sob a barragem, fora do campo visual, e com a camada de controle do parâmetro $H$ inicializada conforme a figura 8.3b, ou seja, definimos a topografia do leito do rio.

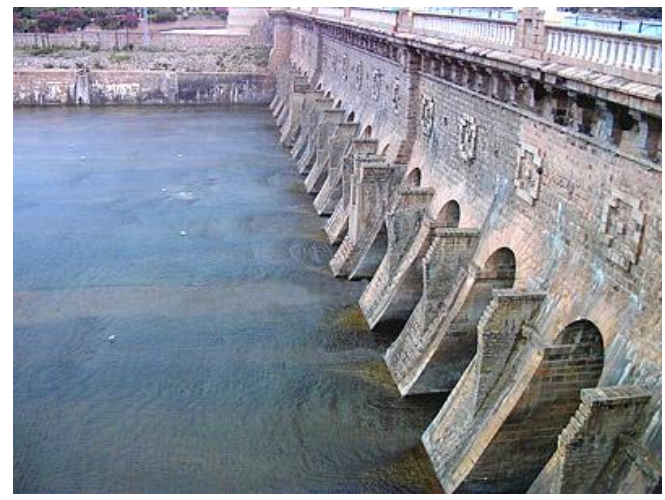

(a)

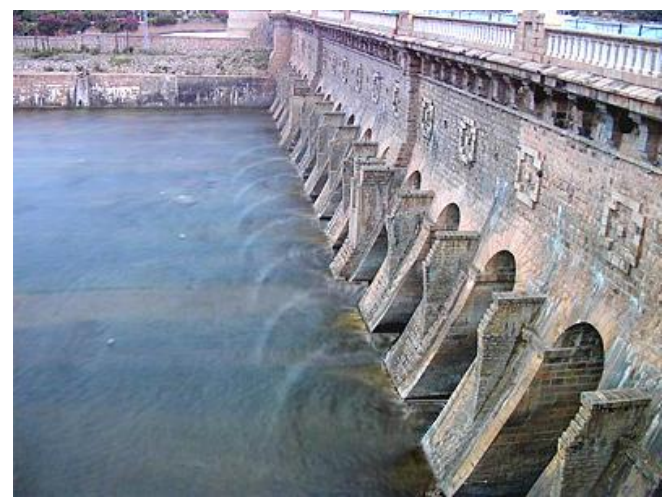

(c)

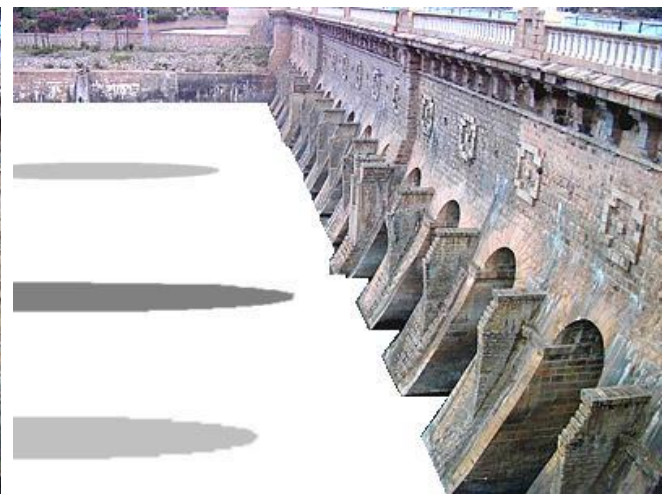

(b)

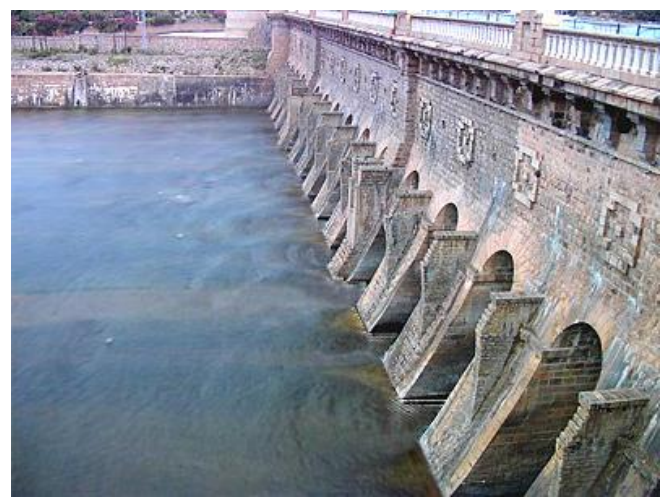

(d)

Figura 8.3: Animação de fluxo em uma represa. (a) Imagem original; (b) camada da imagem utilizada para modificar $H$; (c) e (d) fluxo em dois diferentes passos de tempo.

www.vipigraf.ufu.br/marcos/tese/barragem.wmv 


\subsection{Vulcão}

Neste experimento, vamos ilustrar o movimento de um fluido no interior de um vulcão, alterando a profundidade inicial da fronteira do corpo fluídico randomicamente.

A figura 8.4 mostra a imagem original e a respectiva máscara utilizadas no experimento. Uma sequência do vídeo é mostrada, em close, na figura 8.5 .
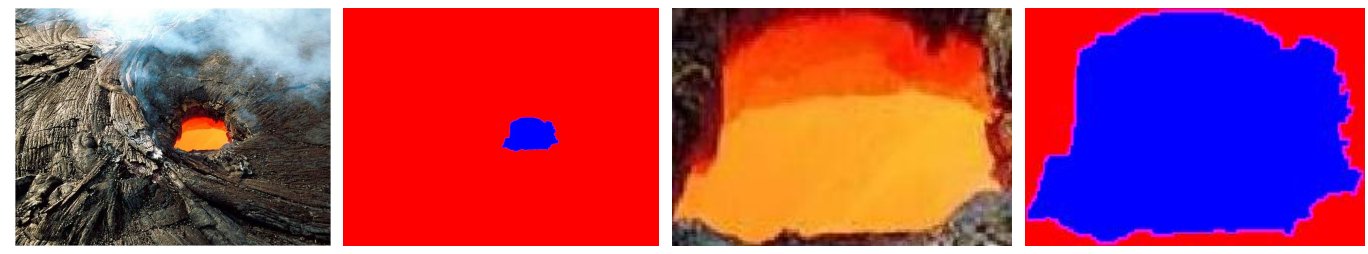

Figura 8.4: Da esquerda para a direita, imagem original e máscara utilizados no experimento, seguidas da textura e malha geradas durante a fase de malhamento.

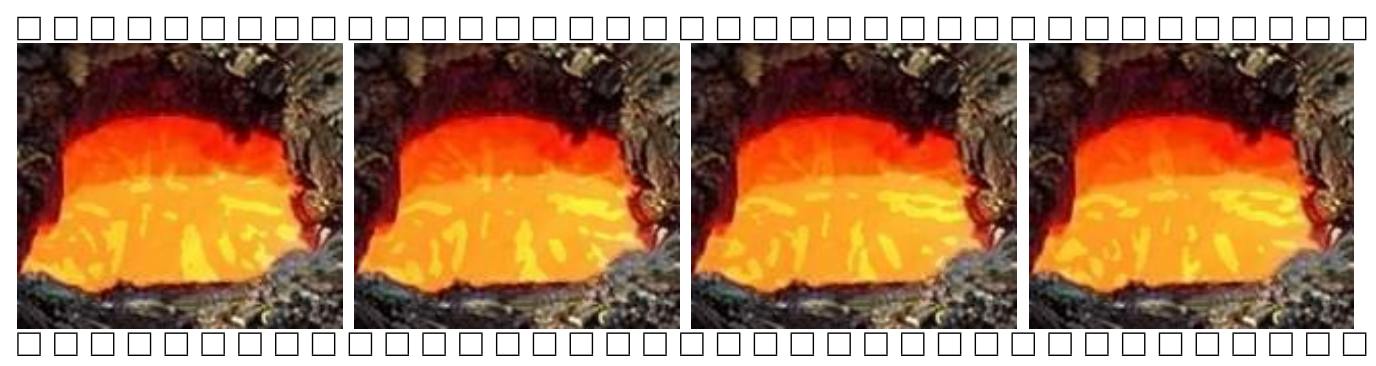

Figura 8.5: Sequência em close do vídeo do experimento vulcão.

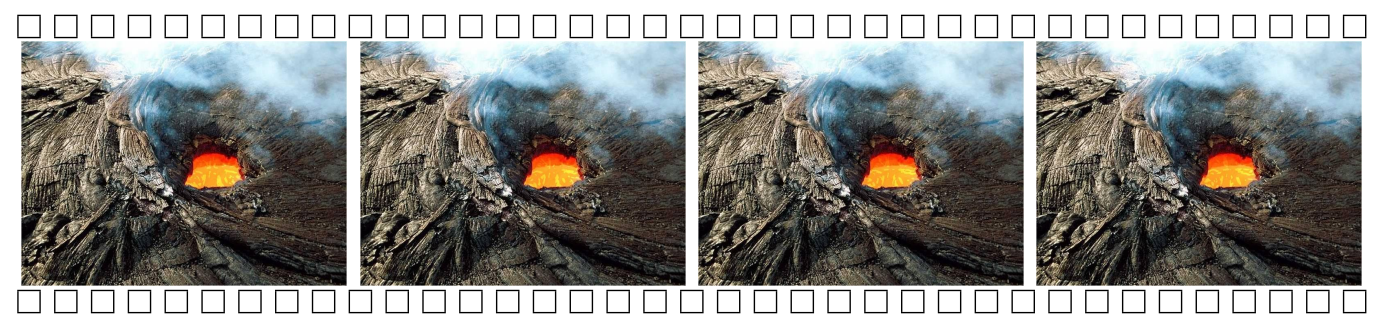

Www.vipigraf.ufu.br/marcos/tese/vulcao.wmv 


\subsection{Chuvas}

Os experimentos desta seção têm o objetivo de apresentar simulações de chuva obtidas pelo nosso método. O efeito de chuva é conseguido através de perturbações no corpo d'água em posições aleatórias, e produzem efeitos agradáveis. Com, respectivamente, $7^{\prime \prime}, 28^{\prime \prime}$ e $6^{\prime \prime}$ de vídeo, a geração destes filmes duraram cerca de 3, 10 e 3 horas, respectivamente.
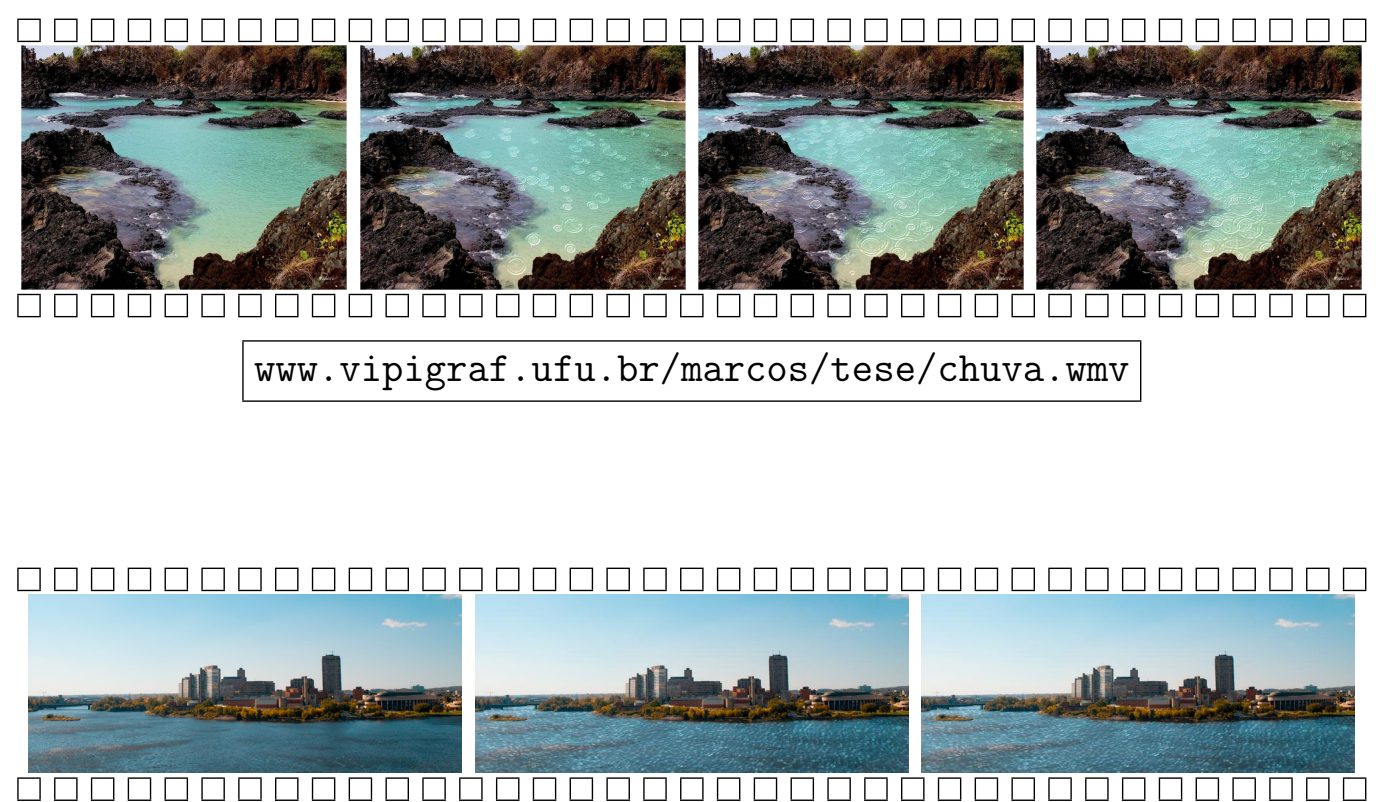

www.vipigraf.ufu.br/marcos/tese/chuvac.wmv

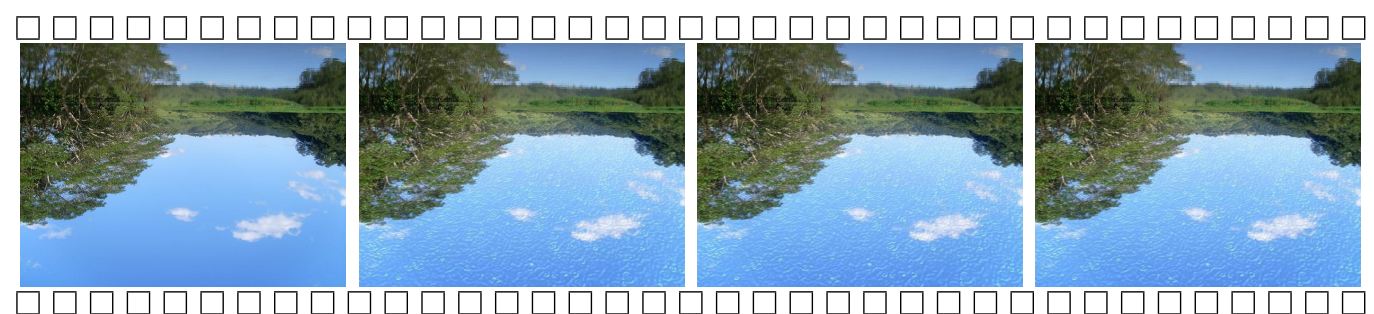

wWw.vipigraf.ufu.br/marcos/tese/chuvan.wmv 


\subsection{Balanço natural}

Estes experimentos mostram o movimento suave de um corpo d'água, gerado pela queda constante de água em determinados pontos da imagem, indicados por cachoeiras ao longe. Estas quedas d'água são simuladas por perturbações no corpo d'água, nas suas respectivas posições.

A renderização foi efetuada, nos dois experimentos, sem acrescentar efeitos de iluminação, apenas utilizando a refração. O efeito resultante é um movimento suave e realístico.

A simulação referente ao primeiro vídeo foi efetuada a partir da imagem e máscaras indicadas na figura 8.6 e alterações randômicas na altura do corpo d'água na posição indicada pelas cachoeiras.
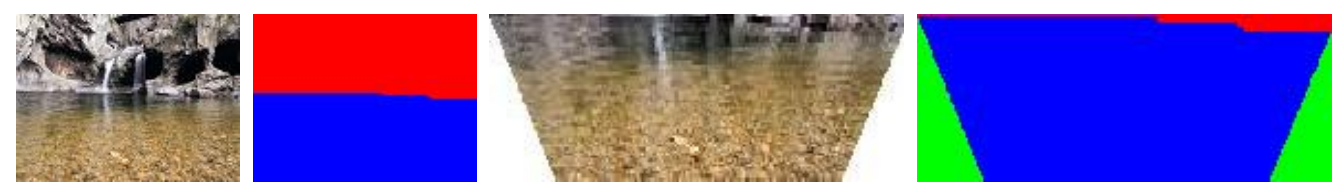

Figura 8.6: Da esquerda para a direita, imagem e máscara utilizadas no primeiro experimento desta seção, textura e malha obtidas durante o malhamento.

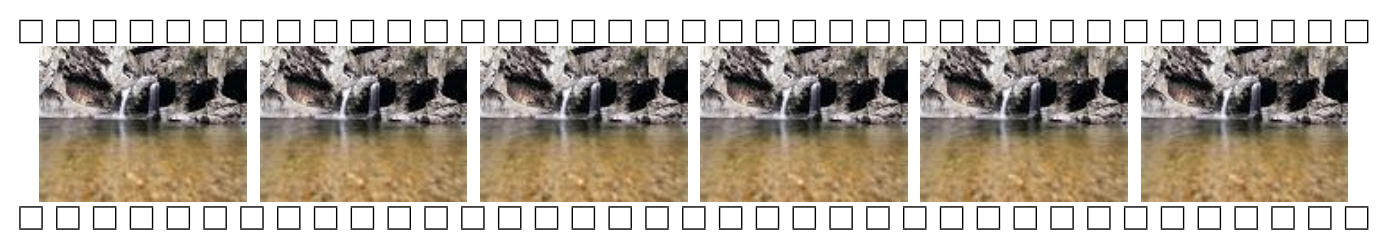

www.vipigraf.ufu.br/marcos/tese/lagoap.wmv 
A simulação referente ao segundo vídeo foi efetuada a partir da imagem ao lado e também alterações randômicas na altura do corpo d'água na posição indicada pelas cachoeiras.

Observe, na figura 8.7, detalhes de quadros do segundo vídeo, referentes ao canto inferior direito da imagem ao lado, destacando a distorção

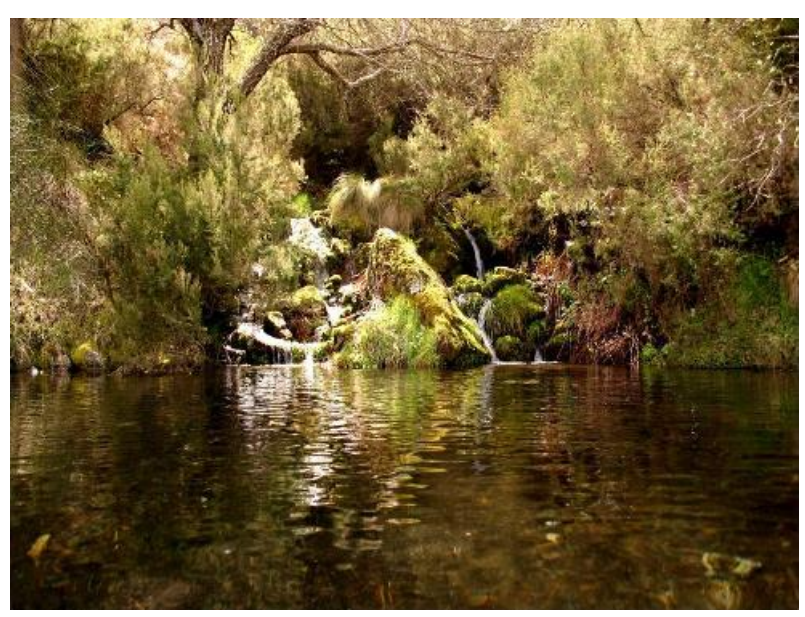
ocorrida devido às refrações distintas, geradas pela variação na altura da água em cada instante.

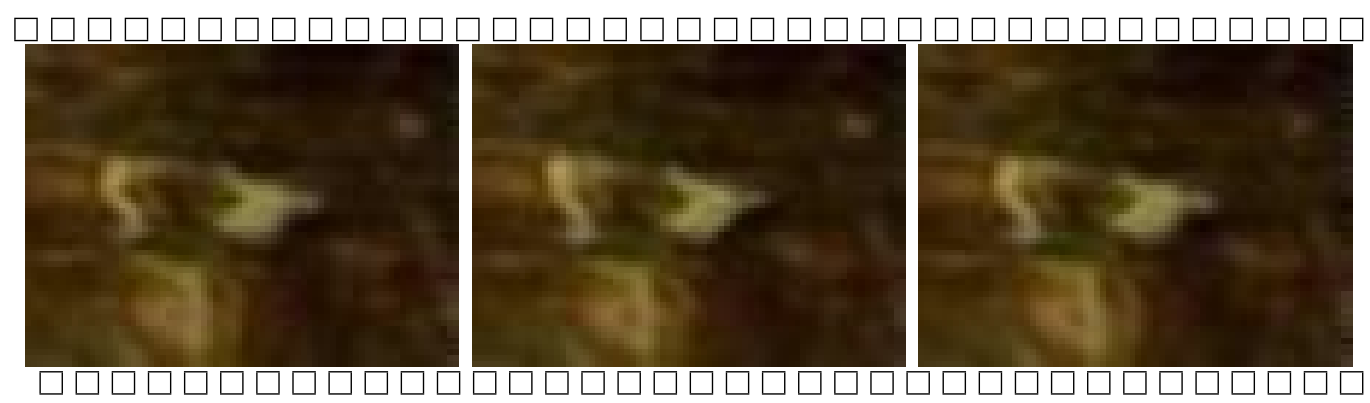

Figura 8.7: Zum referente aos cantos inferiores direitos de quadros do segundo vídeo desta seção.

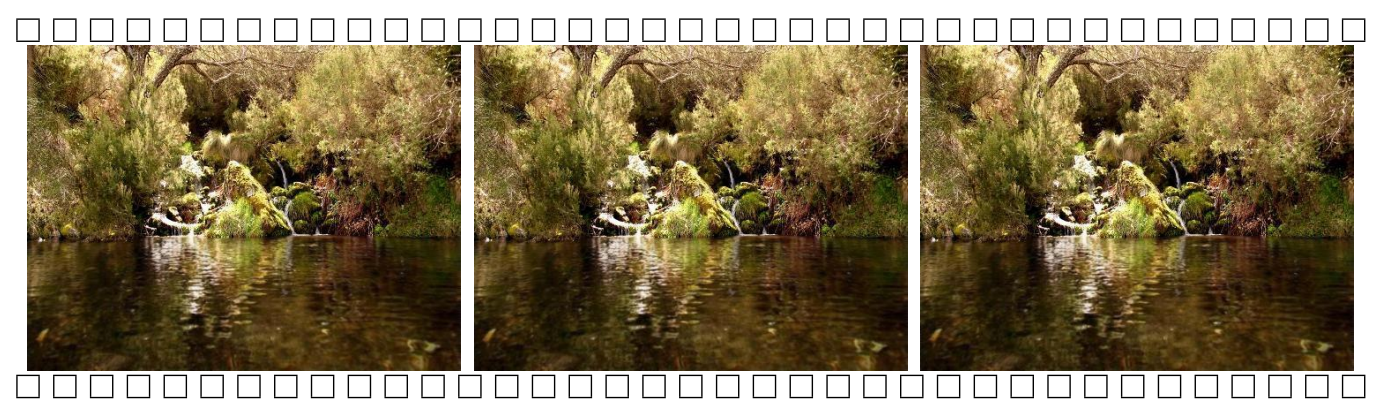

www.vipigraf.ufu.br/marcos/tese/ambrozh.wmv 


\subsection{Transporte de textura}

Nós também podemos combinar os efeitos de onda com o transporte de textura, como mostrado na figura 8.8. O rio na figura 8.8 a recebeu manchas na superfície da água. A animação produzida apenas pela projeção reversa no campo de alturas não pareceu tão realístico quanto ao transportar a mancha. Este efeito pode ser alcançado utilizando as componentes de velocidade $u$ e $v$ para transportar a textura quadro a quadro, aumentando o realismo (figura $8.8 \mathrm{~b}$ e $8.8 \mathrm{c})$.

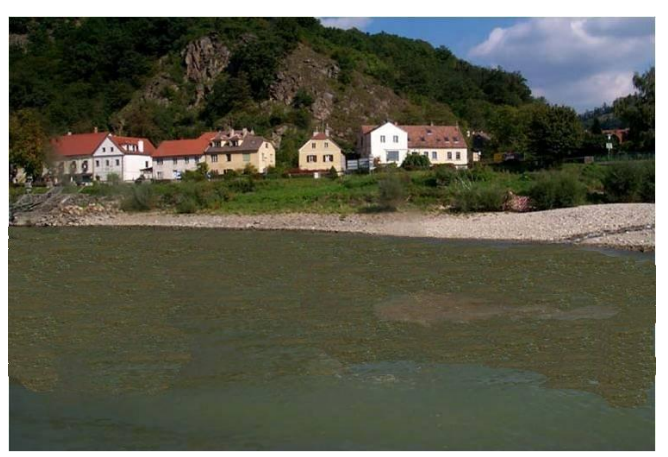

(a)

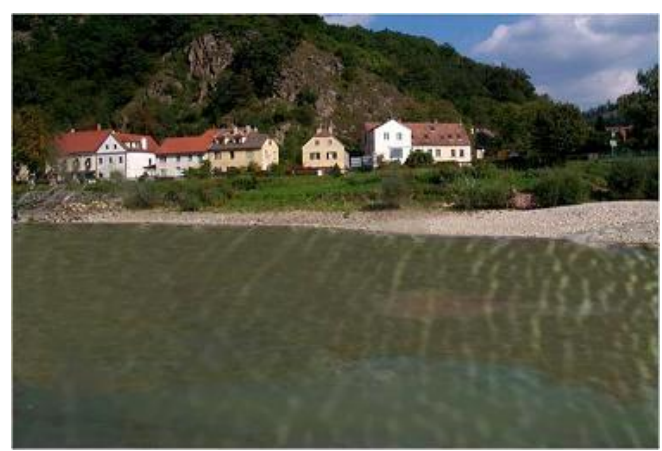

(b)

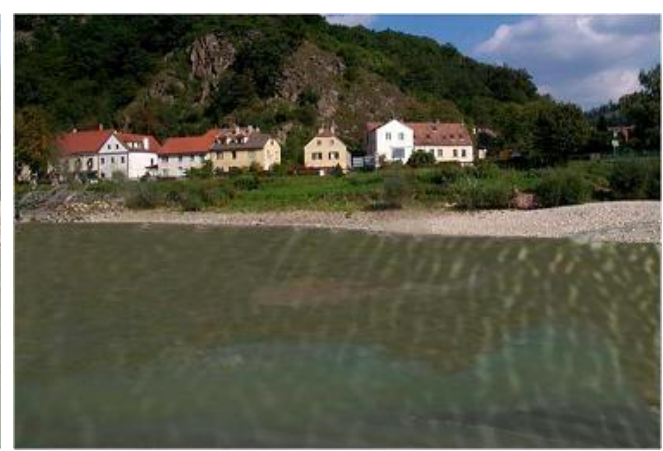

(c)

Figura 8.8: Efeitos de onda combinados com transporte de textura. (a) Imagem original; (b) e (c) transporte de ondas e textura. 


\subsection{Efeito Coriolis}

O objetivo deste experimento é apresentarmos as alterações no movimento de onda provocados pela variação na aceleração de Coriolis. Dois vídeos foram gerados, um indicando as variações no parâmetro $f$ e o outro salientando as cristas e vales das ondas, respectivamente, com tons de vermelho e azul.

A aceleração de Coriolis, $f$, traz para as equações de águas rasas a ação da força aparente provocada pelo movimento de rotação da Terra. Veja, na figura 8.9, a ação desta força, em diversas intensidades, comparada com a inexistência da mesma, na primeira coluna. Cada linha representa um mesmo instante de tempo.

A aceleração de Coriolis é uma das responsáveis pela geração das tempestades e podemos observar a intensificação deste efeito, nos vídeos, à medida que aumentamos o valor de $f$. Veja a causa deste efeito na figura 8.10 onde salientamos a diferença do campo velocidade, em um mesmo instante de tempo, em três valores distintos de $f$. A evolução deste campo velocidades é apresentada na figura 8.11

A figura 8.12 mostra a potencialidade de nosso método ao comparar um dos campos de velocidades obtidos em nosso experimento e uma foto do furacão Dora no Pacífico Sul. 


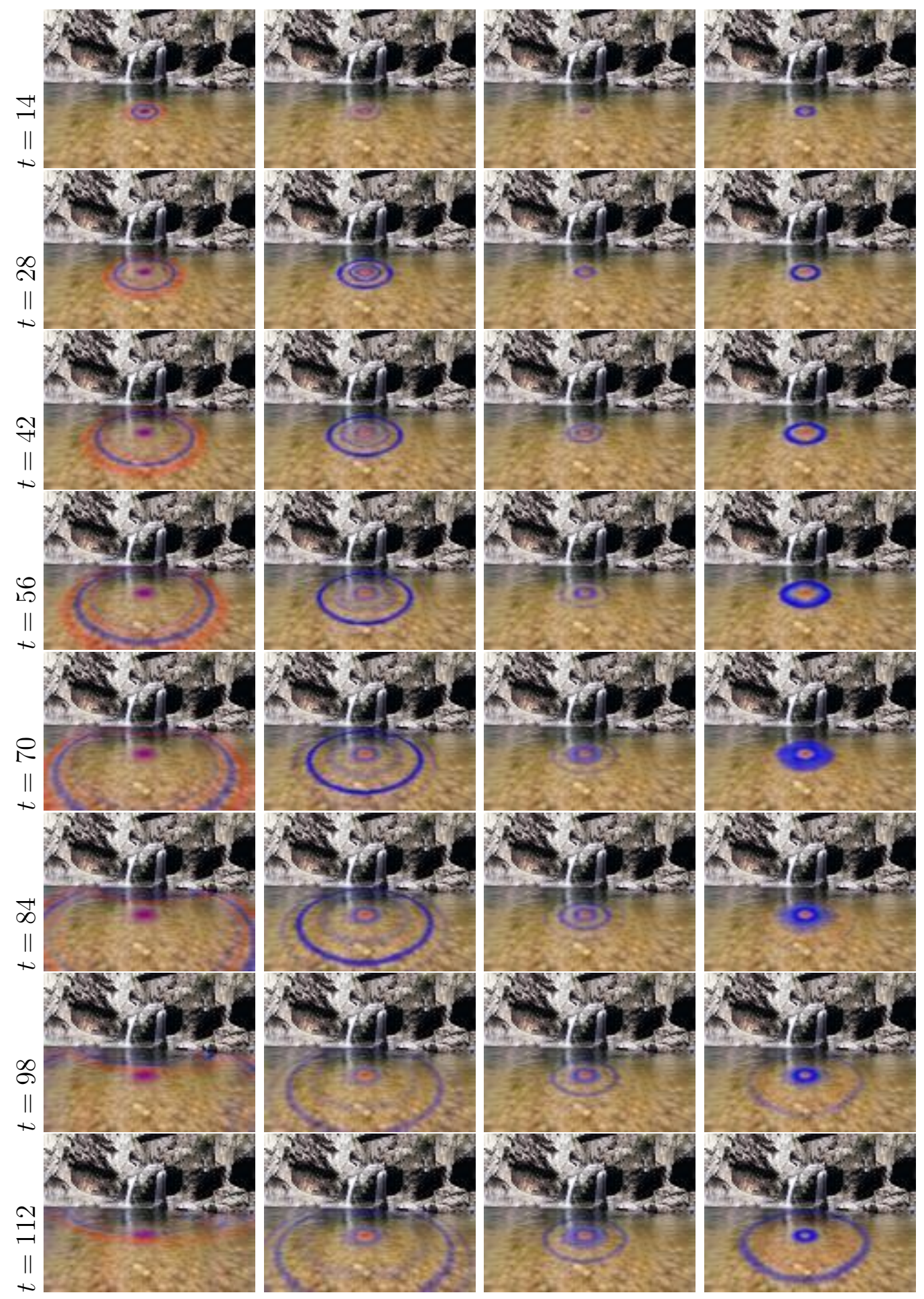

Figura 8.9: Efeito Coriolis. Da esquerda para a direita, $f=0, f=0,5, f=1$ e $f=2$. 


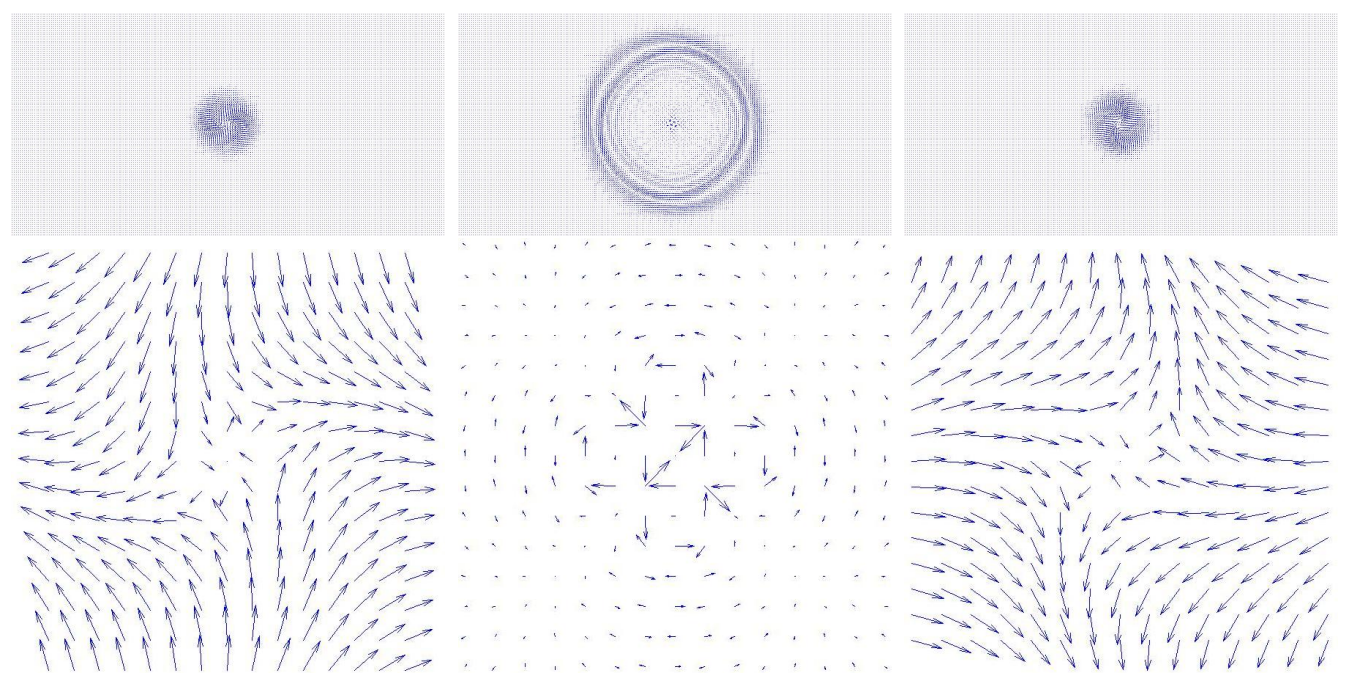

Figura 8.10: Efeito Coriolis: vetores velocidade no plano do objeto em $t=42$. Da esquerda para a direita, $f=-2, f=0$ e $f=2$. Em destaque, zum correspondente no centro do plano do objeto.
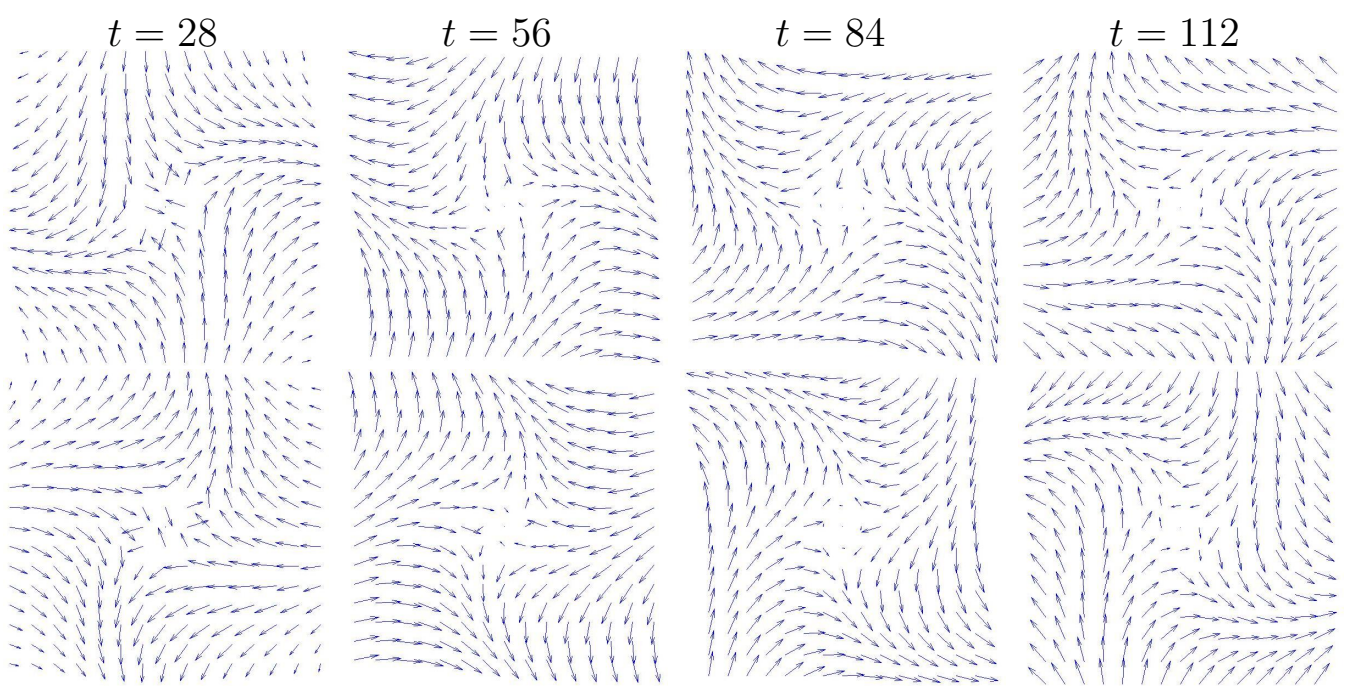

Figura 8.11: Efeito Coriolis: Zum central dos vetores velocidade. Acima, $f=-2$ e abaixo, $f=2$. 

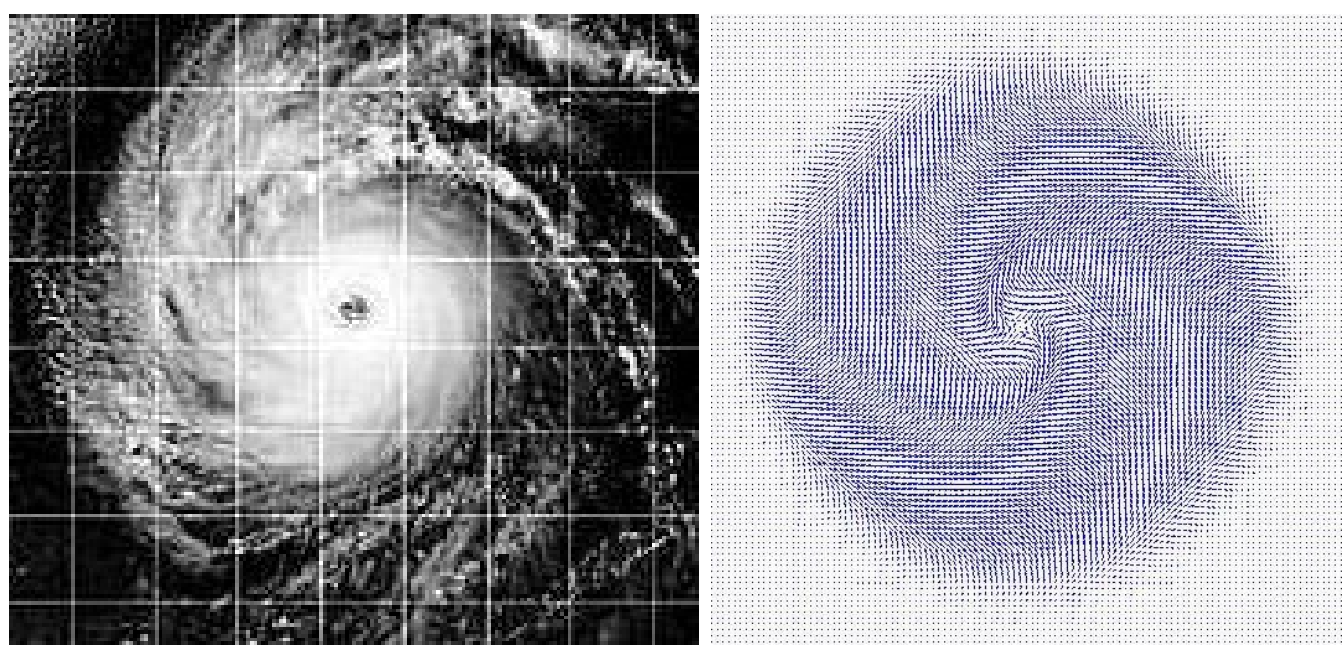

Figura 8.12: Furacão Dora em 1999 à esquerda e campo de velocidades de nosso experimento à direita.
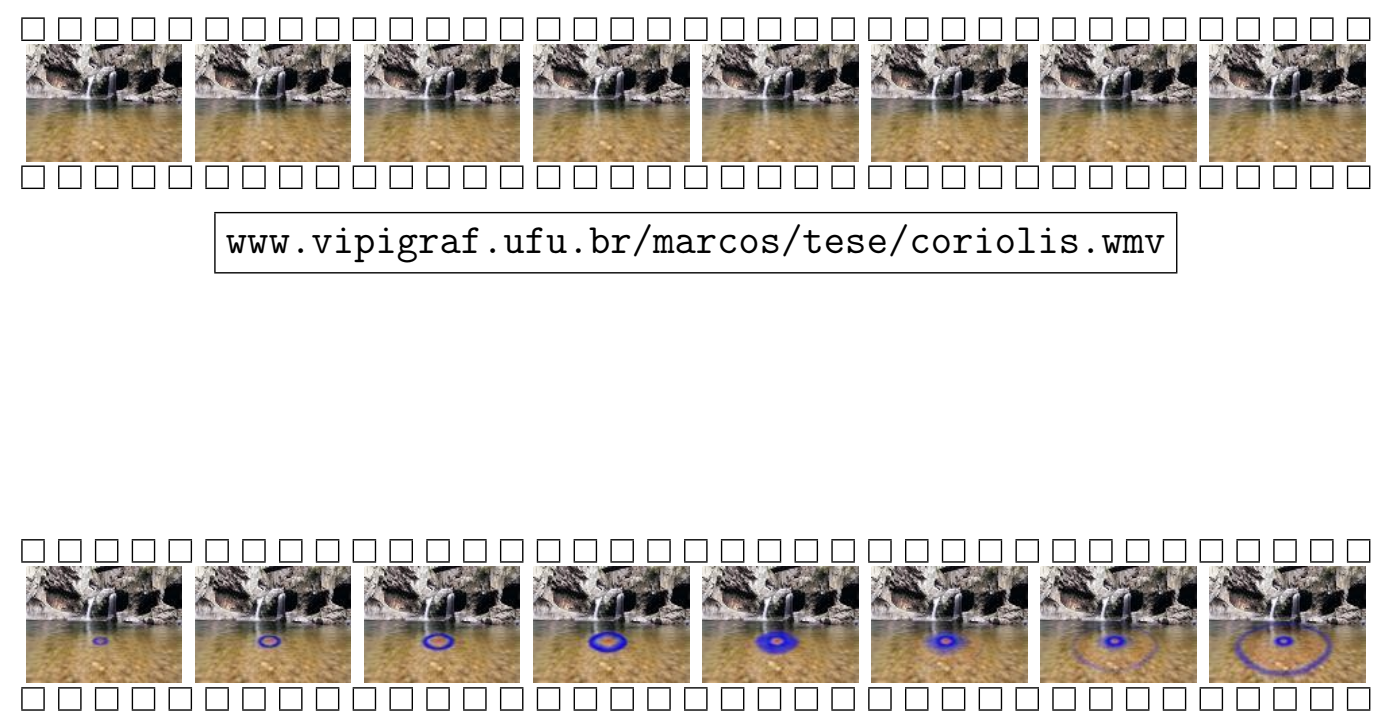

www.vipigraf .ufu.br/marcos/tese/coriolisg. wmv 


\subsection{Inserção de objetos}

Com o objetivo de mostrar a flexibilidade de nosso método na inserção de novos elementos na animação, efetuamos três experimentos:

1. inserindo barcos à cena e efetuando um "branqueamento" (conforme ilustrado no capítulo 7) durante a renderização,

2. inserindo barcos maiores e adicionando iluminação à cena e

3. inserindo peixes à cena e efetuando apenas a refração durante a renderização.

Nos dois primeiros experimentos temos o deslocamento de navios em um corpo d'água a partir da imagem 8.13 .

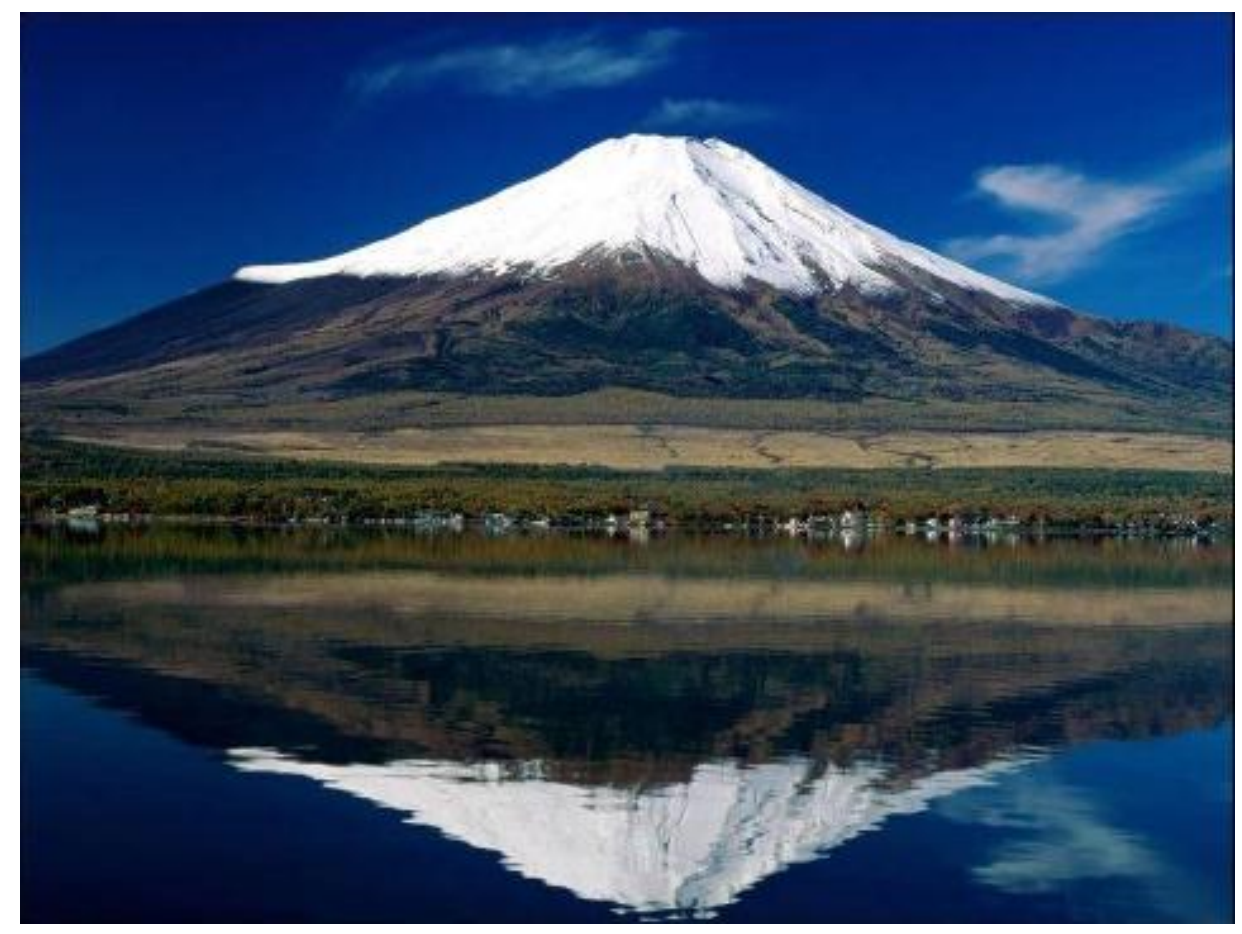

Figura 8.13: Imagem original. 
Os navios, com velocidades aleatórias, são mapeados em nosso objeto em dois momentos distintos, para o navio em si e para sua sombra, que deverá sofrer os mesmos efeitos da refração aplicados ao corpo d'água.

Os passos do primeiro experimento, que podem ser visualizados nas figuras 8.14 e 8.15, são os seguintes para cada quadro:

1. Durante a simulação de águas rasas:

(a) as posições dos navios são determinadas e os mesmos são mapeados,

(b) a textura original do corpo d'água é recuperada e as sombras dos navios são inseridas, e

(c) perturbações na altura da água são aplicadas nas posições referentes aos navios.

2. A renderização é efetuada na textura alterada:

(a) a refração é aplicada,

(b) um branqueamento é aplicado às ondas, e

(c) os navios são inseridos.

3. Durante a quadrinização:

(a) o corpo d'água é projetado de volta ao plano da imagem, e

(b) o quadro é, finalmente, gerado.

A Figura 8.16 mostra o resultado do segundo experimento, no qual a etapa (2b) é substituída pela adição de iluminação à cena.

Podemos observar, pelas figuras 8.15(3b) e 8.16, e também pelos vídeos, que o esquema de perturbação representado pela etapa (1c) resulta em um conjunto de ondas atrás dos barcos, similar ao que acontece na prática. 


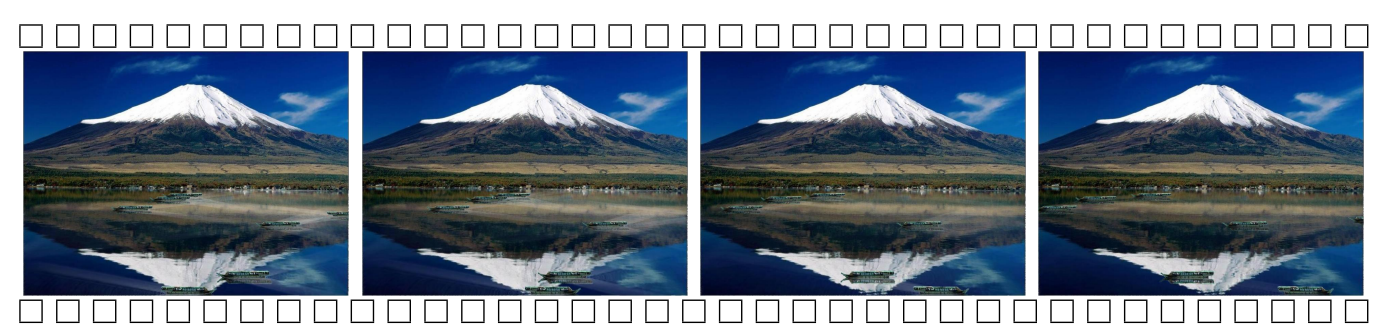

wWw. vipigraf .ufu.br/marcos/tese/navios. wmv

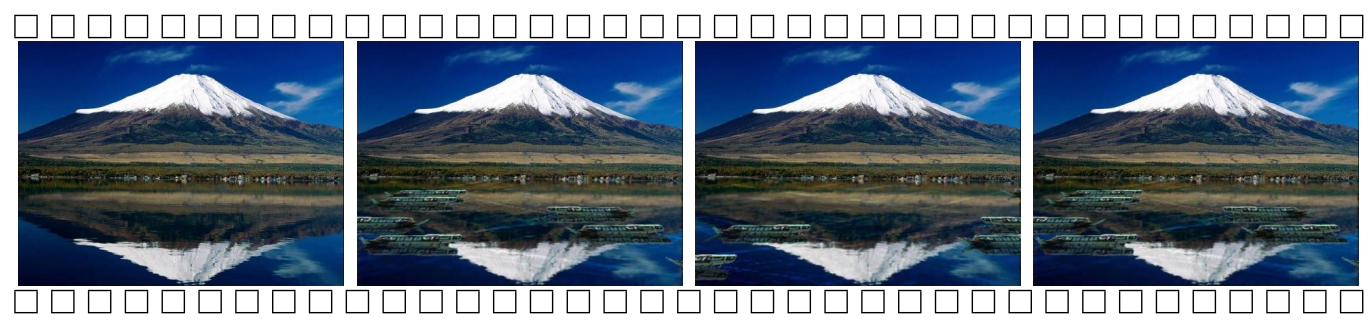

wWw . vipigraf . ufu .br/marcos/tese/naviosc .wmv

O último experimento desta seção simula o movimento da água gerado pelo deslocamento de peixes inseridos na cena. A sequência de criação do experimento é dada na imagem 8.17, similar à efetuada nos experimentos anteriores desta seção.

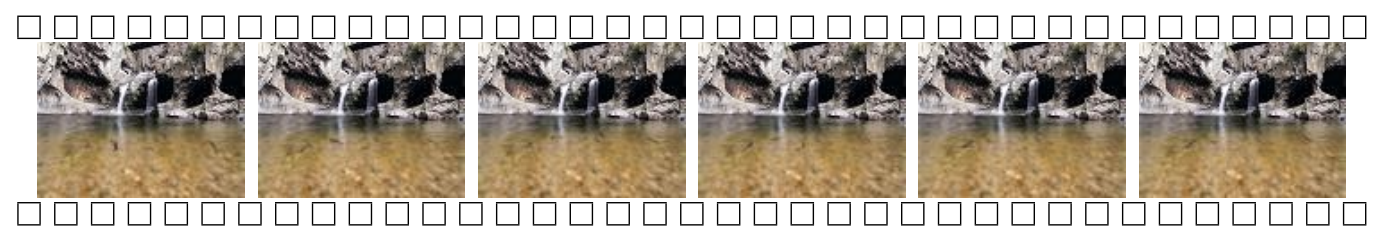

www.vipigraf.ufu.br/marcos/tese/peixesp.wmv 


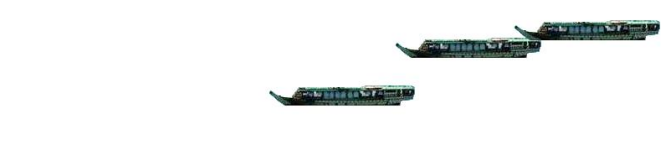

ख
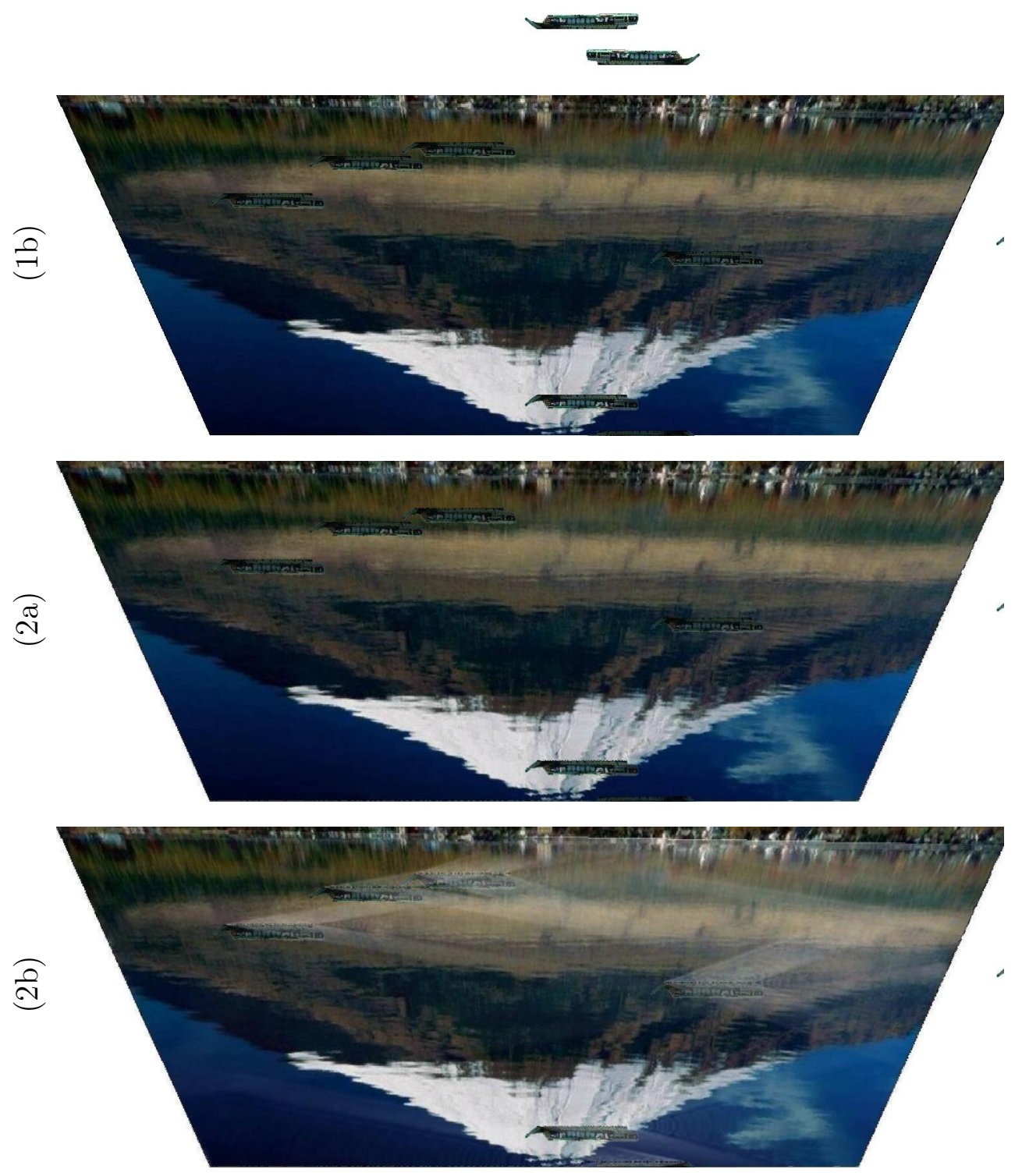

Figura 8.14: Sequência de geração de um quadro. Os ítens correspondem à explanação no corpo do texto. 

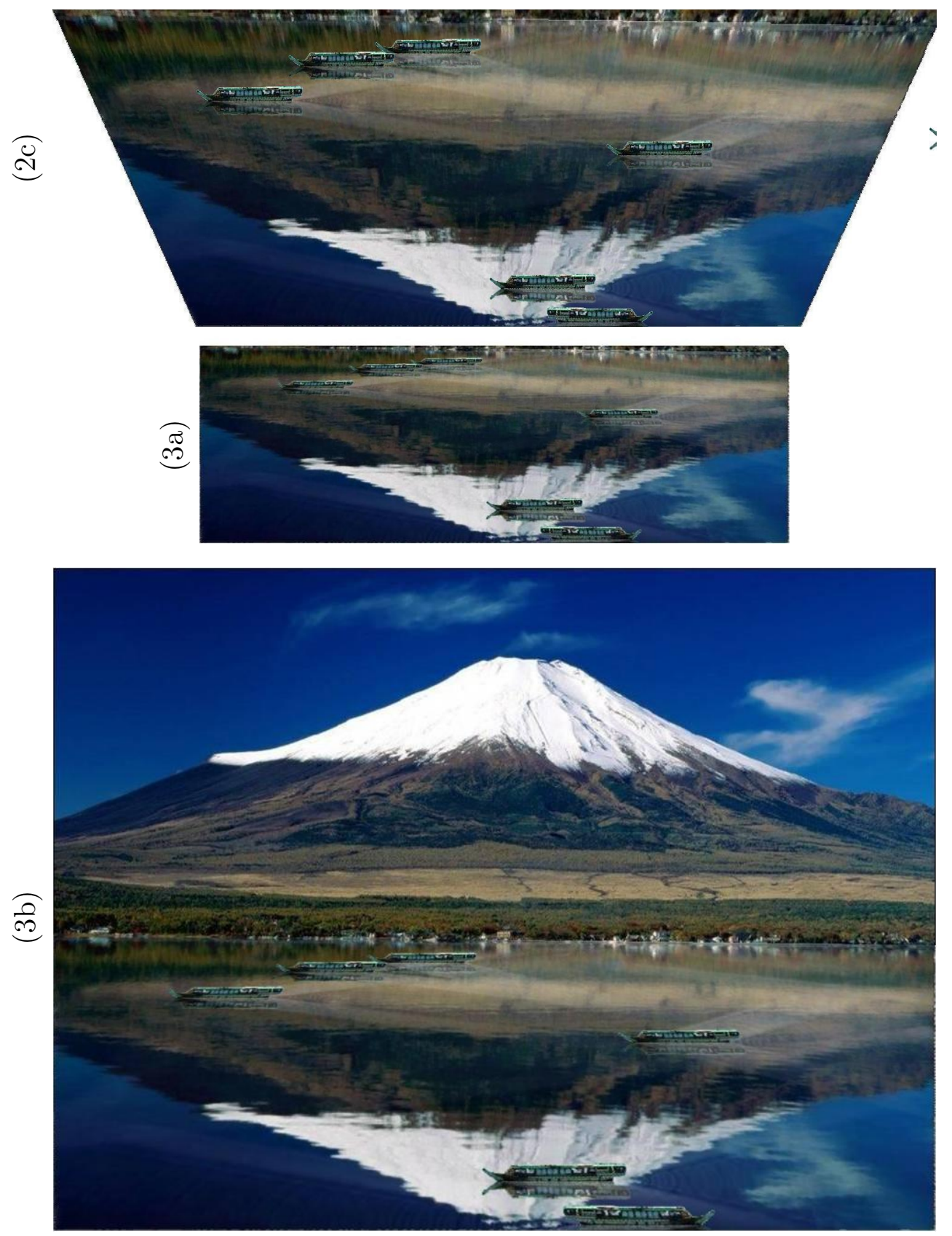

Figura 8.15: Sequência de geração de um quadro. Os ítens correspondem à explanação no corpo do texto. 


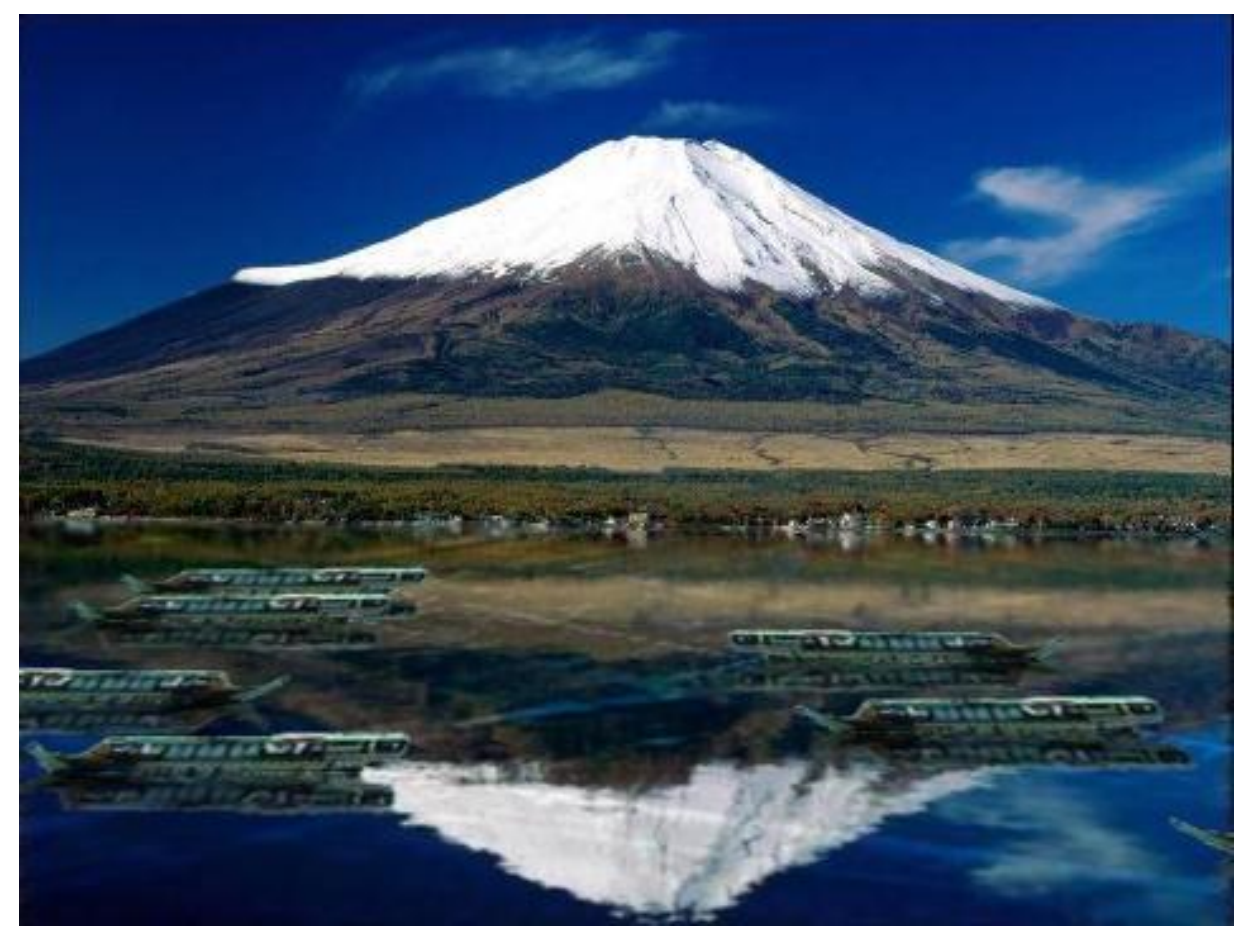

Figura 8.16: Resultado do experimento.

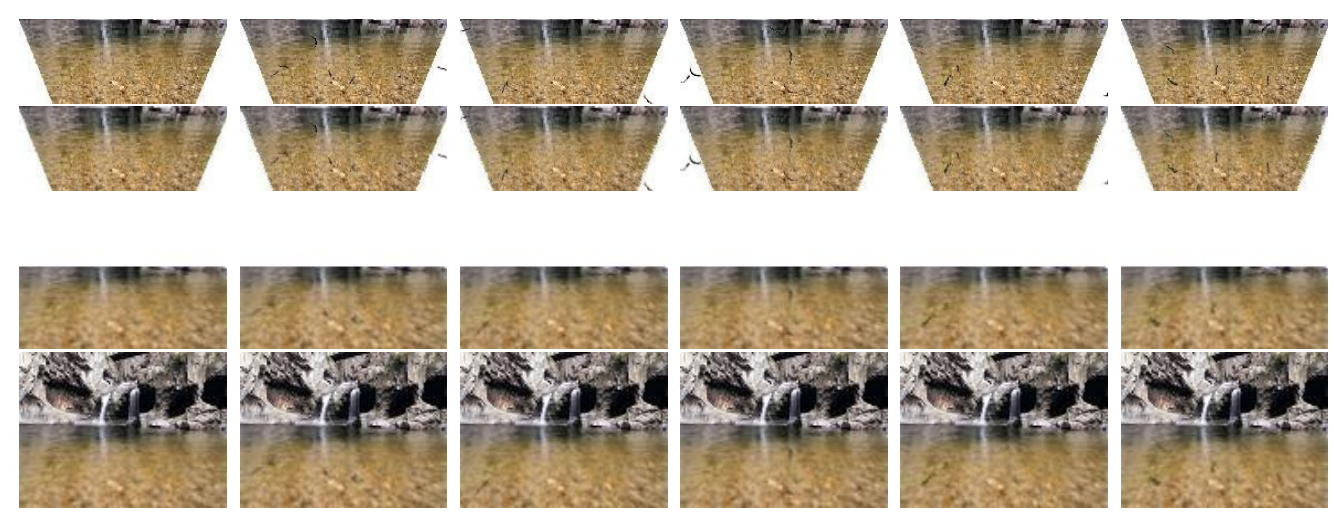

Figura 8.17: Experimento peixes. Sequência de criação. 


\subsection{Comparações}

Nesta seção apresentamos três experimentos cujo objetivo é a comparação com cenas reais.

No primeiro, a partir da textura extraída da imagem real 8.18 a, perturbamos, por tres vezes o corpo d'água na altura dos pingos indicados na referida imagem e obtivemos o resultado dado pela figura 8.18b.

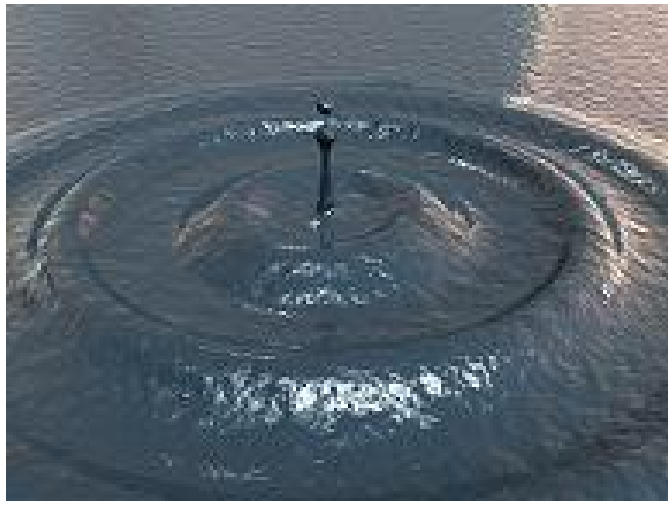

(a)

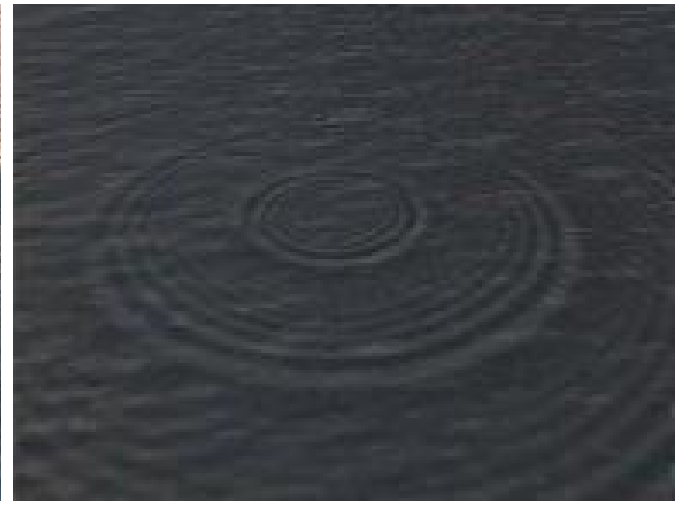

(b)

Figura 8.18: Comparação entre uma fotografia (a) e um quadro gerado pela nossa proposta (b).

No segundo experimento apresentamos o resultado obtido a partir de uma perturbação contínua em um ponto da imagem (figura 8.19b) e o comparamos com uma fotografia (figura 8.19k) obtida no mesmo local da imagem original (figura 8.19a) utilizada no experimento.

Finalmente, apresentamos um vídeo gerado a partir de uma fotografia obtida no instante em que a água estava em estado de repouso que em seguida é parturbada, como apresentado no filme obtido nos instantes seguintes. 


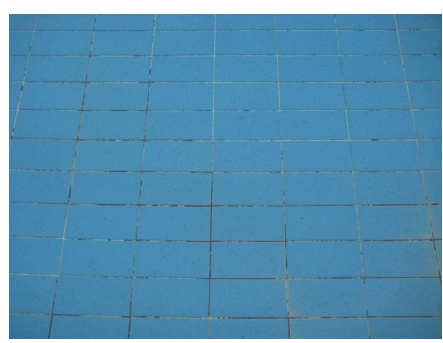

(a)

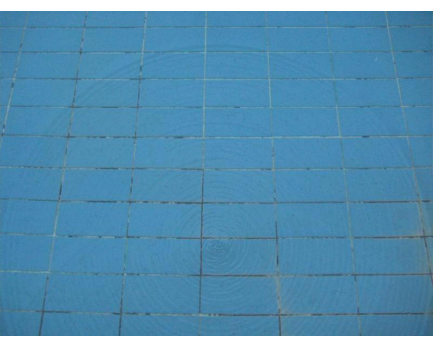

(b)

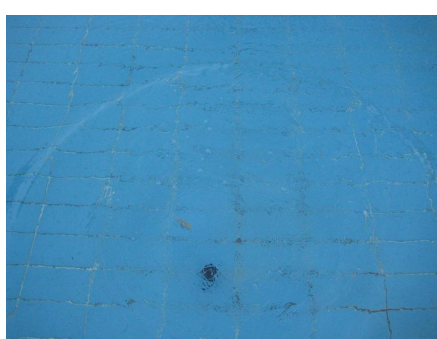

(c)

Figura 8.19: Comparação entre uma fotografia (c) e um quadro gerado pela nossa proposta (b), a partir da imagem capturada em (a).

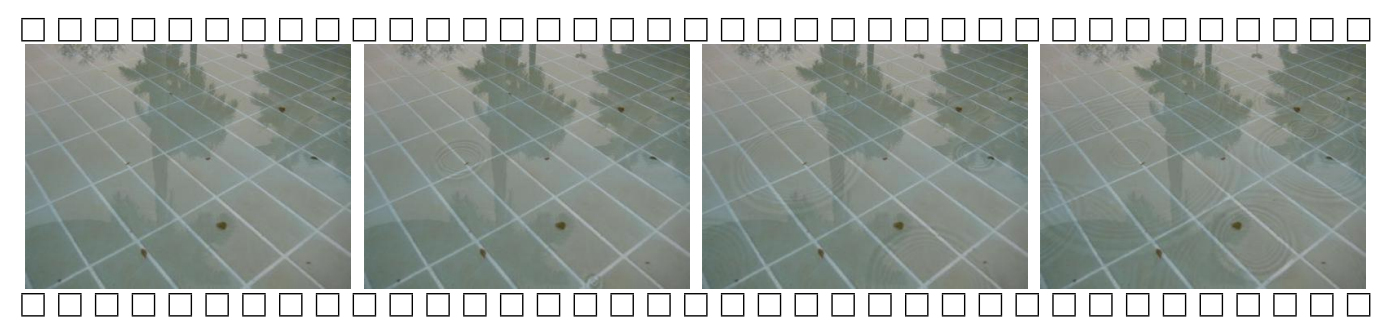

WWW.vipigraf.ufu.br/marcos/tese/filmev.wmv

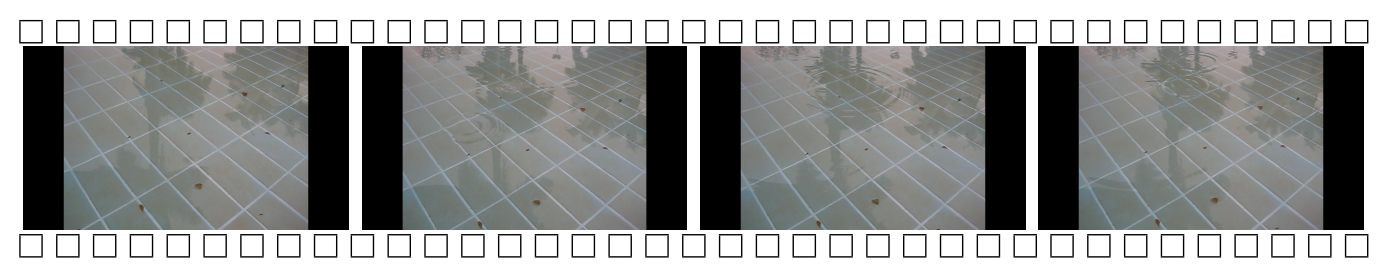

wWw.vipigraf .ufu.br/marcos/tese/filmeo.wmv 


\section{Capítulo 9}

\section{Conclusão}

Neste trabalho propomos um novo método de animação, visando a animação de fluidos em imagens. Em contraste às técnicas existentes, nosso método é baseado em um modelo físico para gerar a animação, resultando em animações bastante realísticas. Além disso, os parâmetros de simulação podem ser modificados por camadas da imagem, o que disponibiliza um mecanismo simples de mudança do comportamento do fluido, dessa forma modificando a animação. Acreditamos que as características de renderização de nosso método de animação são mais potentes e flexíveis que outros métodos descritos na literatura, como podemos observar na figura 9.1, que nos mostra uma comparação entre um resultado de nossa técnica e uma foto resultante de um pingo em uma bacia.

\section{Trabalhos Futuros}

- Nós atualmente estamos investigando como combinar síntese de texturas com a simulação de águas rasas, para produzir efeitos como espuma 

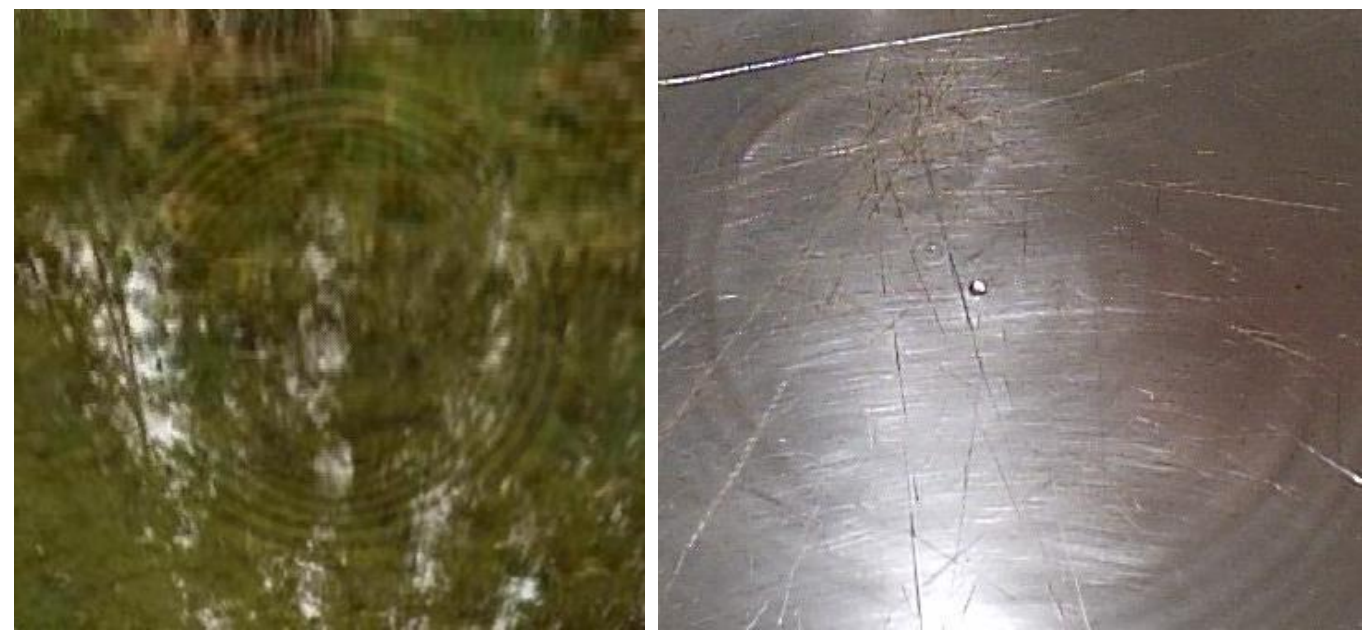

Figura 9.1: Comparação de nossa técnica com uma foto de um pingo em uma bacia.

e formação de bolhas, que são importantes para sustentar o realismo quando animamos águas turbulentas. 


\section{Apêndice A}

\section{Águas rasas}

O equacionamento de águas rasas pode ser considerado uma simplificação das equações de movimento de fluidos (Navier Stokes) a partir de três hipóteses que veremos adiante.

Abordaremos aqui, as principais características das águas rasas e a base do equacionamento de seu movimento.

\section{A.1 Características físicas das águas rasas}

De acordo com [Weiyan 1992], a geometria das águas rasas é caracterizada por:

- Uma superfície livre.

- Uma suave inclinação do fundo:

- O ângulo de inclinação $\phi$ deve ser tal que $\tan \phi \approx \operatorname{sen} \phi$.

- Não há mudanças abruptas na topografia do fundo.

- A profundidade da água $h$ é muito menor que o comprimento de onda ou que a largura característica do aglomerado aquoso $L(h \ll L)$. 
- Normalmente é requerido que $\frac{h}{L}<10^{-3} \sim 10^{-4}$.

- A escala horizontal normalmente varia de $1 \mathrm{~m}$ a $1000 \mathrm{~km}$.

- A escala temporal varia de poucos segundos a vários dias.

Para efeito de nosso trabalho, consideraremos águas rasas todo corpo d'água (aglomerado aquoso) cuja extensão seja muito maior que sua profundidade.

\section{A.2 Equações de Navier-Stokes}

O equacionamento do movimento de fluidos é efetuado a partir de três princípios físicos:

- Conservação de massa.

- Conservação da quantidade de movimento.

- Conservação de energia.

Destes princípios resultam as chamadas equações de Navier-Stokes [Fortuna 2000], um sistema de cinco equações e cinco incógnitas:

- Equação da continuidade:

$$
\frac{\partial \varrho}{\partial t}+\frac{\partial(\varrho u)}{\partial x}+\frac{\partial(\varrho v)}{\partial y}+\frac{\partial(\varrho w)}{\partial z}=0
$$

que, utilizando o operador $\nabla=\left(\frac{\partial}{\partial x}, \frac{\partial}{\partial y}, \frac{\partial}{\partial z}\right)$, pode ser reescrita:

$$
\frac{\partial \varrho}{\partial t}+\nabla \cdot(\varrho \vec{u})=0
$$


- Equações dos momentos:

$\frac{\partial(\varrho \varpi)}{\partial t}+\frac{\partial(\varrho u \varpi)}{\partial x}+\frac{\partial(\varrho v \varpi)}{\partial y}+\frac{\partial(\varrho w \varpi)}{\partial z}=-\frac{\partial p}{\partial \vartheta}+\frac{\partial \tau_{x \vartheta}}{\partial x}+\frac{\partial \tau_{y \vartheta}}{\partial y}+\frac{\partial \tau_{z \vartheta}}{\partial z}+\varrho F_{\vartheta}$ aqui na verdade são três equações, onde o par $(\vartheta, \varpi)$ deve ser substituído pelos pares $(x, u),(y, v)$ e $(z, w)$ e que, utilizando a notação $\tau_{\vec{x} \vartheta}=\left(\tau_{x \vartheta}, \tau_{y \vartheta}, \tau_{z \vartheta}\right)$, são:

$$
\begin{aligned}
& \frac{\partial(\varrho u)}{\partial t}+\nabla \cdot(\varrho \vec{u} u)=-\frac{\partial p}{\partial x}+\nabla \cdot \tau_{\vec{x} x}+\varrho F_{x} \\
& \frac{\partial(\varrho v)}{\partial t}+\nabla \cdot(\varrho \vec{u} v)=-\frac{\partial p}{\partial y}+\nabla \cdot \tau_{\vec{x} y}+\varrho F_{y} \\
& \frac{\partial(\varrho w)}{\partial t}+\nabla \cdot(\varrho \vec{u} w)=-\frac{\partial p}{\partial z}+\nabla \cdot \tau_{\vec{x} z}+\varrho F_{z}
\end{aligned}
$$

- Equação da energia interna:

$$
\begin{aligned}
\frac{\partial(\varrho e)}{\partial t}+\nabla \cdot(\varrho e \vec{u}) & =\varrho \frac{\partial Q}{\partial t}-\nabla \cdot \vec{q}-p(\nabla \cdot \vec{u})+ \\
& +\tau_{x x} \frac{\partial u}{\partial x}+\tau_{x y} \frac{\partial v}{\partial x}+\tau_{x z} \frac{\partial w}{\partial x}+ \\
& +\tau_{y x} \frac{\partial u}{\partial y}+\tau_{y y} \frac{\partial v}{\partial y}+\tau_{y z} \frac{\partial w}{\partial y}+ \\
& +\tau_{z x} \frac{\partial u}{\partial z}+\tau_{z y} \frac{\partial v}{\partial z}+\tau_{z z} \frac{\partial w}{\partial z}
\end{aligned}
$$

ou:

$$
\begin{aligned}
\frac{\partial(\varrho e)}{\partial t}+\nabla \cdot(\varrho e \vec{u}) & =\varrho \frac{\partial Q}{\partial t}-\nabla \cdot \vec{q}-p(\nabla \cdot \vec{u})+ \\
& +\tau_{\vec{x} x} \cdot \nabla u+\tau_{\vec{x} y} \cdot \nabla v+\tau_{\vec{x} z} \cdot \nabla w
\end{aligned}
$$

Neste sistema de equações temos:

- Variáveis independentes:

- $\vec{x}=(x, y, z)$ é o vetor posição (localização espacial).

- $t$ é o tempo (localização temporal). 
- Variáveis dependentes:

- $\vec{u}=(u, v, w)$ é o vetor velocidade instantânea do fluido, em uma localização pontual.

- $p$ é a pressão instantânea do fluido, em uma localização pontual.

- $\varrho$ é a densidade instantânea do fluido, em uma localização pontual.

- Funções auxiliares:

- $\vec{F}=\left(F_{x}, F_{y}, F_{z}\right)$ é a composição de forças de campq $q^{1}$ instantâneas. Cada $F_{\vartheta}$ é a resultante das forças de campo, aplicadas pontualmente, na direção $\vartheta$.

$-\tau_{\vartheta_{1} \vartheta_{2}}$, são nove funções que representam as tensões viscosas instantâneas, aplicadas pontualmente, em cada direção:

* $\tau_{\vartheta \vartheta}$ é a tensão norma $\left.\right|^{2}$ na direção $\vartheta$. Temos três tensões normais: nas direções $x, y$ e $z$.

* $\tau_{\vartheta_{1} \vartheta_{2}}, \vartheta_{1} \neq \vartheta_{2}$, é a tensão de cisalhament ${ }^{3}$ no plano normal a $\vartheta_{1}$ na direção $\vartheta_{2}$. São seis tensões de cisalhamento: no plano normal a $x$ nas direções $y$ e $z$, no plano normal a $y$ nas direções $x$ e $z$ e no plano normal a $z$ nas direções $x$ e $y$.

$-\vec{q}=-\kappa \nabla T$ é o fluxo de calor entre os elementos do fluido e:

* $\kappa$ é o coeficiente de condutividade térmica do fluido.

* T é a temperatura instantânea do fluido, em uma localidade pontual.

\footnotetext{
${ }^{1}$ Forças que agem sobre o elemento de fluido sem contato físico.

${ }^{2}$ Tensão de tração ou de compressão aplicada no elemento de fluido.

${ }^{3}$ Resistência ao movimento provocada pelo atrito entre os elementos de fluido vizinhos.
} 
Podemos agora simplificar este sistema de equações para um sistema governante do problema específico de fluxo de águas rasas.

\section{A.3 Equacionamento do movimento das águas rasas}

Em primeiro lugar vamos estabelecer as hipóteses sobre um fluxo de águas rasas, onde não há rompimento do corpo d'água:

- A superfície da água pode ser mapeada, instantaneamente, pela altura $h$ do corpo d'água em cada ponto do plano do fluxo naquele instante e cada partícula d'água será considerada desta altura, associando o corpo d'água a colunas infinitesimais de partículas d'água, ou seja, o volume do corpo d'água é dado por:

$$
\iiint_{\vec{x} \in \mho} d x d y d z \stackrel{\text { hip }}{\equiv} \iint_{\vec{x} \in \Omega} h d x d y
$$

onde $\mho \subset \mathbb{R}^{3}$ e $\Omega \subset \mathbb{R}^{2}$ são as regiões onde estão mapeados os elementos do fluido, respectivamente, nos ambientes tri e bidimensionais.

- A componente vertical da velocidade de cada partícula d'água é considerada nula, ou seja,

$$
w \stackrel{\text { hip }}{\equiv} 0
$$

- As componentes horizontais da velocidade em cada coluna vertical são consideradas constantes, ou seja,

$$
\frac{\partial u}{\partial z} \stackrel{\text { hip }}{\equiv} 0 \quad \text { e } \quad \frac{\partial v}{\partial z} \stackrel{\text { hip }}{\equiv} 0
$$


A partir destas hipóteses, podemos considerar que um sistema bidimensional representa bem nosso fluxo, tendo em vista que a componente $w$ da velocidade é nula e que não temos variação de velocidade na direção $z$ e, além disso, a altura $h$ só depende de $x, y$ e $t$. Podemos então eliminar as componentes $w$ e $z$ de nosso sistema, vejamos como:

Em primeiro lugar, se nosso sistema é bidimensional, nosso volume infinitesimal agora é área infinitesimal e como a densidade instantânea em uma posição do sistema tridimensional ( $\varrho$ ) depende do volume infinitesimal, devemos recalculá-lo: $\varrho$ é definido como sendo a massa de um elemento de fluido pelo volume infinitesimal, de tal forma que a massa total do corpo d'água é dado por $\iiint_{\vec{x} \in \mho} \varrho d x d y d z$. Por outro lado, tomemos a densidade da água, que consideraremos constante e chamaremos de $\rho$. Como sabemos, pela hipótese A.6 o volume total de nosso corpo d'água é dado por $\iint_{\vec{x} \in \Omega} h d x d y$, então a massa total do corpo d'água é dado por $\rho \iint_{\vec{x} \in \Omega} h d x d y$.

Então temos que:

$$
\begin{aligned}
\iint_{\vec{x} \in \mho} \varrho d x d y d z & \equiv \rho \iint_{\vec{x} \in \Omega} h d x d y \\
& \Downarrow \\
\iiint_{\vec{x} \in \mho} \varrho d x d y d z & \equiv \iint_{\vec{x} \in \Omega} \rho h d x d y \\
& \Downarrow \\
\varrho \cdot(\text { volume infinitesimal) } & \equiv \rho h \cdot(\text { área infinitesimal) } \\
& \Downarrow \\
\varrho & \equiv \rho h
\end{aligned}
$$

Observe que evitamos utilizar a igualdade $(=)$, dando preferência à equivalência (三), tendo em vista que o elemento $\vec{x}$ é, apesar de equivalente, diferente nos dois lados da equação: do lado esquerdo $\vec{x} \in \mathbb{R}^{3}$ e do lado direito $\vec{x} \in \mathbb{R}^{2}$. 
Podemos agora simplificar nossa equação de continuidade, substituindo A.9 em A.1.

$$
\begin{aligned}
& \frac{\partial(\rho h)}{\partial t}+\nabla \cdot(\rho h \vec{u})=0 \\
& \Downarrow \\
& \rho \frac{\partial h}{\partial t}+\rho(\nabla \cdot(h \vec{u}))=0 \\
& \Downarrow \\
& \frac{\partial h}{\partial t}+\nabla \cdot(h \vec{u})=0 \\
& \frac{\partial h}{\partial t}+\frac{\partial(h u)}{\partial x}+\frac{\partial(h v)}{\partial y}+\underbrace{\frac{\partial(h w)}{\partial z}}_{=0 \text { (hip } \mathrm{A.7}}=0 \\
& \Downarrow \\
& \frac{\partial h}{\partial t}+\frac{\partial(h u)}{\partial x}+\frac{\partial(h v)}{\partial y}=0
\end{aligned}
$$

As equações de momento também podem ser simplificadas. Inicialmente, substituindo A.9 em A.2

$$
\begin{aligned}
\frac{\partial(\rho h u)}{\partial t}+\nabla \cdot(\rho h \vec{u} u) & =-\frac{\partial p}{\partial x}+\nabla \cdot \tau_{\vec{x} x}+\rho h F_{x} \\
& \Downarrow \\
\frac{\partial(h u)}{\partial t}+\frac{\partial\left(h u^{2}\right)}{\partial x}+\frac{\partial(h u v)}{\partial y}+\underbrace{\frac{\partial(h u w)}{\partial z}}_{=0 \text { (hip } \sqrt{\mathrm{A} .7})} & =\frac{-1}{\rho} \frac{\partial p}{\partial x}+\frac{1}{\rho}\left(\nabla \cdot \tau_{\vec{x} x}\right)+h F_{x} \\
\Downarrow & \\
\frac{\partial(h u)}{\partial t}+\frac{\partial\left(h u^{2}\right)}{\partial x}+\frac{\partial(h u v)}{\partial y} & =\frac{-1}{\rho} \frac{\partial p}{\partial x}+\frac{\nabla \cdot \tau_{\vec{x} x}}{\rho}+h F_{x}(\mathrm{~A} .11)
\end{aligned}
$$

equivalentemente, substituindo A.9 em A.3, obtemos:

$$
\frac{\partial(h v)}{\partial t}+\frac{\partial(h u v)}{\partial x}+\frac{\partial\left(h v^{2}\right)}{\partial y}=-\frac{1}{\rho} \frac{\partial p}{\partial y}+\frac{\nabla \cdot \tau_{\vec{x} y}}{\rho}+h F_{y}
$$

As equações A.10, A.11 e A.12 formam um sistema de três equações e três incógnitas $(h, u$ e $v)$ o que nos possibilitam dispensar as equações A.4 e A.5. 
Precisamos agora, expandir os termos $p, \tau_{\vec{x} x}, \tau_{\vec{x} y}, F_{x}$ e $F_{y}$. Em conformidade com [Weiyan 1992], consideraremos:

$$
\begin{aligned}
p & =\frac{\rho g h^{2}}{2} \\
\tau_{x x} & =2 \mu h \frac{\partial u}{\partial x} \\
\tau_{y y} & =2 \mu h \frac{\partial v}{\partial y} \\
\tau_{x y}=\tau_{y x} & =\mu h\left(\frac{\partial u}{\partial y}+\frac{\partial v}{\partial x}\right) \\
\tau_{x z}=\tau_{z x}=\tau_{y z}=\tau_{z y}=\tau_{z z} & =0 \\
F & =F_{g}+F_{f}+F_{c}+F_{\tau}+F_{p}
\end{aligned}
$$

onde $g$ é a aceleração da gravidade, $\mu$ é o coeficiente de viscosidade dinâmica (ou turbulenta) e a equação A.18 é a expansão das forças de campo, ignorando as forças de maré, dadas por:

- Ação da gravidade:

$$
F_{g}=g \nabla H=\left(g \frac{\partial H}{\partial x}, g \frac{\partial H}{\partial y}, 0\right)
$$

onde $H$ é a altura média do corpo d'água.

- Força inercial de Coriolis:

$$
F_{f}=\vec{u} \times(0,0, f)=(f v,-f u, 0)
$$

onde $f$ é chamada de aceleração de Coriolis.

- Força de atrito:

$$
F_{c}=\frac{-g|\vec{u}| \vec{u}}{C^{2} h^{2}}=\left(\frac{-g|\vec{u}| u}{C^{2} h^{2}}, \frac{-g|\vec{u}| v}{C^{2} h^{2}}, 0\right)
$$

onde $C$ é o coeficiente de Chezy. 
- Ação do vento:

$$
F_{\tau}=\frac{\left(\tau_{1}, \tau_{2}, 0\right)}{\rho h}=\left(\frac{\tau_{1}}{\rho h}, \frac{\tau_{2}}{\rho h}, 0\right)
$$

onde $\left(\tau_{1}, \tau_{2}\right)$ é a tensão exercida pelo vento na superfície do corpo d'água.

- Força gerada pela pressão atmosférica:

$$
F_{p}=\frac{-1}{\rho} \nabla p_{a}=\left(\frac{-1}{\rho} \frac{\partial p_{a}}{\partial x}, \frac{-1}{\rho} \frac{\partial p_{a}}{\partial y}, 0\right)
$$

onde $p_{a}$ é a pressão atmosférica.

Assim, as expansões das forças de campo são:

$$
F_{x}=g \frac{\partial H}{\partial x}+f v-\frac{g|\vec{u}| u}{C^{2} h^{2}}+\frac{\tau_{1}}{\rho h}-\frac{1}{\rho} \frac{\partial p_{a}}{\partial x}
$$

e

$$
F_{y}=g \frac{\partial H}{\partial y}-f u-\frac{g|\vec{u}| v}{C^{2} h^{2}}+\frac{\tau_{2}}{\rho h}-\frac{1}{\rho} \frac{\partial p_{a}}{\partial y}
$$

Desenvolvendo os termos à direita das equações A.11 e A.12, obtemos, a partir da equação A.13.

$$
\begin{aligned}
& \frac{-1}{\rho} \frac{\partial p}{\partial x}=\frac{-1}{\rho} \frac{\partial \frac{\rho g h^{2}}{2}}{\partial x}=-g h \frac{\partial h}{\partial x} \\
& \frac{-1}{\rho} \frac{\partial p}{\partial y}=\frac{-1}{\rho} \frac{\partial \frac{\rho g h^{2}}{2}}{\partial y}=-g h \frac{\partial h}{\partial y}
\end{aligned}
$$

a partir das equações A.14, A.16 e A.17.

$$
\frac{\nabla \cdot \tau_{\vec{x} x}}{\rho}=\nabla \cdot \frac{\tau_{\vec{x} x}}{\rho}=\frac{\partial}{\partial x}\left(\frac{2 \mu h}{\rho} \frac{\partial u}{\partial x}\right)+\frac{\partial}{\partial y}\left(\frac{\mu h}{\rho}\left(\frac{\partial u}{\partial y}+\frac{\partial v}{\partial x}\right)\right)
$$

a partir das equações A.15, A.16 e A.17.

$$
\frac{\nabla \cdot \tau_{\vec{x} y}}{\rho}=\nabla \cdot \frac{\tau_{\vec{x} y}}{\rho}=\frac{\partial}{\partial x}\left(\frac{\mu h}{\rho}\left(\frac{\partial u}{\partial y}+\frac{\partial v}{\partial x}\right)\right)+\frac{\partial}{\partial y}\left(\frac{2 \mu h}{\rho} \frac{\partial v}{\partial y}\right)
$$

a partir da equação A.24.

$$
h F_{x}=g h \frac{\partial H}{\partial x}+f h v-\frac{g|\vec{u}| u}{C^{2} h}+\frac{\tau_{1}}{\rho}-\frac{h}{\rho} \frac{\partial p_{a}}{\partial x}
$$


e a partir da equação A.25.

$$
h F_{y}=g h \frac{\partial H}{\partial y}-f h u-\frac{g|\vec{u}| v}{C^{2} h}+\frac{\tau_{2}}{\rho}-\frac{h}{\rho} \frac{\partial p_{a}}{\partial y}
$$

Agora, substituindo a equação A.26 na equação A.11:

$$
\begin{aligned}
& \frac{\partial(h u)}{\partial t}+\frac{\partial\left(h u^{2}\right)}{\partial x}+\frac{\partial(h u v)}{\partial y}=-g h \frac{\partial h}{\partial x}+\frac{\nabla \cdot \tau_{\vec{x} x}}{\rho}+h F_{x} \\
& \frac{\partial(h u)}{\partial t}+\frac{\partial\left(h u^{2}\right)}{\partial x}+\frac{\partial(h u v)}{\partial y}+g h \frac{\partial h}{\partial x}=h F_{x}+\frac{\nabla \cdot \tau_{\vec{x} x}}{\rho} \\
& \Downarrow \\
& \frac{\partial(h u)}{\partial t}+\frac{\partial\left(h u^{2}\right)}{\partial x}+\frac{\partial(h u v)}{\partial y}+g h \frac{\partial h}{\partial x}+g H \frac{\partial H}{\partial x}-g H \frac{\partial H}{\partial x}=h F_{x}+\frac{\nabla \cdot \tau_{\vec{x} x}}{\rho} \\
& \Downarrow \\
& \frac{\partial(h u)}{\partial t}+\frac{\partial\left(h u^{2}\right)}{\partial x}+\frac{\partial(h u v)}{\partial y}+g\left(h \frac{\partial h}{\partial x}-H \frac{\partial H}{\partial x}\right)= \\
& \frac{\partial(h u)}{\partial t}+\frac{\partial\left(h u^{2}\right)}{\partial x}+\frac{\partial(h u v)}{\partial y}+\frac{g}{2}\left(\frac{\partial h^{2}}{\partial x}-\frac{\partial H^{2}}{\partial x}\right)= \\
& \Downarrow \\
& \frac{\partial(h u)}{\partial t}+\frac{\partial\left(h u^{2}\right)}{\partial x}+\frac{\partial(h u v)}{\partial y}+\frac{\partial}{\partial x}\left(\frac{g}{2}\left(h^{2}-H^{2}\right)\right)= \\
& \frac{\partial(h u)}{\partial t}+\frac{\partial(h u v)}{\partial y}+\frac{\partial}{\partial x}\left(h u^{2}+\frac{g}{2}\left(h^{2}-H^{2}\right)\right)= \\
& \left(^{*}\right)=h F_{x}+\frac{\nabla \cdot \tau_{\vec{x} x}}{\rho}-g H \frac{\partial H}{\partial x}
\end{aligned}
$$

incorporando a equação A.30.

$$
\begin{aligned}
\left(^{*}\right) & =g h \frac{\partial H}{\partial x}+f h v-\frac{g|\vec{u}| u}{C^{2} h}+\frac{\tau_{1}}{\rho}-\frac{h}{\rho} \frac{\partial p_{a}}{\partial x}+\frac{\nabla \cdot \tau_{\vec{x} x}}{\rho}-g H \frac{\partial H}{\partial x} \\
& \Downarrow \\
\left(^{*}\right) & =g(h-H) \frac{\partial H}{\partial x}+f h v-\frac{g|\vec{u}| u}{C^{2} h}+\frac{\tau_{1}}{\rho}-\frac{h}{\rho} \frac{\partial p_{a}}{\partial x}+\frac{\nabla \cdot \tau_{\vec{x} x}}{\rho}
\end{aligned}
$$


e incorporando a equação A.28

$$
\begin{aligned}
\left(^{*}\right) & =g(h-H) \frac{\partial H}{\partial x}+f h v-\frac{g|\vec{u}| u}{C^{2} h}+\frac{\tau_{1}}{\rho}-\frac{h}{\rho} \frac{\partial p_{a}}{\partial x}+ \\
& +\frac{\partial}{\partial x}\left(\frac{2 \mu h}{\rho} \frac{\partial u}{\partial x}\right)+\frac{\partial}{\partial y}\left(\frac{\mu h}{\rho}\left(\frac{\partial u}{\partial y}+\frac{\partial v}{\partial x}\right)\right)
\end{aligned}
$$

assim, a equação A.32 fica:

$$
\begin{aligned}
\frac{\partial(h u)}{\partial t} & +\frac{\partial(h u v)}{\partial y}+\frac{\partial}{\partial x}\left(h u^{2}+\frac{g}{2}\left(h^{2}-H^{2}\right)\right)=f h v+ \\
& +g(h-H) \frac{\partial H}{\partial x}-\frac{g|\vec{u}| u}{C^{2} h}+\frac{\tau_{1}}{\rho}-\frac{h}{\rho} \frac{\partial p_{a}}{\partial x}+ \\
& +\frac{\partial}{\partial x}\left(\frac{2 \mu h}{\rho} \frac{\partial u}{\partial x}\right)+\frac{\partial}{\partial y}\left(\frac{\mu h}{\rho}\left(\frac{\partial u}{\partial y}+\frac{\partial v}{\partial x}\right)\right)
\end{aligned}
$$

de maneira equivalente, substituindo a equação A.27 na equação A.12, obtemos:

$$
\begin{array}{r}
\frac{\partial(h v)}{\partial t}+\frac{\partial(h u v)}{\partial x}+\frac{\partial}{\partial y}\left(h v^{2}+\frac{g}{2}\left(h^{2}-H^{2}\right)\right)=\left({ }^{* *}\right) \\
\left(^{* *}\right)=h F_{y}+\frac{\nabla \cdot \tau_{\vec{x} y}}{\rho}-g H \frac{\partial H}{\partial y}
\end{array}
$$

incorporando a equação A.31.

$$
\left({ }^{* *}\right)=g(h-H) \frac{\partial H}{\partial y}-f h u-\frac{g|\vec{u}| v}{C^{2} h}+\frac{\tau_{2}}{\rho}-\frac{h}{\rho} \frac{\partial p_{a}}{\partial y}+\frac{\nabla \cdot \tau_{\vec{x} y}}{\rho}
$$

e incorporando a equação A.29.

$$
\begin{aligned}
\left(^{* *}\right) & =g(h-H) \frac{\partial H}{\partial y}-f h u-\frac{g|\vec{u}| v}{C^{2} h}+\frac{\tau_{2}}{\rho}-\frac{h}{\rho} \frac{\partial p_{a}}{\partial y}+ \\
& +\frac{\partial}{\partial x}\left(\frac{\mu h}{\rho}\left(\frac{\partial u}{\partial y}+\frac{\partial v}{\partial x}\right)\right)+\frac{\partial}{\partial y}\left(\frac{2 \mu h}{\rho} \frac{\partial v}{\partial y}\right)
\end{aligned}
$$

assim, a equação A.34 fica:

$$
\begin{aligned}
\frac{\partial(h v)}{\partial t} & +\frac{\partial(h u v)}{\partial x}+\frac{\partial}{\partial y}\left(h v^{2}+\frac{g}{2}\left(h^{2}-H^{2}\right)\right)=-f h u \\
& +g(h-H) \frac{\partial H}{\partial y}-\frac{g|\vec{u}| v}{C^{2} h}+\frac{\tau_{2}}{\rho}-\frac{h}{\rho} \frac{\partial p_{a}}{\partial y}+ \\
& +\frac{\partial}{\partial x}\left(\frac{\mu h}{\rho}\left(\frac{\partial u}{\partial y}+\frac{\partial v}{\partial x}\right)\right)+\frac{\partial}{\partial y}\left(\frac{2 \mu h}{\rho} \frac{\partial v}{\partial y}\right)
\end{aligned}
$$


O sistema formado pelas equações A.10, A.33 e A.35 foi apresentado por [Peraire, Zienkiewicz \& Morgan 1986] com a proposta de resolver situações complexas envolvendo águas rasas. Nossa proposta aqui é resolver este sistema, sem a parte relativa à turbulência, utilizando um método numérico adaptado do método tradicional de Lax-Wendroff.

\section{A.4 As equações de águas rasas}

Algumas observações antes de apresentarmos as equações governantes do movimento de águas rasas que utilizaremos:

- Não consideraremos o efeito de turbulência ou seja, consideraremos $\mu=0$, tendo em vista que o significado físico do mesmo contraria as hipóteses A.7 e A.8.

- Consideraremos a pressão atmosférica constante ou seja, $\frac{\partial p_{a}}{\partial x}=\frac{\partial p_{a}}{\partial y}=0$.

A partir destas considerações, a equação A.33 torna-se:

$$
\begin{aligned}
\frac{\partial(h u)}{\partial t}+\frac{\partial(h u v)}{\partial y} & +\frac{\partial}{\partial x}\left(h u^{2}+\frac{g}{2}\left(h^{2}-H^{2}\right)\right)=f h v+ \\
& +g(h-H) \frac{\partial H}{\partial x}-\frac{g|\vec{u}| u}{C^{2} h}+\frac{\tau_{1}}{\rho}
\end{aligned}
$$

e a equação A.35 torna-se:

$$
\begin{aligned}
\frac{\partial(h v)}{\partial t}+\frac{\partial(h u v)}{\partial x} & +\frac{\partial}{\partial y}\left(h v^{2}+\frac{g}{2}\left(h^{2}-H^{2}\right)\right)=-f h u+ \\
& +g(h-H) \frac{\partial H}{\partial y}-\frac{g|\vec{u}| v}{C^{2} h}+\frac{\tau_{2}}{\rho}
\end{aligned}
$$

As equações A.10, A.36 e A.37 constituem o sistema de águas rasas para o qual apresentamos um método de resolução numérica no capítulo 6 . 


\section{Referências Bibliográficas}

Bar-Joseph, Z., El-Yaniv, R., Lischinski, D. \& Werman, M. [2001], 'Texture mixing and texture movie synthesis using statistical learning', IEEE Transactions on Visualization and Computer Graphics 7(2), 120-135.

Barrett, W. A. \& Cheney, A. S. [2002], 'Object-based image editing', $A C M$ Transactions on Graphics 21(3), 777-784.

Bhat, K. S., Seitz, S. M., Hodgins, J. K. \& Khosla, P. K. [2004], 'Flow-based video synthesis and editing', ACM Transactions on Graphics 23(3), 360363.

Bonilla, D., Velho, L., Nachbin, A. \& Nonato, L. [2009], Fluid warping, in 'Proceedings of the IV Iberoamerican Symposium in Computer Graphics', pp. 181-188.

Chu, H.-K., Hsu, W.-H., Mitra, N. J., Cohen-Or, D., Wong, T.-T. \& Lee, T.-Y. [2010], 'Camouflage images', ACM Trans. Graph. 29, 51:1-51:8.

Chuang, Y.-Y., Goldman, D. B., Zheng, K. C., Curless, B., Salesin, D. H. \& Szeliski, R. [2005], 'Animating pictures with stochastic motion textures', ACM Transactions on Graphics 24(3), 853-860.

Corrêa, W. T., Jensen, R. J., Thayer, C. E. \& Finkelstein, A. [1998], Texture mapping for cel animation, in 'Proceedings of the 25th annual confe- 
rence on Computer graphics and interactive techniques', SIGGRAPH '98, ACM, New York, NY, USA, pp. 435-446.

Criminisi, A., Reid, I. \& Zisserman, Z. [2000], 'Single view metrology', International Journal of Computer Vision 40(2), 123-148.

Doretto, G., Chiuso, A., Wu, Y. N. \& Soatto, S. [2003], 'Dynamic textures', International Journal of Computer Vision 51(2), 91-109.

Drasek III, J. V., Bookout, D. \& Lake, A. [2009], 'Real-time parametric shallow wave simulation', Advanced Visual Computing White Paper, 1-8.

Drori, I., Cohen-Or, D. \& Yeshurun, H. [2003], 'Fragment-based image completion', ACM Trans. Graph. 22, 303-312.

Foley, J. D., van Dam, A., Feiner, S. K. \& Hughes, J. F. [1996], Computer Graphics: principles and practice, Addison-Wesley.

Fortuna, A. O. [2000], Técnicas Computacionais para Dinâmica dos Fluidos, edUSP.

Freeman, W. T., Adelson, E. H. \& Heeger, D. J. [1991], 'Motion without movement', Computer Graphics 25(4), 27-30.

Galdi, G. P. [1998a], An Introduction to the Mathematical Theory of the Navier-Stokes Equations, Vol. I: Linearised Steady Problems, SpringerVerlag.

Galdi, G. P. [1998b], An Introduction to the Mathematical Theory of the Navier-Stokes Equations, Vol. II: Nonlinear Steady Problems, SpringerVerlag.

Gomes, J. \& Velho, L. [1994], Computação Gráfica: Imagem, IMPA/SBM. 
Hagen, T. R., Hjelmervik, J. M., Lie, K. A., Natvig, J. R. \& Henriksen, M. O. [2005], 'Visual simulation of shallow-water waves', Simulation Modelling Practice and Theory 13, 716-726.

Hashimoto, R., Johan, H. \& Nishita, T. [2003], Creating various styles of animations using example-based filtering, in 'Proceedings of CGI', pp. 312317.

Hertzmann, A., Jacobs, C. E., Oliver, N., Curless, B. \& Salesin, D. H. [2001], Image analogies, in 'Proceedings of ACM SIGGRAPH', pp. 327-340.

Hilbert, D. \& Cohn-Vossen, S. [1952], Geometry and the Imagination, Chelsea.

Hornung, A., Dekkers, E. \& Kobbelt, L. [2007], 'Character animation from 2d pictures and 3d motion data', ACM Transactions on Graphics 26(1), 19 .

Horry, Y., Anjyo, K. \& Arai, K. [1997], Tour into the picture: Using a spidery mesh interface to make animation from a single image, in 'Proceedings of SIGGRAPH', pp. 225-232.

Igarashi, T., Moscovich, T. \& Hughes, J. F. [2005], 'As-rigid-as-possible shape manipulation', ACM Transactions on Graphics 24(3), 1134-1141.

Irving, G., Guendelman, E., Losasso, F. \& Fedkiw, R. [2006], 'Efficient simulation of large bodies of water by coupling two and three dimensional techniques', ACM Transactions on Graphics 25(3), 805-811.

Kass, M. \& Miller, G. [1990], 'Rapid, stable fluid dynamics for computer graphics', Computer Graphics 24(4), 49-57. 
Kinnmark, I. [1984], The Shallow Water Wave Equations: Formulation, Analysis and Application, Springer-Verlag.

Kwatra, V., Essa, I., Bobick, A. \& Kwatra, N. [2005], 'Texture optimization for example-based synthesis', ACM Transactions on Graphics 24(3), 795-802.

Lax, P. \& Wendroff, B. [1960], 'Systems of Conservation Laws', Communications on pure and applied mathematics 13, 217-237.

Layton, A. T. \& van de Panne, M. [2002], 'A numerically efficient and stable algorithm for animating water waves', The Visual Computer 18, 41-53.

Lin, Z., Wang, L., Wang, Y., Kang, S. B. \& Fang, T. [2007], 'High resolution animated scenes from stills', IEEE Transactions on Visualization and Computer Graphics 13(3), 562-568.

Litwinowicz, P. \& Williams, L. [1994], Animating images with drawings, in 'Proceedings of SIGGRAPH '94', pp. 409-412.

Narain, R., Kwatra, V., Lee, H.-P., Kim, T., Carlson, M. \& Lin, M. C. [2007], Feature-guided dynamic texture synthesis on continuous flows, in 'Proceedings of Eurographics Symposium on Rendering', pp. 361-370.

Oh, B. M., Chen, M., Dorsey, J. \& Durand, F. [2001], Image-based modeling an photo editing, in 'Proceedings of ACM SIGGRAPH', pp. 433-442.

Okabe, M., Anjyo, K., Igarashi, T. \& Seidel, H.-P. [2009], 'Animating pictures of fluid using video examples', Computer Graphics Forum 28(2), 677686. 
Ono, Y., Chen, B.-Y. \& Nishita, T. [2004], 3d character model creation from cel animation, in 'Cyberworlds, 2004 International Conference on', pp. $210-215$.

Peraire, J., Zienkiewicz, O. C. \& Morgan, K. [1986], 'Shallow water problems: a general explict formulation', International Journal for numerical methods in engineering 22, 547-574.

Rademacher, P. [1999], View-dependent geometry, in 'Proceedings of the 26th annual conference on Computer graphics and interactive techniques', SIGGRAPH '99, ACM Press/Addison-Wesley Publishing Co., New York, NY, USA, pp. 439-446.

Schaefer, S., McPhail, T. \& Warren, J. [2006], 'Image deformation using moving least squares', ACM Trans. Graph. 25, 533-540.

Schödl, A., Szeliski, R., Salesin, D. H. \& Essa, I. [2000], Video textures, in 'Proceedings of ACM SIGGRAPH', pp. 489-498.

Shesh, A. \& Chen, B. [2008], 'Peek-in-the-pic: Flying through architectural scenes from a single image', Computer Graphics Forum 27(8), 21432153.

Shesh, A., Criminisi, A., Rother, C. \& Smyth, G. [2009], 3d-aware image editing for out of bounds photography, in 'Proceedings - Graphics Interface', pp. $47-54$.

Shoup, R. G. [1979], 'Color table animation', Computer Graphics 13(2), 813.

Sun, J., Jia, J., Tang, C.-K. \& Shum, H.-Y. [2004], 'Poisson matting', ACM Trans. Graph. 23, 315-321. 
Sun, J., Liang, L., Wen, F. \& Shum, H.-Y. [2007], 'Image vectorization using optimized gradient meshes', ACM Transactions on Graphics 26(3), 11:1-7.

Wang, H., Miller, G. \& Turk, G. [2007], Solving general shallow wave equations on surfaces, in 'Eurographics / ACM SIGGRAPH Symposium on Computer Animation', pp. 229-238.

Wang, Y. \& Zhu, S.-C. [2003], Modeling textured motion: Particle, wave and sketch, in 'Proceedings of IEEE ICCV', Vol. 1, pp. 213-220.

Wei, L.-Y. \& Levoy, M. [2000], Fast texture synthesis using tree-structured vector quantization, in 'Proceedings of ACM SIGGRAPH', pp. 479-488.

Weiyan, T. [1992], Shallow Water Hydrodynamics, Water \& Power Press.

Wolberg, G. [1998], 'Image morphing: a survey', The Visual Computer 14(89), 360-372.

Wu, T.-P., Sun, J., Tang, C.-K. \& Shum, H.-Y. [2008], 'Interactive normal reconstruction from a single image', ACM Transactions on Graphics $\mathbf{2 7}(5), 119: 1-9$.

Xu, X., Wan, L., Liu, X., Wong, T.-T., Wang, L. \& Leung, C.-S. [2008], 'Animating animal motion from still', ACM Transactions on Graphics $\mathbf{2 7}(5), 117: 1-8$.

Zhang, M.-M., Pan, Z.-G., Ren, L.-F. \& Wang, P. [2007], 'Image-based virtual exhibit and its extension to 3d', International Journal of Automation and Computing 04(1), 18-24. 
(c) Marcos Aurélio Batista

sob a orientação do Prof. Dr. Luis Gustavo Nonato

e a colaboração da $\operatorname{Prof}^{\mathrm{a}} \operatorname{Dr}^{\mathrm{a}}$ Célia Aparecida Zorzo Barcelos

Rua João Catanduva, 315 - Santa Mônica

38.408-240 Uberlândia (MG) - Brasil

marcos@catalao.ufg.br

Animação de Fluidos em Imagens Digitais (versão 21)

Tese de Doutorado em Ciência da Computação

documento escrito em $\operatorname{LATEX}_{\mathrm{E}} 2_{\varepsilon}$

USP - Universidade de São Paulo

ICMC - Instituto de Ciências Matemáticas e de Computação www.icmc.usp.br

UFG - Universidade Federal de Goiás CAC - Campus Catalão www.catalao.ufg.br 